Florida International University

FIU Digital Commons

6-30-2020

\title{
From Record Keepers to Decision Makers?: Perspectives of University Registrars about their Role in Higher Education
}

Miguel Sahagun

msaha001@fiu.edu

Follow this and additional works at: https://digitalcommons.fiu.edu/etd

Part of the Higher Education Commons, and the Other Education Commons

\section{Recommended Citation}

Sahagun, Miguel, "From Record Keepers to Decision Makers?: Perspectives of University Registrars about their Role in Higher Education" (2020). FIU Electronic Theses and Dissertations. 4484.

https://digitalcommons.fiu.edu/etd/4484

This work is brought to you for free and open access by the University Graduate School at FIU Digital Commons. It has been accepted for inclusion in FIU Electronic Theses and Dissertations by an authorized administrator of FIU Digital Commons. For more information, please contact dcc@fiu.edu. 


\title{
FLORIDA INTERNATIONAL UNIVERSITY
}

Miami, Florida

FROM RECORD KEEPERS TO DECISION MAKERS?: PERSPECTIVES OF UNIVERSITY REGISTRARS ABOUT THEIR ROLE IN HIGHER EDUCATION

A dissertation submitted in partial fulfillment of the requirements for the degree of DOCTOR OF PHILOSOPHY

\author{
in \\ HIGHER EDUCATION \\ by
}

Miguel Sahagun

2020 
To: Dean Michael R. Heithaus

College of Arts, Sciences and Education

This dissertation, written by Miguel Sahagun, and entitled From Record Keepers to Decision Makers?: Perspectives of University Registrars About Their Role in Higher Education, having been approved in respect to style and intellectual content, is referred to you for judgment.

We have read this dissertation and recommend that it be approved.

Norma Goonen

Rebekah Schulze

Eric Dwyer

Benjamin Baez, Major Professor

Date of Defense: Tuesday, June 30, 2020

The dissertation of Miguel Sahagun is approved.

Dean Michael R. Heithaus

College of Arts, Sciences and Education

Andrés G. Gil

Vice President for Research and Economic Development and Dean of the University Graduate School

Florida International University, 2020 
(C) Copyright 2020 by Miguel Sahagun

All rights reserved. 


\section{DEDICATION}

Li abtelal lie ja' yu'unik li antsetike ti li' schinikon ta jkuxlejale. Ti yipalike, sp'ijilike xchi'uk ti kanele, ja' yipalil skuenta stsuts ti abtelale. Marchuk ti skoltasvaike mu'yuk bu tsuts yechuke. Kolaval Nichim, me' Noemi, Aivory, muk' ta me' Guille, Jun me' Raquel, Ale, Michelle, Lila, Lanca Xchi'uk Abi. 


\section{ACKNOWLEDGMENTS}

Thank you to my committee members: Dr. Baez, thank you for your patience and sticking with me through this process; especially thank you for mentoring me not only in class but through my transition to my new institution. Dr. Norma Goonen, thank you for mentoring me and for your helpful feedback. Drs. Rebekah Schulze and Eric Dwyer thank you for helpful feedback.

Mamá, Noemi Perea. She never attended college or even finished middle school. Instead, she worked hard to make sure my brother and I had a proper education. Thank you mami por creer en mí; you are the true "doctor" of this family. Te amo!

Papá, Miguel Sahagun Nieto, lo rojo lo llevamos en la sangre y el azul en la nobleza, somos de una raza distinta. Te amo.

Hermano, Guillermo Sahagun, I am proud of you; your tenacity and love for your family inspired me to never give up and to finish my study.

Finally, Aivory, my wonderful wife; thank you for loving me the way you do. We did it! 


\begin{abstract}
OF THE DISSERTATION
FROM RECORD KEEPERS TO DECISION MAKERS?: PERSPECTIVES OF UNIVERSITY REGISTRARS ABOUT THEIR ROLE IN HIGHER EDUCATION
\end{abstract}

by

Miguel Sahagun

Florida International University, 2020

Miami, Florida

Professor Benjamin Baez, Major Professor

The purpose of my study was to understand the experiences of university registrars, particularly their perspectives on their professional practice, development, and identity. Empirical research on university registrars is sparse at best. We do not know the real meaning of the position, how university registrars spend their time, and what is meaningful and gratifying about their role. There is not enough information on career paths that they followed to become a university registrar. The lack of empirical studies about the true meaning of the evolving role is a problem needing study. My dissertation addresses the following singular research question: How do university registrars perceive their roles in higher education?

I used a qualitative interview study and document analysis to gain insight into the experiences of nine registrars from public and private universities that belong to the American Association of Collegiate Registrars and Admissions Officer (AACRAO). More specifically, my study used a semi-structured interview scheme adapted from 
Seidman (2013). The transcripts were transcribed entirely by me; then, these were coded and analyzed to identify four salient and emerging themes.

First, the dissertation explains the participants' pathway to become a registrar. Second, the participants discussed what they really do by sharing their perspectives on their roles and responsibilities. Third, my study provides an insight into the participants' perceptions of the challenges, emerging trends, and professional development associated with their profession. Finally, the participants discussed how they described their job when they are in family reunions.

The findings indicate that none of the participants were looking to become a registrar as part of their career path. Participants stated that they love what they do, and six of them suggested that they want to retire as a registrar. Participants indicated that diplomacy is the most important skill to have in this profession as it allows them to build collaborations with multiple departments within the university. Finally, implications include a contribution to the literature of the role of the registrar and a call for AACRAO to work with institutions to develop programs to standardize the role of the registrar. 


\section{TABLE OF CONTENTS}

CHAPTER

PAGE

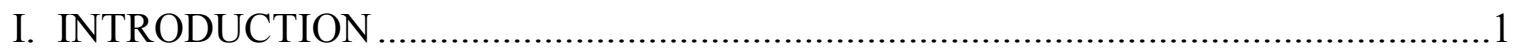

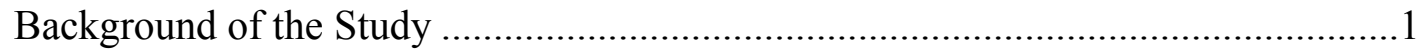

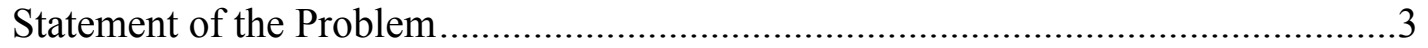

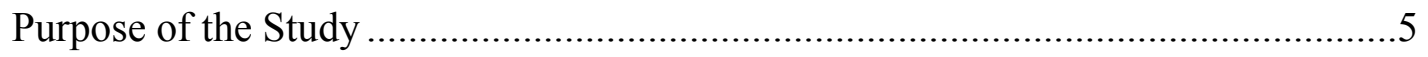

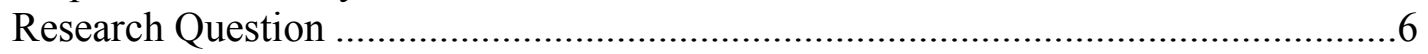

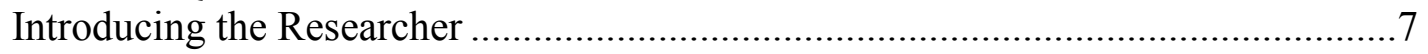

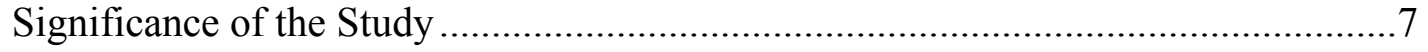

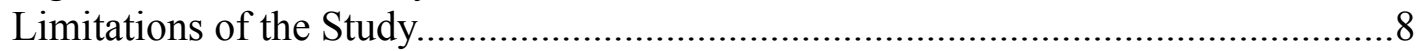

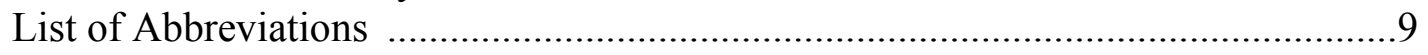

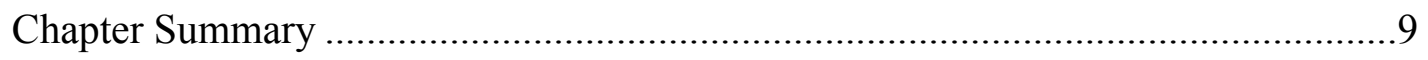

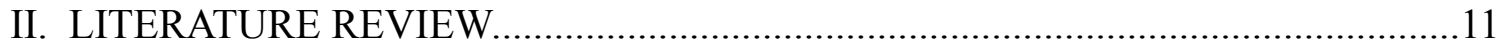

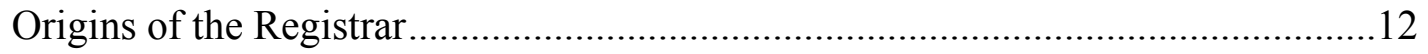

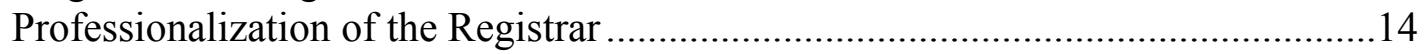

American Association of Collegiate Registrars and Admissions Officers .........16

Training, Education and Professional Development of the Registrar......................19

The Evolving Role and Functions of the Registrar.............................................20

2015 U.S. Registrar Career Profile ...........................................................................23

Office of the Registrar Functional Responsibilities ...............................................27

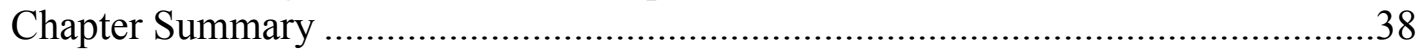

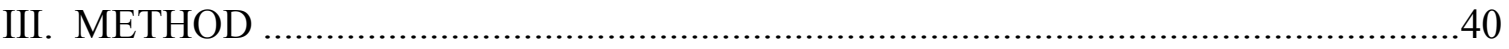

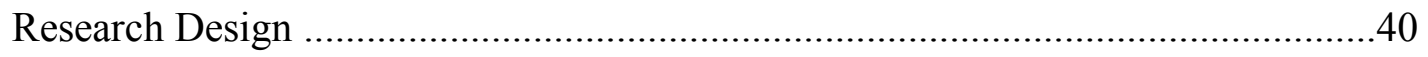

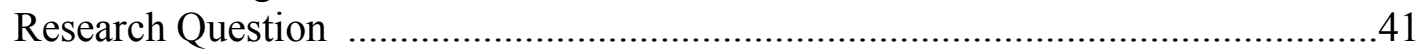

Theoretical Perspectives on Qualitative Research and Interviews ........................41

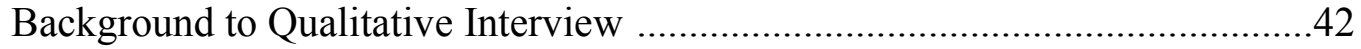

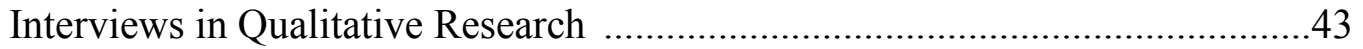

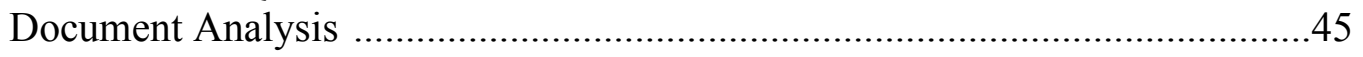

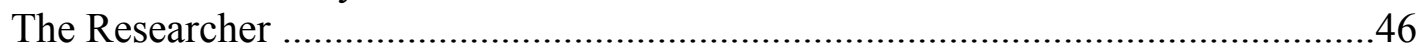

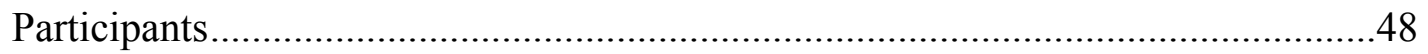

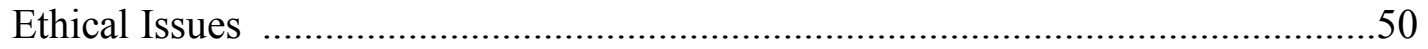

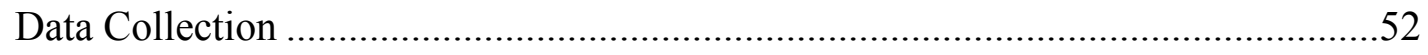

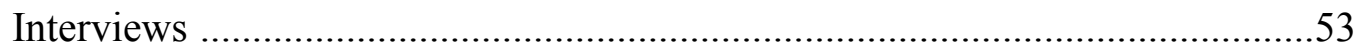

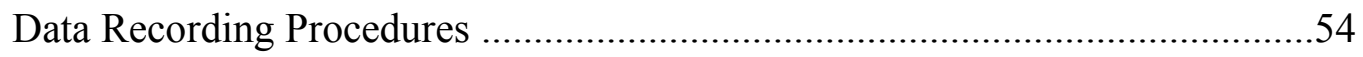

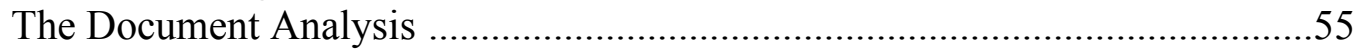

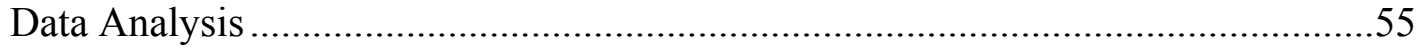

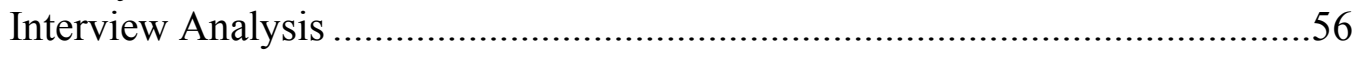

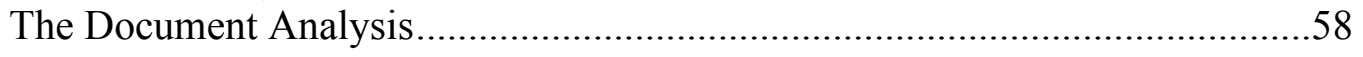

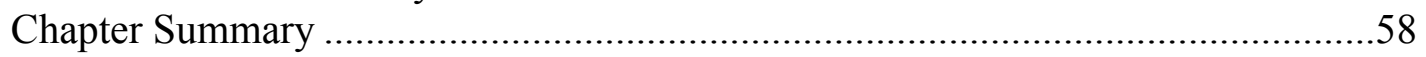




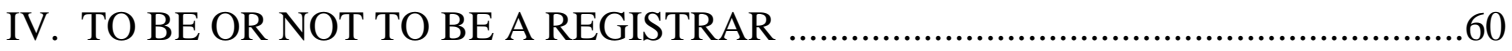

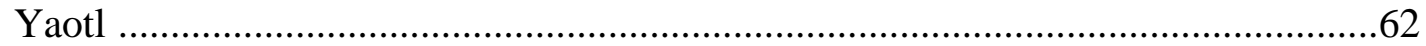

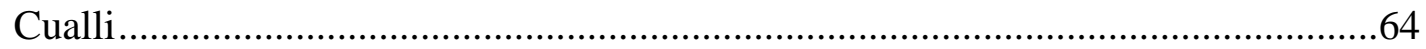

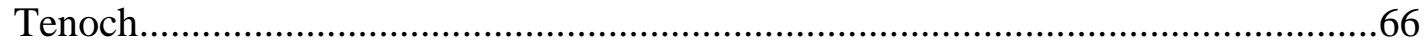

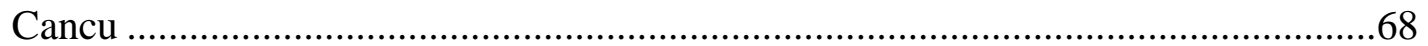

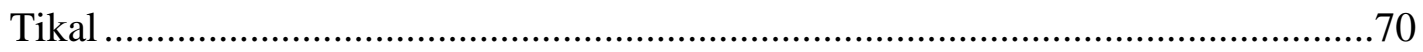

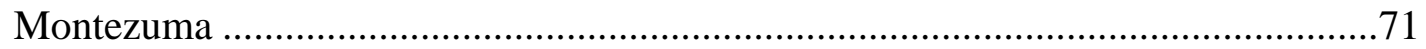

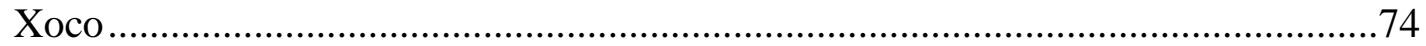

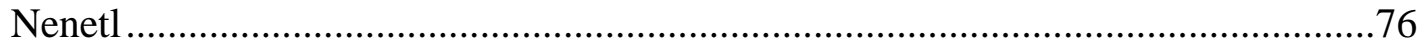

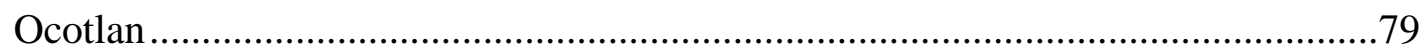

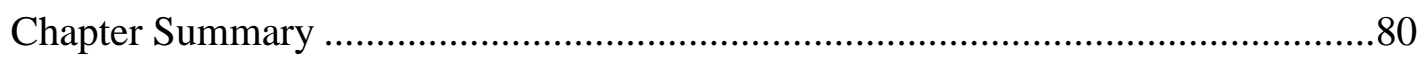

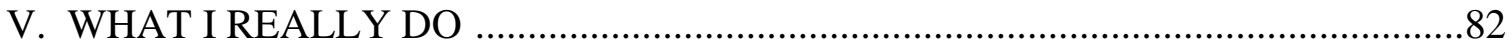

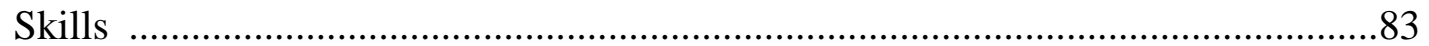

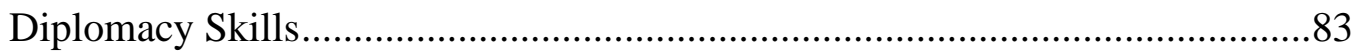

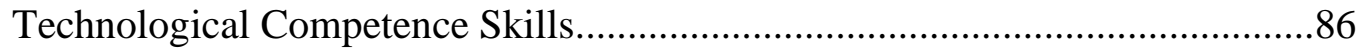

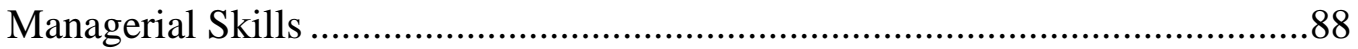

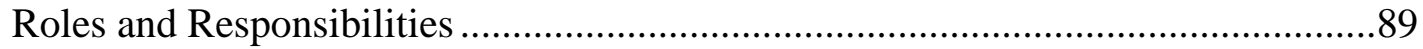

Staff Development and Management.............................................................89

Policy Making ...............................................................................................92

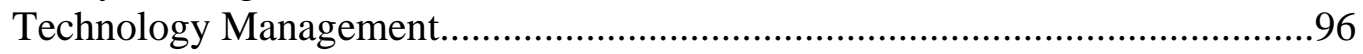

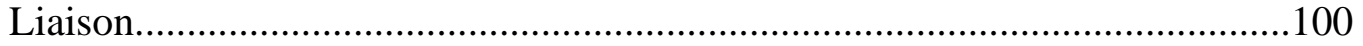

Chapter Summary ……………………………………………………....105

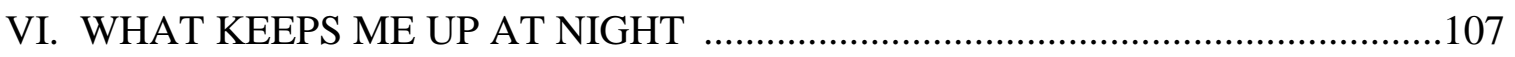

Challenges and Emerging Trends ..................................................................107

Professional Development ..........................................................................114

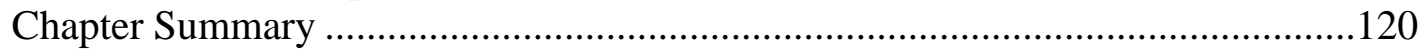

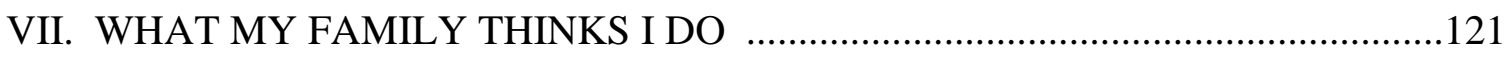

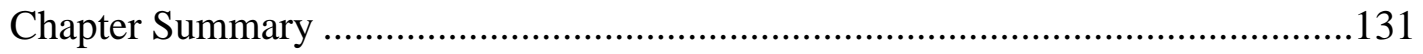

VIII. DISCUSSION AND CONCLUSION ……………….................................133

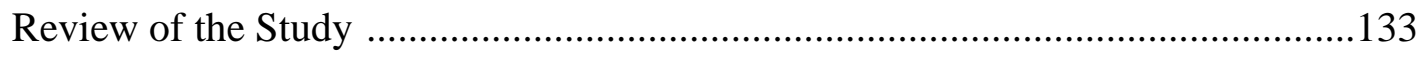

To Be or Not to Be a Registrar ………………….....................................135

How did I get here anyways? ....................................................................136

What my institution thinks I do ................................................................138

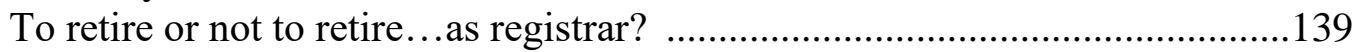

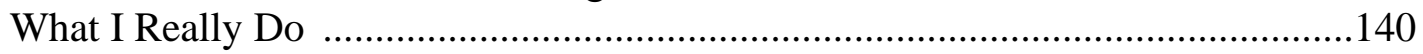

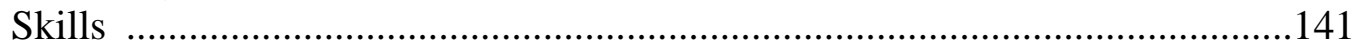

Roles and Responsibilities .....................................................................142

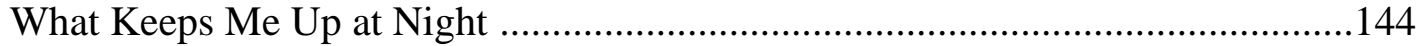

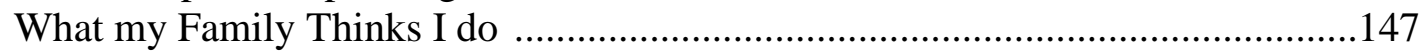

Recommendations for Practice and Research .......................................................148 


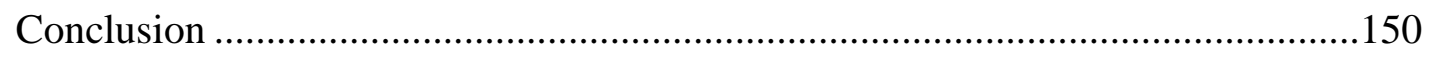

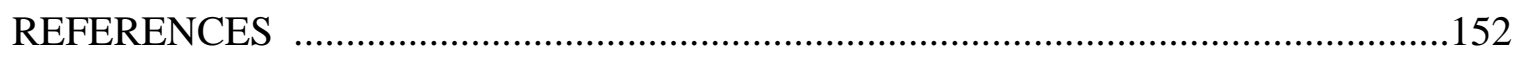

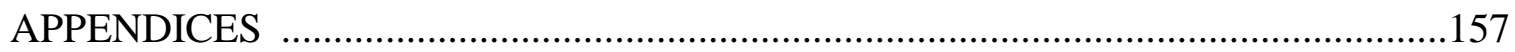

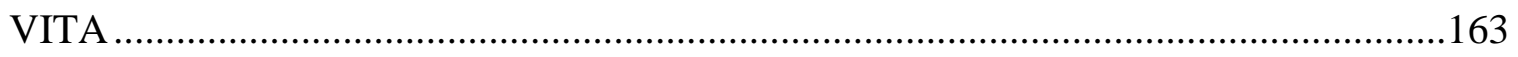




\section{CHAPTER I}

\section{INTRODUCTION}

The student is the primary reason for the existence of the registrar's office. No plan of operation should be set up, nor administrative procedure adopted, which precludes the possibility of giving full consideration to the problems of the individual student.

(Preinkert, 2005)

The present study provides an understanding of the role of university registrars, particularly their perspectives on their professional practice, professional development,

and professional identity. Chapter I presents the background to the study, statement of the problem, purpose of the study, significance of the study, and research question. These are followed by limitations of the study and definition of terms.

\section{Background to the Study}

According to Taylor (2015, p. 1), the president of the university or the college in the United States, used to run the administration of it by himself (or herself), but with increased enrollment, and the demand for expanded services, one person could no longer handle all the administrative functions. Taylor stated that "due to the necessity of increased record-keeping, one of the earliest of these administrative positions to emerge was the registrar."

When the American Association of Collegiate Registrars (AACR) met in 1916, according to Cattell et al. (1922), President Butler pointed out that in the "current university" setting, there was a special enumeration of administrative officers, and that among these is the registrar. The registrar was classed with the provost, the dean, and the controller as a major administrative officer. "The registrar is an officer whose business it 
is to see that the work of the university runs smoothly" (1922). It is important to mention that the history of AACR and AACRAO will be discussed in Chapter II.

According to Coffman (1926), the position of the registrar was a "glorified clerkship," chiefly responsible for keeping an accurate record of grades; the registrar was not involved in the determination of academic policies, and because the registrar was not a scholar, s/he had no standing with the faculty. A registrar is more than a recording and rating officer; as pointed out by Coffman, the registrar "sits at the center of the university's administrative life" (as cited in Von Munkwitz-Smith 2016).

The American Association of Collegiate Registrars and Admissions Officers (AACRAO) states that the central role of the university registrar historically has been "to preserve the integrity, accuracy, and privacy of all academic records; to interpret institutional and governmental policies to members of the academic and general community; and to efficiently distribute these records in full compliance with applicable policies, laws, and regulations" (Lauren, 2006, p. 2).

According to Lauren (2006), university registrars are the record keepers of their institutions. However, the role of the office of the registrar has expanded to include scheduling and registering students for classes, scheduling space and times for classes, ensuring that students meet graduation requirements, planning commencement ceremonies, processing grades and preparing transcripts and diplomas for students, collecting data about students and classes, maintaining the academic records of the institution, and ensuring that student data privacy requirements are met. As the office of 
the registrar role has evolved, the role of the university registrar has evolved as well and has played a central part in the history of higher education.

Today, the university registrar operates at the interface of all organizational functions in university life: between academic and administrative work, between governance and policymaking, and between faculty and students' interactions. Empirical research on university registrars, their professional development, training, and their role identity is sparse at best. The available literature on the university registrar role is little more than subjective guides, best practices manuals, and surveys on their duties, but there is not empirical research conducted on the role of the registrar seen from the perspectives of those holding the position.

\section{Statement of the Problem}

According to Preinkert (2005), the duties and relationships of the registrar's office in "universities" differ widely (p. 1). The character of the organization and operation of a registrar's office must be determined by the educational policies of the institution which

it serves. As defined by Preinkert, the "registrar" should have a broad, thorough, general education, followed by specialized study, including training in the problems of administration and education.

Commonly under-acknowledged as a backroom function focused on routine processing tasks, relatively little has been written about the university registrar role. The American Association of Collegiate Registrars and Admissions Officers, the sole professional association directly affiliated with the work of registrars, has accumulated, 
over the years, a number of articles, essays, manuals, surveys, and books documenting the historical evolution of the registrar and the registration profession.

The lack of empirical studies about the true meaning of the evolving role of the registrar is a problem needing study. No one wakes up one day and says, "I want to study to become a university registrar," and as of today, new colleagues, even seasoned, to the profession have the same question: what are my responsibilities as a university registrar? Wolk (2019, p. 34) pointed out that "the first year as a registrar will be invaluable"; he mentioned that it would increase the capacity to lead and learn the value of strategic partnerships across campus and have a better appreciation of the work that registrars do.

These are the bodies of literature about the registrar's role: The Work of the Registrar: A Summary of Principles and Practices in American Universities and Colleges 1910-1939 was an important contribution to the literature of the field when it was compiled in 1940 (reissued by AACRAO in 2005). Their next publication was in 2006, The Registrar's Guide: Evolving Practices in Records and Registration. The next publication was in 2014, Handbook of Strategic Enrollment Management, in which only one chapter was dedicated to the role of the university registrar. In August 2015, AACRAO released its first "Registrar Career Profile" survey. Finally, in 2018, AACRAO released their Registrar's Basic Guide.

Even within AACRO literature, there seems to be a misconception on how to differentiate the role of the registrar versus the role of the "office" of the registrar. In 2018, the Registrar's Basic Guide was released by AACRAO. The "guide" contains ten chapters, and each one is written by a different author. While Meyers (2018, p. 27) 
referred to the registrar as "an administrator, a manager, and a leader of an essential office that provides services to students, faculty, and administrators," Schipporeit (p. 43) described that the "registrar's office" is in a prime position to "influence" the development of academic policy at the institution. The two quotes described above are clear examples of the divided understanding of the role of the registrar versus the role of the office of the registrar, even within AACRAO's authors.

According to Sauter and Shanken (2014, p. 310), the importance of the registrar role has not been well documented. The available literature on the university registrar role is little more than subjective guides, best practices manuals, and surveys on their duties. We do not know the real meaning of the registrar position, how university registrars spend their time, and what is meaningful and gratifying about their role. There is no empirical research conducted on the role of the registrar from their perspectives of the position. There is not enough information on career paths that they followed to become a university registrar.

Finally, I consider important to mention that the intent of $m$ study is not to discredit the valuable efforts, information, training, articles, and conferences that AACRAO has to offer to their membership which is valuable to the registrar's office staff, but rather, my study is an attempt to identify the gap between subjective guidelines and the lack of empirical research of the actual role of the university registrar.

\section{Purpose of the Study}

Empirical research on university registrars, their professional development, training, and their role identity is sparse. My study contributes to the empirical research 
and literature on the role of the university registrar. Therefore, I conducted my qualitative interview study to provide rich narratives and descriptions of the role of the university registrar form the participants' perspectives.

Using qualitative interviewing and document analysis of job descriptions and resumes, the purpose of my study is to understand the experiences of university registrars, particularly their perspectives on their professional practice, development, and identity. I chose to study registrars across the country that belong to AACRAO because of my close ties with the association as well as personal connection and interest in this particular profession.

Because little is known about how university registrars spend their time or how they make sense of their role, professionally and personally, a qualitative interview study is appropriate. I used a qualitative interview study and document analysis to gain insight into the experiences of nine registrars from public and private universities. More specifically, my study used a semi-structured interview scheme adapted from Seidman (2013). The transcripts were transcribed, coded, and analyzed entirely by me; once themes and sub-themes were identified, I was able to organize my findings to answer the research question in my study.

\section{Research Question}

The purpose of the qualitative interview study is to understand the nature of the role of the university registrar from the participants' perspectives, given the changing nature of higher education. The following singular research question is answered by the present study: How do university registrars perceive their roles in higher education? 


\section{Introducing the Researcher}

I have been working in higher education for the last sixteen years, the last ten of which have been with direct contact with university registrars. At FIU, I interacted directly with three different registrars; at Harvard University, each school has a registrar, and therefore I have interacted with ten registrars. Most importantly, as an active member of AACRAO, FACRAO, and NEACRAO, I have interacted with dozens of university registrars around the country, even with a couple from international locations. During these interactions and observations, new registrar colleagues - even seasoned - to the profession have the same question: what are my responsibilities as a registrar?

To broaden my perspective, I have attended AACRAO, FACRAO, and NEACRAO conferences and served in different positions in the executive committee including the president - at FACRAO, Director of Membership - at NEACRAO, and Chair of Latinx Caucus - at AACRAO. At the same time, I continue reviewing AACRAO's literature about the role of the registrar or the office of the registrar to grasp the main concepts of the role of the profession. It was then that I became aware of the absence of empirical studies and reports concerning the role of the registrar at universities.

\section{Significance of the Study}

According to AACRAO’s 2015 U.S. Registrar Career Profile, it was anticipated that 1,672 registrars will change their employment in three years or less (p. 2); this number represents $25 \%$ of the registrar population of the United States. According to the U.S. Department of Education, National Center for Education Statistics (NCES) (2020), 
in 2017 there were 4,360 postsecondary Title IV degree-granting institutions in the United States and 2,246 non-degree-granting institutions - 6,606 institutions/registrars in total. While the anticipated change of $25 \%$ of the registrar population provides opportunities for other individuals seeking to become registrars, it will also likely pose challenges for institutions in succession planning and in the ability to recruit qualified candidates for the position.

My study purports to give universities a better understanding of the role and responsibilities of the registrar by providing insight into what registrars actually do. It might prove useful in helping universities search for "qualified candidates," and individual registrars might find it important in preparing better for their roles. The findings show the pathways the participants followed to become a registrar, their skills, roles, responsibilities, challenges, and professional development--all derived from their own perspectives. We thus can have a better understanding of the university registrar role.

Additionally, I hope to create an avenue for AACRAO and institutions to work together and create programs to standardize the role of the registrar. My study should serve to create the core functions of the role of the registrar as well as challenges and emerging trends. My study should also contribute to adding knowledge to the existing literature on the role of the registrar.

\section{Limitations of the Study}

The study focuses solely on university registrars and not assistant or associate registrars. Also, the study explores the self-perception of the registrars' role in higher 
education. It does not intend to examine colleague perceptions of the registrar role; consequently, no provision has been made to obtain data from others, that is, the subordinates, peers, and superiors of registrars. Finally, my study is also limited by its reliance on self-perception as a data source. It is possible that some registrars will emphasize particular areas and deemphasize others because of the lack of a complete understanding of their own role.

\section{List of Abbreviations}

The following are terms used throughout this dissertation that may be unfamiliar or have multiple meanings to the reader:

1. AACR: American Association of Collegiate Registrars

2. AACRAO: American Association of Collegiate Registrars and Admissions Officers

3. $A A U$ : Association of American Universities

4. FACRAO: Florida Association of Collegiate Registrars and Admissions Officers

5. FIU: Florida International University

6. NEACRAO: New England Association of Collegiate Registrars and Admissions Officers

7. ROs: Registrar's Office

8. SUS: State University System

\section{Chapter Summary}

In Chapter I, I discussed how the role of the university is perceived in higher education and how the empirical research about it is sparse. A registrar is more than a recording and rating officer; as pointed out by Coffman, the registrar "sits at the center of the university's administrative life" (as cited in Von Munkwitz-Smith, 2016). My study 
aims to contribute to empirical research and literature on the role of the university registrar. I also described how AACRAO, the sole professional association directly affiliated with the work of registrars, has accumulated, over the years, a number of articles, essays, manuals, surveys, and books documenting the historical evolution of the registrar and the registration profession.

However, the lack of empirical studies about the true meaning of this evolving role is a problem needing study. Even within AACRO literature, there seems to be a misconception on how to differentiate the role of the registrar versus the role of the "office" of the registrar. My study provides an understanding of the role of the university registrar by conducting in-depth qualitative research by interviewing university registrars about their perceptions of the meaning of their role in order to understand and contribute to the existing literature.

In Chapter I, I presented the study's single research question, which is centered on how university registrars perceive their roles in higher education. I gave the statement of the problem, the background to the study, and the purpose of the study, which summarized how I addressed the problem. Following this, I described this study's significance and explained the limitations of the study. Limitations include reliance on self-perception as the data source. It is possible that some registrars will emphasize particular areas and deemphasize others based on the lack of a complete understanding of their own role. The following chapter consists of a review of the literature on the role of the university registrar. 


\section{CHAPTER II}

\section{LITERATURE REVIEW}

According to Sauter and Shanken (2014, p. 310), the importance of the registrar role has not been well documented. Commonly under-acknowledged as a backroom function focused on routine processing tasks, relatively little has been written about the registrar role. The sole professional association, AACRAO, directly affiliated with the work of registrars, has accumulated, over the years, a small number of significant articles, guidelines, essays, manuals, and books documenting the historical evolution and the role of the registrar.

The purpose of this qualitative interview study was to understand the role of the university registrar from the participants' perspectives. A study of the role of the registrar in higher education requires a review of the literature on the history and responsibilities of the university registrar, as described by AACRAO. There is a small body of literature that will provide a useful framework for understanding the evolution of the position as well as the expectations and responsibilities associated with the university registrar.

However, it is important to mention that the following literature on the university registrar role is really more subjective guidelines and best practices than empirical research on the topic, and at times it reflects the role of the "office of the registrar" rather than the role of the registrar. I consider it important to mention that the intent of the study is not to discredit or criticize the valuable information, training, articles, and conferences that AACRAO offers to their membership, but rather it is an attempt to identify the gap between subjective guidelines and the actual role of the university registrar. 


\section{Origins of the Registrar}

The office of the registrar dates back at least to fifteenth-century Oxford. As noted by Young $(2006$, p.2), it often fell to the beadles of the three great medieval universities Bologna, Paris, and Oxford - to collect, maintain, and disseminate academic records and institutional communications. According to Young, from the medieval origins of the office of the registrar to its challenges in the twenty-first century, its central mission has remained remarkably the same: "to preserve the integrity, accuracy, and privacy of all academic records; to interpret institutional and governmental policies to members of the academic and general community; and to efficiently distribute these records in full compliance with applicable policies, laws, and regulations" (p. 3).

"In the early colleges and universities in the United States, administrations were typically run by the president alone; however, with increased enrollment, and the demand for expanded services, one man could no longer handle all the administrative functions. Due to the necessity of increased record-keeping, one of the earliest of these administrative positions to emerge was the registrar." (Taylor, 2015, p.1)

According to Kisling (2014), the role of registrar developed out of the faculty from the need to record and authenticate student educational records. This is supported by Young (2006, p.3), by mentioning that while these fundamental functions of the registrar appear to have emerged almost simultaneously with the academy itself, academic recordkeeping in nineteenth-century America still fell predominantly as a part-time duty to faculty or to the president of the university. 
This is supported as well by Taylor $(2015$, p. 1), she mentioned that duties

originally performed by the president, with assistance from a secretary, were delegated to faculty members. However, because increased demands for teaching and research became too burdensome, then positions such as deans, business offices, deans of men and women, and the registrar were created.

As cited by Taylor (2015, p. 32 ), in a speech presented to the seventh annual meeting of the American Association of Collegiate Registrars at Columbia in 1916, Nicholas Murray Butler, president of Columbia University (King's College, est.1754), gave a brief history of the beginnings of the registrar at his institution and others of that time:

The Registrar here at Columbia was at first the President, and you will find here in these old records which are assembled in this room, original entries in the handwriting of the President of the College. Then it was usual to assign these duties to a professor, who was the recording officer of the Faculty. Then later a clerk was provided; not a Registrar, but a clerk. He assisted the President in writing letters, in keeping records, in checking up the very small and insignificant accounts of those days. That officer developed eventually into the Registrar with his group of assistants, with his clerical staff, and with all the modern paraphernalia of an office of record and account. That illustrates two things: first, it illustrates how extensive and in a way how rapid this evolution has been; and it illustrates in the second place what I want most to insist upon, how personal the relationship of this work is, and how it grew out of the most intimate personal relationship in American college life, that is the original relationship between the eighteenth century or early nineteenth-century president, and the students who were committed to his care.

Historical research of when appointments or position creation took place can be a challenging process. According to Young (p. 4), Stanford was the first university that hired the first full-time registrar in 1891; Ohio State University and Dartmouth instated full-time registrars shortly thereafter. This contradicts with Taylor's (2015, p. 33) 
research, where she mentioned that "while reference to a registrar is made in various writings that imply the role existed at Harvard from its beginning and at Yale by at least 1745, a survey conducted in the late 1930s indicates that Brown University (est. 1764) actually had the first registrar (1828), but not under the specific title of registrar."

Having a faculty member as a part-time record keeper was acceptable in 1770, when Harvard, one of the twelve small colleges in the county, "admitted only 413 students" (Young, 2006). However, as more and more institutions of higher education opened their doors, this approach became less and less reasonable. According to Young (2006, p. 1), by 1910, the founding year of the American Association of Collegiate Registrars - AACR, now AACRAO - 76 percent of universities belonging to the American Association of Universities had registrars. The successful registrar's office serves the entire community, both within and outside the academy, as a set of valves of the beating heart of the institution. Forty-two percent of AAU universities had designated registrars by 1900 and 76 percent by 1910 .

According to the NCES (2020), in 2017, there were 4,360 post-secondary Title IV degree-granting institutions in the United States and 2,246 not degree-granting institutions $-6,606$ institutions in total. Today, every college and university in the United States has an administrator or registrar in charge of student records.

\section{Professionalization of the Registrar}

In the early days, student records were kept by the president with some assistance from his secretary; later, it was delegated to faculty. Taylor (2015, p. 39) pointed out that the duties as registrar were not time-consuming in the early days because faculty 
appointed as registrars also had teaching obligations. McGrath's survey shows that over time, the number of registrars who also taught decreased significantly, from 75 percent in 1860 to 21.4 percent in 1933, as cited in Taylor (p. 40).

The most recent survey about the career profile of the registrar was conducted by AACRAO in 2018. The survey does not have any indicators, metrics, or evidence that the current role of the registrar has any teaching responsibilities as part of the role. As part of my study, the registrars I interviewed did not mention they hold any teaching responsibilities as part of their role.

As the number of registrars who also taught declined, it was unavoidable that the highest degree held by registrars would correspondingly decline. As cited in Taylor (2005, p. 40), about 40 percent of the registrars holding office from 1860 to 1933 held a Master's degree as their highest degree; over time, that percentage decreased to 25 percent and the percentage of those holding a Bachelor's degree increased from 25 to 57 percent.

There is no evidence of additional surveys conducted about the profile of the registrar between 1933 and 2015. Therefore, it is unknown how the percentages of the highest degree that the role of the registrar held changed between these years. Based on the 2015 AACRAO's U.S. Registrar Career Profile, 60 percent of the registrars held a master's degree, 27 percent held a bachelor's degree, and 8 percent held a Doctorate degree. This is evidence that as the role shifted from being an additional task appointed to faculty to a role by itself, it required training different from that of a scholar. 


\section{American Association of Collegiate Registrars and Admissions Officers}

Since my study contributes to the empirical research and literature of the role of the registrar, I considered it important to discuss the origins and formation of the sole professional association dedicated to the registrar's office: AACRAO. AACRAO is a “non-profit, voluntary, professional association of more than 11,000 higher education professionals who represent approximately 2,600 institutions in more than 40 countries" (American Association of Collegiate Registrars and Admissions Officers [AACRAO], n.d.).

AACRAO’s mission is “to provide professional development, guidelines, and voluntary standards to be used by higher education officials regarding the best practices in records management, admissions, enrollment management, administrative information technology, and student services" (American Association of Collegiate Registrars and Admissions Officers [AACRAO], n.d.).

According to AACRAO, the association "represents institutions in every part of the higher education community, from large public institutions to small, private liberal arts colleges. The association promotes the well-being and advancement of professionals in the higher education community by engaging members in the collaborative pursuit of excellence in admissions, registration, and enrollment services. The association provides relevant programs, professional development tools, and information resources necessary to chart the course for professional success" (n.d.).

According to Taylor (2015, p. 44), between the winter of 1909 and spring of 1910, Alfred Parrot, registrar at the University of North Dakota (North Dakota 
Agricultural College), sent about 50 letters to other registrars across the country proposing a meeting to discuss their professions as registrars and to talk about their mutual problems. According to Taylor (2015, p. 45), attendees to the first meeting were encouraged to bring samples of forms used on their campuses and invited them to submit discussion questions. The response was "overwhelmingly" positive, and on August 5, 1910, fifteen registrars and nine college accountants and financial secretaries met in Detroit, Michigan.

This small band of professional pioneers tackled the pressing issues of their day and, in so doing, left a record of what now seems a timeless agenda. According to Henderson, (2006, p. 466) the 1910 meeting dealt with pressing issues such as "duties or functions of a college registrar; academic transfer from one college to another; how to secure a prompt report of students' grades from instructors; grade inflation; faculty advisers for students; issues with late registration; and others." Before adjourning this first meeting, these pioneers decided to form a permanent national organization of registrars to meet annually. Therefore, the American Association of Collegiate Registrars (AACR) was born in 1910, one of the first specialized higher education professional associations in the United States, as stated by Henderson.

Given our current issues of diversity and inclusion of underrepresented minorities in leadership positions in higher education in the United States, I think it is important to note that in the first meeting of AACR, out of the 24 attendees, only two female registrars were in attendance. According to Taylor (2005, p. 52), the two only females in attendance were Miss Elida Yakely, Michigan Agricultural College, and Mrs. E.A. Balentine, 
University of Maine. In keeping with "roles traditionally assigned to females," Miss Yakely was appointed Secretary of the meeting.

Taylor commented further that E.A Balentine was very much aware that as a female registrar, she was a minority; therefore, her attendance at the first meeting was a surprise as she had signed her letter of attendance as E.A. Balentine since it did not have an indication of her gender. In keeping with the stereotypical tradition of the time, Balentine was appointed Secretary of the association in its second year. Additionally, there is no trace of Black or African American, American Indian or Alaska Native, Asian, or Hispanic or Latino persons in attendance at the first meeting.

The formation of AACRAO in 1910, first known as AACR, was a key element in the efforts to professionalize the occupation of the registrar. As described by Taylor (2005, p. 72), two factors led to the early growth and exposure of the newly formed association: initiation of the publication Bulletin in 1925 and the branching out of the national association into regional and state organizations, beginning as early as 1921. It was during the 1922 Annual Meeting in St. Louis that registrars were urged to organize by states and regions. The state and regional branches all survived and grew, providing more local, less expensive educational opportunities for many. Today, there are 39 active state and regional branches of AACRAO; they are called ACRAOs.

According to Henderson (2006, p. 465), since its inception, AACRAO has provided services for its members by sharing issues of mutual interest amongst registrars. This soon evolved into an effort to change the perception from that of a clerk to an 
administrative officer. The association gradually became the means by which members could develop guidelines and standards of practice in defining the registrar profession.

\section{Training, Education and Professional Development of the Registrar}

According to Preinkert (2005, p. 5), the registrar should have a broad, thorough, general education, followed by specialized study, including training in the problems of administration and education, and possibly experience in teaching and research in some field of knowledge. As described by Taylor (2015, p. 78), in a 1926 presentation and subsequent paper, from the Fourth Annual Institute for Registrars, J.R. Robinson, Registrar of Eastern State Teachers College, listed 44 specific duties of the Registrar. However, it was Robinson's (as cited in Taylor) conclusion that the minimum amount of training for registrars should include:

1. A four-year college course;

2. Post-graduate work in education for at least one year with major in supervision and training in research; and

3. A course in office work, keeping of records, office management, and person-management.

Aside from Robinson's conclusion on the minimum amount of education and training of the registrar, there has not been additional discussion or recommendations made by AACRAO. Today, each institution has different requirements, job descriptions, minimum education, and experience required for its registrar position based on the institution's needs and culture.

As mentioned before, AACRAO is the sole association that supports professional development for registrars. Preinkert (2005) emphasized that AACRAO furnishes real assistance to "all registrars" in furthering their training. It provides literature problems 
that cannot be obtained elsewhere--which I debate because each institution is different, and training of the registrar cannot be treated as a one size fits all. One of the advantages of AACRAO is its national and regional meetings; these meetings allow novice and even seasoned registrars to connect with experienced registrars within their state or region.

Registrars and members of their staff who are able to attend institutes for registrars will find these meetings of value and interest. Registrars new to the position may profit by correspondence with other registrars about academic calendars, technology, policies, etc. Preinkert (2005) also recommends to novice registrars that observation is valuable training; this can be accomplished by participation or internship in a registrar's office. Finally, as part of the study, one of the purposes is to understand what other types of professional development, aside from AACRAO and ACRAOs, registrars attend to in order to keep up with the demands of their profession these days.

\section{The Evolving Role and Functions of the Registrar}

Registrars have the greatest opportunity to assume a leading role in the administration of the affairs of our educational system that we ever had. How well we shall assume and discharge these responsibilities remains in the main to be seen. Indications and trends are that we shall succeed.

(Heaton, 1947)

The registrars, through their own efforts, have been able to attain this enviable position. They have risen from the status of a glorified office clerk to that of an administrative officer attending to affairs that affect the lifestream of an institution. The duties and relationships of registrars differ widely; the character of the organization and operation of a registrar's office must be determined by the educational policies of the institution which it serves. 
As the steward of the student academic record and keeper of institutional data, the registrar is in a unique role at the institution. According to Preinkert (2005, p. 7), one of the first functions of the registrar is to perfect the technique of his office so that the administrative machinery moves with the minimum amount of friction and gives a service proportionate to the energy expended - "the most efficient system is also the simplest system (p. 7).

It is interesting how Kisling (2014) emphasized that:

One problem with office functions such as registration and records is that, as they have moved further from direct faculty involvement, they have devolved at many institutions to be primarily clerical in nature. Student record data is received from admissions and is prepared for registration. Student registration data is received, and class rosters are developed and maintained. Grades for classes are received and transcripts are produced. Transcripts are reviewed for completion of program requirements and degrees are awarded (para. 3).

Many of these functions are clerical in nature and require detailed and efficient processes to maintain accurate records of enrollment data. An interesting observation, according to Kisling (2014), is that "technological solutions now exist that allow software systems to do most of these basic clerical functions. If that technology is implemented, what then becomes the responsibility of the registrar's office staff?" Although Kisling brings up a good point about automation, technology in higher education is not made to replace humans but to enhance productivity, increase efficiencies, reduce costs, and contribute to the institution's mission, as mentioned by Spaulding (2018, p. 69). 
Sauter \& Shanken (2014) asserted that beyond those basics, registrars possess policy and process expertise that underpin academics, as well as several other vital campus functions, and thus are of vital importance. The registrar is in prime position to influence the development of academic policy at the institution. Registrar's policy expertise includes enforcing academic policy, monitoring student academic progress, and complying with federal and state regulations, including often being the chief institutional officer for adherence with the Federal Educational Rights and Privacy Act (FERPA). Schipporeit $(2015$, p. 43) pointed out that although the role of the registrar in policy creation and enforcement varies among institutions, most have the opportunity to affect policy creation, revision, or enforcement at some level.

The Registrar's Basic Guide, published in 2018, is AACRAO's first attempt to differentiate the role of the registrar versus the role of the office of the registrar. This "guide" contains ten chapters, and each one is written by a different author. While Meyers (2018, p. 27) referred to the registrar as "an administrator, a manager, and a leader of an essential office that provides services to students, faculty, and administrators," Schipporeit (p. 43) described that the "registrar's office" is in a prime position to "influence" the development of academic policy at the institution. This is a clear example of the divided idea of the role of the registrar versus the office of the registrar, even within AACRAO.

Schipporeit (2018, p. 3) described that key elements of the registrar's role include professional, functional, and technology roles; as mentioned above, this is the first time that an AACRAO publication attempts to leave behind the functional aspect of the 
registrar's office as part of the registrar role and treats the position as a leadership role. However, a few pages later, even the same author starts going back to the same approach of merging both roles. For example, he mentioned that the registrar often administers services such as "scheduling, registration, and commencement." (p. 5) One thing is clear; the role of the registrar is increasingly analytical rather than transactional. Since this publication is the most current guideline about the role and responsibilities of the registrar, I will be using it as well as part of the findings chapter of the study.

\section{U.S. Registrar Career Profile}

The American Association of Collegiate Registrars and Admissions Officers released in 2015 its first career profile survey about the role of the registrar. This is the first time AACRAO attempted to get some data about the role of the registrar. Although the intent of my study was not to dive deep into gender and ethnicity, I consider important to acknowledge the results of the survey about the ethnic and racial profile of this cohort; nearly nine out of ten registrars identified as white; just 5 percent identified as Hispanic or Latino; 6 percent identified as Black or African American; and 3 percent identified as Asian.

To better describe the role of the registrar, table 2.1 displays the comparison of the functions of the registrar from four different AACRAO publications. The First one is from the "first meeting" in 1910; the second one is from 1934 when the committee from AACR publicly defined the first list of functions of the registrar (Preinkert, 2005). The third one is from The Registrar's Guide (Lauren, 2006). The fourth and last one is the most recent list described in AACRAO’s 2015 Registrar Career Profile survey. As we 
can observe, the functions of the registrar (and the registrar's office) have changed over time; however, this information has been provided by AACRAO.

It is important to mention that the survey of 2015 was the first attempt by AACRAO to build a foundation of understanding of the career profile and position responsibilities for the registrars in the United States. There is a better survey released in 2018; however, it was opened to all registrars in the world, and since this study only relates to registrars in the United States, it will not be used as part of this research.

Table 2.2 displays the 27 registrar's portfolios of responsibilities, as described in the 2015 survey. According to AACRAO, the results attempted to gauge levels of involvement for each. Each level of involvement is defined as follows:

- Responsible $=$ not a delegated function

- Supervise $=$ delegated and supervised

- Participate $=$ neither delegate nor supervise but influence in decisions

- Inform = relay information about a function but have no decision making

- $\mathrm{N} / \mathrm{A}=$ none of these

A weakness that I find about this part of the survey is that each function is not defined as part of the survey; this leaves ample stipulation to what each of these functions entitles. It is important to mention that some of these functions are not included as part of any training materials, guidelines, or articles within AACRAO. The survey does not indicate either how these 27 functions were selected. Each of these functions will be defined as part of this literature review for the sole purpose of demonstrating that these are more closely related to the role of the office of the registrar rather than to the role of the registrar. 
Table 2.1

\begin{tabular}{|c|c|c|c|}
\hline 1910 AACR & $\begin{array}{c}1934 \text { AACR } \\
\text { (Preinkert, 2005) }\end{array}$ & $\begin{array}{l}\text { Registrar's Guide } \\
\text { (Lauren, 2006) }\end{array}$ & $\begin{array}{c}\text { AACRAO Career Profile } \\
\text { (2015) }\end{array}$ \\
\hline Admissions & Admissions & Academic Policy & $\begin{array}{l}\text { Academic Calendar } \\
\text { Development }\end{array}$ \\
\hline $\begin{array}{c}\text { Recorder of } \\
\text { Students Credits }\end{array}$ & Registration Procedures & Curriculum Development & Ad-hoc reporting and research \\
\hline Correspondence & Time and room scheduling & Managing Registrar's Office & Athletic eligibility certification \\
\hline Attendance & Scholastic Records & Project Management & Budget development \\
\hline Roster or Schedule & Reports and Transcripts & $\begin{array}{l}\text { Implementation and } \\
\text { maintenance of student } \\
\text { information systems }\end{array}$ & Class schedule development \\
\hline Bulletin \& Catalog & Graduation & $\begin{array}{l}\text { Registration and related } \\
\text { functions }\end{array}$ & Commencement ceremony \\
\hline $\begin{array}{c}\text { Discipline \& } \\
\text { Administration }\end{array}$ & Assessment of fees & Academic Scheduling & $\begin{array}{l}\text { Curriculum/program approval } \\
\text { and revision process }\end{array}$ \\
\hline \multirow[t]{20}{*}{$\begin{array}{c}\text { Secretary of } \\
\text { Faculty \& Trustees } \\
\end{array}$} & Advising & Academic Calendar & $\begin{array}{l}\text { Degree audit maintenance } \\
\text { (coding) }\end{array}$ \\
\hline & $\begin{array}{l}\text { Minutes of faculty and } \\
\text { committees }\end{array}$ & $\begin{array}{l}\text { Communication to } \\
\text { constituents }\end{array}$ & Early academic alert \\
\hline & Editorial work & $\begin{array}{l}\text { Records Retention and } \\
\text { Disaster Recovery }\end{array}$ & Enrollment reporting/research \\
\hline & Information service & $\begin{array}{c}\text { Certification of enrollment } \\
\text { status }\end{array}$ & Facilities/activities scheduling \\
\hline & $\begin{array}{l}\text { Statistical studies and } \\
\text { reports }\end{array}$ & Student Athletes & $\begin{array}{l}\text { FERPA compliance and } \\
\text { training }\end{array}$ \\
\hline & & Veteran Students & IPEDS reporting \\
\hline & & Degree Audit & Non-degree admission \\
\hline & & Transfer and Articulation & $\begin{array}{c}\text { Academic records } \\
\text { management }\end{array}$ \\
\hline & & Graduation & Re-admit processing \\
\hline & & Reporting & Residency determination \\
\hline & & FERPA & $\begin{array}{l}\text { Student information system } \\
\text { management and development }\end{array}$ \\
\hline & & & Transfer credit evaluation \\
\hline & & & $\begin{array}{c}\text { Veterans education } \\
\text { certification and reporting }\end{array}$ \\
\hline & & & Advising \\
\hline & & & Classroom scheduling \\
\hline & & & Course evaluation \\
\hline & & & $\begin{array}{l}\text { Certify candidates for } \\
\text { graduation }\end{array}$ \\
\hline & & & Degree verification \\
\hline & & & Transcript processing \\
\hline & & & Tuition and fees \\
\hline
\end{tabular}


Table 2.2

\begin{tabular}{|c|c|c|c|c|c|c|}
\hline & Responsible & Supervise & Participate & Inform & N/A & Count \\
\hline Academic calendar development & $51.7 \%$ & $11.8 \%$ & $26.9 \%$ & $6.6 \%$ & $3.1 \%$ & 685 \\
\hline Ad-hoc reporting and research & $33.5 \%$ & $25.1 \%$ & $32.9 \%$ & $5.0 \%$ & $3.4 \%$ & 680 \\
\hline Athletic eligibility certification & $20.8 \%$ & $24.4 \%$ & $11.7 \%$ & $8.9 \%$ & $34.2 \%$ & 684 \\
\hline Budget development & $49.1 \%$ & $5.9 \%$ & $24.0 \%$ & $11.4 \%$ & $9.5 \%$ & 682 \\
\hline Class schedule development & $23.8 \%$ & $38.9 \%$ & $21.1 \%$ & $9.8 \%$ & $6.4 \%$ & 686 \\
\hline $\begin{array}{l}\text { Commencement/graduation } \\
\text { ceremony(s) }\end{array}$ & $35.4 \%$ & $16.8 \%$ & $35.0 \%$ & $6.4 \%$ & $6.4 \%$ & 686 \\
\hline $\begin{array}{l}\text { Curriculum/program approval and } \\
\text { revision process }\end{array}$ & $9.7 \%$ & $11.4 \%$ & $56.7 \%$ & $13.9 \%$ & $8.3 \%$ & 683 \\
\hline Degree audit maintenance (coding) & $40.6 \%$ & $45.6 \%$ & $6.8 \%$ & $3.1 \%$ & $3.9 \%$ & 687 \\
\hline Early academic alert & $11.3 \%$ & $13.0 \%$ & $32.7 \%$ & $19.8 \%$ & $23.2 \%$ & 682 \\
\hline Enrollment reporting/research & $35.2 \%$ & $19.6 \%$ & $29.6 \%$ & $8.7 \%$ & $6.9 \%$ & 682 \\
\hline Facilities/activities scheduling & $6.2 \%$ & $21.7 \%$ & $19.1 \%$ & $14.4 \%$ & $38.6 \%$ & 681 \\
\hline FERPA compliance and training & $72.3 \%$ & $13.8 \%$ & $9.7 \%$ & $2.5 \%$ & $1.8 \%$ & 683 \\
\hline IPEDS reporting & $21.6 \%$ & $7.7 \%$ & $24.1 \%$ & $21.8 \%$ & $24.7 \%$ & 684 \\
\hline Non-degree admission & $13.0 \%$ & $19.9 \%$ & $19.5 \%$ & $12.9 \%$ & $34.6 \%$ & 682 \\
\hline Academic records management & $63.4 \%$ & $35.3 \%$ & $1.2 \%$ & $0.1 \%$ & $0.0 \%$ & 685 \\
\hline Re-admit processing & $13.8 \%$ & $26.1 \%$ & $27.0 \%$ & $12.2 \%$ & $21.0 \%$ & 682 \\
\hline Residency determination & $15.6 \%$ & $19.2 \%$ & $9.4 \%$ & $6.9 \%$ & $48.9 \%$ & 681 \\
\hline $\begin{array}{l}\text { Student information system } \\
\text { management and development }\end{array}$ & $34.4 \%$ & $16.5 \%$ & $42.1 \%$ & $5.0 \%$ & $2.0 \%$ & 684 \\
\hline Transfer credit evaluation & $29.0 \%$ & $46.5 \%$ & $10.1 \%$ & $7.3 \%$ & $7.1 \%$ & 686 \\
\hline $\begin{array}{l}\text { Veterans education certification } \\
\text { and reporting }\end{array}$ & $21.7 \%$ & $30.6 \%$ & $12.8 \%$ & $10.5 \%$ & $24.5 \%$ & 687 \\
\hline Advising & $7.2 \%$ & $11.0 \%$ & $46.0 \%$ & $25.0 \%$ & $10.9 \%$ & 681 \\
\hline Classroom scheduling & $26.6 \%$ & $40.4 \%$ & $10.7 \%$ & $8.8 \%$ & $13.5 \%$ & 683 \\
\hline Course evaluation & $11.2 \%$ & $15.2 \%$ & $14.0 \%$ & $16.2 \%$ & $43.4 \%$ & 679 \\
\hline Certify candidates for graduation & $47.1 \%$ & $44.2 \%$ & $6.1 \%$ & $1.3 \%$ & $1.3 \%$ & 688 \\
\hline Degree verification & $38.8 \%$ & $55.8 \%$ & $3.4 \%$ & $1.2 \%$ & $0.9 \%$ & 685 \\
\hline Transcript processing & $29.3 \%$ & $67.7 \%$ & $1.8 \%$ & $1.2 \%$ & $0.0 \%$ & 685 \\
\hline Tuition and fees & $2.5 \%$ & $3.8 \%$ & $21.1 \%$ & $24.7 \%$ & $47.9 \%$ & 681 \\
\hline
\end{tabular}




\section{Office of the Registrar Functional Responsibilities}

One of the registrar's major responsibilities is to manage the office of the registrar in an effective, efficient, and responsible manner, but that does not mean that the registrar should be involved in every single transaction. According to Geyer (2018, p. 27), the administration of academic records, registration, and schedule adjustment, class schedule, transfer credit, official transcripts, graduation, and many more all fall under the purview of the "registrar's office." The 27 functions of the responsibilities of the registrar will be defined below using different AACRAO's guidelines, articles, books, and publications. Finally, it is important to mention that each function described below might make a reference to the "survey results"; these results are the percentages provided in Table 2.2 (from the 2015 U.S. Registrar Career Profile).

\section{Academic Calendar Development}

On most universities, academic calendar dates for the beginning and end of terms normally are approved by the faculty senate. According to Laudeman (2006, p. 26), the "registrar" presents the background information and presents the calendar to the faculty senate or any other approval committee. Involvement in this process ensures that the registrar is aware of critical dates.

Voorhis \& Falkner (2006, p. 122) mentioned that the academic calendar should be established four years in advance; this will allow students to view the calendar for their entire career. The university community wants to know when holidays and breaks are, when grades are posted, and fees are due, faculty want to know when their grades are due, etcetera. According to Voorhis \& Falkner, a comprehensive calendar should include: 
- Deadlines for tuition and fees refunds

- Deadlines for withdrawing from classes

- Dates when grades are available for students at the end of term

- Deadlines for graduation application

- Deadlines for changing major

- Dates of registration

- Last date to register without incurring a late fee

- Last dates to add and drop courses

- Deadlines for applying for and accepting financial aid

- Date that final grades are due from faculty

\section{Ad-hoc Reporting and Research \& Enrollment reporting and Research}

As with many other functions and tasks, reporting is an example where the role of the registrar is not well defined. According to Preinkert (2005, p. 127), one of the most important professional functions of the "registrar" is to analyze and interpret data and to make reports and recommend changes and/or new policies which will be of use in improving the educational and administrative facilities of the institution. Also, as part of this role, reporting to the National Student Clearinghouse is an important task for the registrar's office.

As described by Preinkert (2005), the amount of information the registrar should assemble will depend not only on administrative demands, but also on the type, scope, and purposes of the institution. "Without an adequate number of competent assistants and the necessary equipment, the registrar cannot attack the problem of statistics in an effective way" (p. 127). It is interesting how Preinkert mentioned that this is an important role of the registrar; however, in many instances, this role falls under an associate registrar, business analysts, or even under the institutional research office. 


\section{Athletic Eligibility Certification}

According to Katz (2006), student-athletes must be certified as eligible to participate in college and university athletics under the rules of the applicable governing bodies within and outside the institution. Katz (2006) stated that the registrar plays a key role in an institution's effort to certify academic eligibility of student-athletes under the "National Collegiate Athletic Association (NCAA) rules for Division I, II, or III."

However, this task is so complex and time-consuming that according to the AACRAO profile career survey, only 20.8 percent of the registrars are responsible for this process. It is also interesting to point out that none of my participants mentioned NCAA as part of their roles and responsibilities.

\section{Budget Development}

According to AACRAO's career profile survey, 49.1 percent of the registrars are directly responsible for this function. According to Sauter (2006, p. 453)," it has never been more important for registrars to possess basic knowledge of budgeting. the need to do more with less, even as students' and society's expectations increase, seems more urgent than ever."

Sauter (2006, p. 454) described that most of the registrars' education, training, and experience has not primarily been in finance or business. 'Nevertheless, the registrar has the dual responsibility of running the office in a fiscally prudent manner and of serving as the office's advocate for increased funding to carry out its responsibilities" (p.454). 
Sauter (2006, p.455) recommends that registrars new to fiscal administration should first read the policies and procedures manual that sets forth their institution's guidelines for disbursing money. A key aspect of the registrar is knowing the basics of their campuses' initiatives regarding enrollment projections since these will eventually affect their budget. Normally, this function falls under the associate registrar of operations or the office manager.

\section{Class Schedule Development, Classroom, Facilities, and Activities Scheduling}

Registrars that are responsible for this function represent only 23.8 percent of the survey. Lonabocker and Wager (2006, p. 101) described academic scheduling as a core set of services:

The institutions' delivery of its courses and academic programs. This includes those courses that faculty teach, the classrooms in which courses and sections meet, the days and times that are assigned, the method of publishing the course schedule, and pertinent curricular issues such as general education, writing, and qualification requirements. Also, academic and class scheduling includes the necessity for future planning; planning as driven by enrollments, time to graduation, and the physical capacity of the instructional facilities. This task not only involves the "registrar," but normally, all academic departments are involved in this responsibility (p. 102).

\section{Commencement Ceremony}

Commencement is a significant commemoration of the academic experience. Pikowsky (2006, p. 288) refers to commencement as an "event that influences how 
students, their parents, and partners will relate to the institution after they leave. Every facet of graduation should be planned and managed to maximize the effectiveness and appeal of the services and events associated with this significant milestone."

Commencement exercises vary by institution and normally require collaboration from different offices. The most common processes that are handled at the office of the registrar are: Applying for graduation, final degree checks, posting degrees to transcripts, and diplomas. According to the survey, 35.4 percent of the registrars are responsible for this function; I think the high percentage response is due to this task being divided in the processes mentioned above. I think the percentage might decrease if graduation application and degree requirements check are considered as different tasks.

\section{Curriculum/Program Approval and Revision}

According to Lauderman (2006, p. 19), "institutional policy issues involving the curriculum and many allied areas can cover a wide range of topics." The survey results demonstrate that only 9.8 percent of the registrars are responsible for this function. Generally, this task is handled by a committee that, in many cases, includes faculty (or faculty senate).

According to Lauderman (2006), "the relationship of the registrar to curriculum development only includes serving as an adviser to the curriculum committee, providing data and benchmarking information, and then executing approved academic policies.

Given the registrars' exposure on a daily basis to the complexity of academic issues and their knowledge of the technology needed to implement solutions, registrars have much 
to add to any institution's curriculum committee and academic decision-making infrastructure" (p. 20).

\section{Degree Audit Maintenance (coding), Advising and Early Academic Alert}

According to the AACRAO's registrar profile survey, 40.6 percent of the registrars are responsible for the coding of degree audits. This, 40.6 percent, is a high percentage, and according to my experience, this percentage makes me doubt the validity of this survey. Degree audit is my strength; I have worked for many projects in public, private, and Ivy League universities; also, I have represented the degree audit advisory group at a national level. Based on my interactions with registrars at many institutions and associations, one out of approximately fifty registrars is responsible for coding degree audit rules and maintenance.

Medley (2006, p. 249) described degree audit as an "extremely useful function when it is set up, maintained, and supported properly." Not too far ago, the most common way to conduct a degree audit was to compare, on paper, courses earned against a checklist of requirements. According to Medley (p. 250), "in the 1980s, companies with an interest in higher education software began to offer off-the-shelf packages that make this comparison with relatively little human intervention."

According to Medley (2006, p. 250), "over the past 20 years, many colleges and universities either have purchased or created home-grown audit systems to automate the process." As an example, supporting Medley's statement, FIU implemented their degree audit system in 2010. Another example is Harvard University-- degree audit has currently been implemented in 2016-2017 for a group of schools. Universities with large student 
populations can benefit greatly by using a computerized solution to complete graduation audits.

As mentioned by Medley (2006, p. 251), "setting up a computerized degree audit system is a very involved process, with many choices and decisions having to be made in order to achieve the best outcome. The person setting up a degree audit system must understand the existing political and cultural makeup of the institution and try to minimize issues and anxieties that may arise." Based on my experience, the political aspect is very important; even more, when new technology is introduced, that will affect the current culture. Degree audit configuration requires a lot of time and dedication; this is not a task for a registrar.

\section{FERPA Compliance and Training}

It is not a surprise that this task has a 72.3 percent response as a task associated with the registrar. However, this task should be 100 percent owned by the registrar. There is enough information to write a book about FERPA. The purpose of this section is only to define FERPA. According to Backes (2006, p. 363), the Family Educational Rights and Privacy Act (FERPA) is a "student records privacy law that registrars must understand and apply on a daily basis."

FERPA is a "federal law that protects the privacy of student education records. The law applies to all schools that receive funds under an applicable program of the U.S. Department of Education” (p. 363). According to Backes (2006, p. 363), FERPA affords students who have attended a post-secondary institution the following rights related to their education records: 
- Inspect and review information in their educational records.

- Request a correction to their record.

- Have some control of the disclosure of personally identifiable information from these records (restrict the release of directory information or authorize the disclosure of non-directory information).

- File complaints with the U.S. Department of Education Family Policy Compliance Office (600 Independence Ave. SW, Washington, DC 20202).

Finally, FERPA does not apply to records of applicants for admission who are denied acceptance or, if accepted, do not attend an institution.

\section{Integrated Post-Secondary Education Data System (IPEDS) Reporting}

As with many other functions and tasks, IPEDS reporting is an example where the role of the registrar is not well defined. According to the National Center for Education Statistics (NCES) website, "IPEDS consist of a series of inter-related surveys administered by the NCES, within the U.S. Department of Education. The IPEDS surveys provide the core data on the enrollments, program completions, faculty, staff, and finances of postsecondary education institutions. It is mandatory for all institutions that participate in any Federal financial assistance programs authorized by Title IV" (n.d.). This is the only information available about IPEDS. Although 21.6 percent of the registrars are responsible for this function, there is no available information about this process within AACRAO resources.

\section{Non-degree Admissions and Re-admit Processing}

As with many other functions and tasks, non-degree admissions and re-admit processing is an example where the role of the registrar is not well defined. Based on my experience, non-degree enrollment status does not require a formal admission process or 
formal entrance requirements. Non-degree enrollment status is designed for students who wish to take courses but do not plan to pursue a degree. In many universities, non-degree seeking students' admissions process is handled at the registrar's office. This function is normally handled by the staff of the office of the registrar and not by the registrar. AACRAO does not offer additional information on how to process these students at the office of the registrar.

\section{Academic Records Management}

This function has the highest percentage, $64.3 \%$, after FERPA compliance and training. The function itself is not well defined and leaves ample room for interpretation. Academic records management may include registration, degree certification, transcripts, student-athletes, etc. It basically includes every aspect of the daily operations of the registrar's office.

\section{Student Information Systems Management and Development}

Faculty and staff often complain that software and technology are constantly driving decision making and policy. Krogh (2006 p. 66) described that Enterprise Resource Planning (ERP) is not software but is rather a system that manages information processes across the institution so as to provide more efficient and integrated operations. "The goal to supply through a software system all the knowledge an institution may need is ambitious indeed. Furthermore, the ability to meet this goal may have more to do with the implementation process and the people involved than with the software itself." (p. 66)

While the registrar may not be involved in the decision making on all the implementation, it is important for him or her to be aware of the answers and to 
contribute to the discussions. Of all the modules to be implemented - from finance, human resources, admissions, to financial aid - the records area is the largest, the most complex, and affects the greatest number of people and administrative units. For planning to be effective, the registrar must be involved; only then, the project will have the information needed to implement successfully.

\section{Transfer Credit Evaluation}

According to DiPaolo (2006, p. 259), "registrars at both the sending and receiving institutions can have a significant influence on the transferability of coursework." DiPaolo (2006, p. 261) also quoted a classic definition related to articulation that may resonate with registrars deeply involved in education policy and planning. Articulation is "the entire range of processes and relationships involved in the systematic movement of students interinstitutionally and intersegmentally throughout postsecondary education."

As mentioned by DiPaolo (2006, p. 261), articulation involves matching and substitution of courses deemed equivalent to some portion of the receiving institution's curriculum. According to Di Paolo (2006, p. 261), the aim of sound articulation is deceptively simple: "to facilitate the student's progress towards degree in an efficient manner."

\section{Veterans Education Certification and Reporting}

According to Krecek (2006, p. 239), the "Department of Veteran Affairs (VA) administers a number of programs to serve the nations' veterans; these include, most pertinently for academic administrators, the education programs of the GI Bill. Before an institution can certify students to participate in educational programs and services for 
eligible veterans and dependents, the institution itself must be certified by a State Approving Agency (SAA).”

Certification of veterans frequently is the responsibility of the registrar's office. However, based on my experience in working and collaborating with other universities, this responsibility rests instead in other offices such as the financial aid office or a standalone veterans affair office; the survey results, in my opinion, give conflicting information again with a 21.7 of the registrars actually processing these students.

\section{Course Evaluation}

No information was found at AACRAO. Normally this process falls outside the registrar's office.

\section{Certify Candidates for Graduation}

As with many other functions and tasks, certifying candidates for graduation is an example where the role of the registrar is not well defined. The academic advisor typically maintains a file in which, during each advising session, he or she makes notes against a checklist of degree requirements. However, each school has different processes for these checks and balances. Often, when a student applies to graduate, the appropriate staff will conduct a preliminary degree requirement check; then, in many instances, the application is sent to the registrar's office. The registrar's offices will determine if the student satisfies graduation requirements and proceed to post degrees. No further information is available at AACRAO. 


\section{Degree Verification}

No information was found at AACRAO. Normally, the registrar's office certifies letters in-house for degree verification. Also, the National Clearinghouse has agreements with schools to provide for this service.

\section{Transcript Processing}

No information was found at AACRAO. This process varies by school, but it can be either printed in-house or outsourced to external vendors.

\section{Tuition and Fees}

No information was found at AACRAO. Tuition and fees are established by the state (public universities) and/or the board of trustees (public/private universities).

\section{Chapter Summary}

In Chapter II, I presented the origins of the university registrar and how it transitioned from being a role embedded within the functions of the university president to then being part of the duties of a selected faculty; and finally how it evolved to be an appointed administrative position within the university. Following this, I described the professionalization and training of the registrar and the origins of AACRAO. This allowed us to understand how the role of the registrar has evolved during the last century.

I also discussed the 2015 U.S. Registrar Career Profile released by AACRAO in 2015. The results of this survey helped to describe the 27 "functions" of the registrar using AACRAO guidelines and literature. It is important to mention that some of these functions are not included as part of any training materials, guidelines, or articles within AACRAO. 
I considered it important to mention that, according to the U.S. Bureau of Labor Statistics, below is the description for the university registrar; however, it does not capture the essence of what it connotes to be a registrar. Once again, the duties of the role of the "office" of the registrar seem to continue getting confused with the actual role of the registrar.

Registrars have different duties throughout the school year. Before students register for classes, registrars must prepare schedules and course offerings. During registration and for the beginning of the semester, they help students sign up for, drop, and add courses. Toward the end of the semester, they plan graduation and ensure that students meet the requirements to graduate. Registrars need computer skills to create and maintain databases (n.d.).

As we can see from the literature review in Chapter II, there is not enough information about the role of the registrar but only origins, definition of processes, and guidelines about the profession. Today's challenges demand the university registrars to be prepared to deal with change in policies, cuts on public funding, and technology and innovation. There is not enough information or training that prepares university registrars for current challenges. 


\section{CHAPTER III}

\section{METHOD}

Empirical research on university registrars, their professional development, training, and their role identity is sparse. My study contributes to the empirical research and literature on the role of the university registrar. Therefore, I conducted this qualitative interview study to provide rich narratives and descriptions of the role of the university registrar form the participants' perspectives.

I used qualitative interviews and document analysis to gain insight into the experiences of nine registrars from public and private universities. More specifically, my study used a semi-structured interview scheme adapted from Seidman (2013). According to Seidman (p. 9), "at the root of in-depth interviewing is an interest in understanding the experiences of people as they see it, as well as the meaning they make of those experiences." The document analysis provided additional qualitative data that supported the interviews. Chapter III is organized as follows: the research design, research question, theoretical perspectives in qualitative research, document analysis, the researcher, participants, ethical issues, data collection, and data analysis.

\section{Research Design}

According to Sauter and Shanken (2014, p. 310), the importance of the registrar role has not been well documented. The research design is grounded in a qualitative interview study using two different data-collecting techniques to develop a comprehensive and meaningful understanding of the role of the registrar as suggested by Locke et al. (2004) and Rubin \& Rubin (1995). 
As mentioned by Bogdan and Biklen (2007, p.115), I am trying to avoid using the imprecise and abstract term "triangulation" to define the research design as a

multimethod strategy. In my project, a qualitative interview study and document analysis were selected as the basis of the research because the goal is to find meaning to the university registrar's role.

\section{Research Question}

As was stated in Chapter I, since this qualitative interview study seeks to understand the nature of the role of the university registrar from the participants' perspectives, given the changing nature of higher education, the following question forms the basis of my study: How do university registrars perceive their roles in higher education?

\section{Theoretical Perspectives on Qualitative Research and Interviews}

As was stated in Chapter I, the lack of empirical research on the role of the registrar was a motivator to conduct this research. The need to know more about the role of the registrar can be examined in multiple forms. For example, the 2015 Career Profile Survey about the role of the registrar used a semi-structured interview approach to gather simple information, skills, or portfolios in a one-size-fits all-approach. In this case, AACRAO focused on the basic functions of the role of the registrar, such as coding degree audit, printing transcripts, scheduling courses, etcetera. The role of the registrar is a study that needs to be understood in a deeper, more intimate, and in-depth approach; therefore, selecting a qualitative research approach seemed appropriate to conduct the study. 
According to Bogdan and Biklen (2007), the following are five elemental features to conduct a qualitative study:

1) Qualitative researchers are instruments and go to a particular setting to explore a situation that occurs in a specific time and place. 2) Qualitative data are descriptive; researchers examined their topics with assumptions that nothing is trivial and that everything has a potential of being a clue that might unlock a more comprehensive understanding of what is being studied. 3) Qualitative researchers are concerned with the process rather than simply outcomes or products. 4) Qualitative researchers tend to analyze data inductively. They do not search out data or evidence to test hypotheses they hold before entering the study; rather, the abstractions are built as the particulars that have been gathered are grouped together. And finally, 5) Researchers that use qualitative research are interested in how different people make sense of their lives, roles, etcetera (p. 4).

In other words, researchers are concerned with what are called "participant perspectives" -- and that is the purpose of my study, to investigate the registrar's perspectives of their roles.

\section{Background to Qualitative Interview}

The role of the registrar is a study that needs to be understood in a more intimate and in-depth approach than just subjective guidelines as Provided by AACRAO; that is why I decided to use a generic qualitative interview approach adapted from Locke et al. (2004); according to the authors (p. 152), generic studies are a form of interpretative 
research. Researchers that are trying to describe or understand something without a perspective or specific tradition use a generic study approach.

In most cases, according to Locke et al. (p. 153), researchers using a generic study approach use these steps: " identify a conceptual model for thinking about the research problem, collect data through interviews, observations, or document analysis, analyze the data through a process that identifies recurring patterns and thematic regularities, and present conclusions."

According to Rubin \& Rubin (1995, p. 7), generic qualitative interviews share three pivotal characteristics that distinguish them from other forms of data gathering. "First, qualitative interviews are modifications or extensions of ordinary conversations, but with important distinctions. Second, these are more interested in the understanding, knowledge, and insights of the interviewees than in categorizing people or events in terms of academic theories. Third, the content of the interview changes to match what the individual interviewee knows and feels."

\section{Interviews in Qualitative Research}

According to Bogdan and Biklen (2007, p. 103), interviews may be used in two ways--as a dominant strategy for data collection or in conjunction with observation, document analysis, or other techniques. I used interviews as a dominant strategy and document analysis as a support technique to gather more information from the registrars' curricula vitae and current position job description. Since my study seeks to understand the role of the registrars from their own perspectives, the interviews included elements more associated with the in-depth interview style from Seidman (2013). 
My study used a semi-structured single interview of a sample of nine university registrars to gather qualitative data for the study. The reason a single interview was selected was because of the nature of the role of the registrar and how busy they are. Interviews provide the opportunity to obtain fuller and more detailed data than would be possible through reliance on a mailed survey questionnaire. As mentioned by Rubin and Rubin, "the researcher is looking for rich and detailed information, not for yes-or-no responses" (2012, p. 29).

As mentioned by Rubin and Rubin (2012, p. 30), casual conversations take place when a participant and the "researcher" cross paths. As indicated by Merriam (2002), I was the primary instrument of the study: "the researcher is interested in understanding how participants make meaning of a situation, this meaning is mediated through the researcher as an instrument, the strategy is inductive, and the outcome is descriptive." As mentioned above, I used an adaptation of Seidman's in-depth interview scheme. Seidman (2013) proposed a three-interview design in which each interview lasted 90 minutes. According to Seidman (p.21), the first interview should focus on life history, where the interviewee can tell as much as possible about the topic up to the present time. The hope is that the interviewees reconstruct and narrate a range of constitutive events in their past. Interview two should focus on the details of the experience by concentrating "on the concrete details of the participants' present lived experience in the topic area of the study. Finally, interview three should focus on the reflection on the meaning of their experience. 
Because registrars were not likely to sit for three 90-minute interviews, I only interviewed the participants in one session for up to 2 hours in which I focused on their experiences as registrar and their roles by following Seidman's three-part scheme. The interviews attempted to get additional information about how they became registrars, their current roles and responsibilities,, and finally to reflect on their role.

Since participants reside in states from all over the country, each participant was interviewed via video conference call. Video conferencing is inexpensive and allows for recording conversations, which has the benefits of preserving the words of the participants and original data. Seidman (2013, p. 112) pointed out that there are occasions when researchers and participants agree to interviews by telephone or video conference; when an interview is conducted by phone or video conference, he recommended that interviewers' greatest resources in their interviews are their own sensibilities and their abilities to use those sensibilities not only to draw out their participants but also to value more their participants since all communication is conducted remotely.

According to Seidman (2013, p. 106), sometimes English-speaking interviewers interview participants for whom English is not their first language. In my case, English is not my first language, and some of my participants had English as a second language; therefore, I had to be cognizant that even this could not be a communication barrier issue. I had to be careful and thoughtful about the importance of language and culture.

\section{Document Analysis}

Content analysis of the participants' job descriptions and curricula vitae was used to supplement data from the semi-structured interviews and to gain another perspective 
on the role of registrar. According to Bogdan and Biklen (2007, p. 1064), documents refer to materials that can be used as supplemental information as part of the study whose main data source is interviewing.

Bogdan and Biklen described three main types of documents that are most commonly used in qualitative research: personal, official, and popular documents. My study used personal and official documents. Job descriptions, as defined by Bogdan and Biklen, are a form of official documents that are produced by an organization for dissemination and recruiting purposes. Job descriptions were analyzed for indications in providing insight into the universities' expectations regarding the registrars' role. The curriculum vitae is a form of personal documents as defined by Bogdan and Biklen, and it is produced by individuals for private purposes. The curricula vitae of the registrars were analyzed and provided details on the educational and employment background of the registrars.

\section{The Researcher}

I have been working in higher education for the last sixteen years, the last ten of which have been with direct contact with university registrars. At FIU, I interacted directly with three different registrars; at Harvard University, each school has a registrar, and therefore I have interacted with plenty of registrars, and as an active member of AACRAO, FACRAO, and NEACRAO I have interacted with dozens of university registrar around the country, even with a couple from around the world. During these interactions and observations, new registrar colleagues - even seasoned - to the profession have the same question: what are my responsibilities as a registrar? 
To broaden my perspective, I have attended AACRAO, FACRAO, and NEACRAO conferences and served in different positions in the executive committee including the president - at FACRAO, Director of Membership - at NEACRAO and Chair of Latinx Caucus - at AACRAO. At the same time, I continue reviewing AACRAO's literature about the role of the registrar or the office of the registrar to grasp the role concepts of the role of the profession. It was then that I became aware of the absence of empirical studies and reports concerning the role of the registrar at universities.

Additionally, to understand the registrars' perceptions about their role, I needed to switch hats and wear one as a primary investigator and researcher. Switching hats was not an easy task since I had to forget for a moment that although I am an expert in the matter; my role is as a researcher, and most importantly, I needed to transmit this to the registrars I interviewed since many of them know me for my involvement in AACRAO. My own perceptions and vision about the role of the registrar, my interaction with many of them, and my involvement with AACRAO and NEACRAO as an active member and member of the Board have been identified and recognized; these perceptions could bias the study.

Therefore, to maintain the subjectivity in the study, I created a researcher journal; that way, I was able to identify, track, and confront my biases. Peshkin (1988, p.18) suggested that it is important to monitor one's feelings constantly during the research in order to identify the subjectivity of the researcher; that way, researchers can become aware of their personal biases. 
In addition, as mentioned by Bogdan and Biklen (2007), I kept notes of observations during and after the interview process. The notes were reviewed for biases before and during the interpretation of the data. I am aware of the importance of asking open-ended questions, and I allowed the participants to share their experiences and meanings that are personally associated with the topic of the interview questions. I took all the necessary steps to avoid biases and put all assumptions aside.

The techniques mentioned above were implemented to ensure accuracy in order to provide a study that is verifiable and in order to avoid biases and address accuracy. As suggested by Merriam (2002), a researcher's position is essential and very important for the study; it is important to conduct a self-reflection in order to avoid assumptions and biases to the study that may affect the investigation. Avoiding assumptions and biases was accomplished by keeping a journal.

\section{Participants}

The study focused on university registrars in the United States. As part of the study, I interviewed nine university registrars at public and private institutions. According to Seidman (2013, p. 58), there are two criteria to know how many participants are enough for your study: sufficiency and saturation. Merriam and Tisdell (2016, p. 101) emphasized that a qualitative study requires an adequate number of participants to answer the question posed at the beginning of a study; they recommended sampling until a point of saturation is reached.

According to Seidman (2013, p. 58), a sufficient number of participants "is an interactive reflection of every step of the interview process and different for each study 
and each researcher." The number of participants selected for my study allowed for a diversity of opinions and institutions while also being a small enough pool to allow for in-depth interviewing.

Purposeful sampling is a key characteristic of interview studies (Bogdan \& Biklen, 2007, p. 73). Purposeful sampling entails choosing particular subjects because they are believed to facilitate the expansion of the developing purpose of the study. The sample of my study was a pool of university/college registrars from public and private universities who are members of AACRAO.

The American Association of Collegiate Registrars and Admissions Officers is a "non-profit, voluntary, professional association of more than 11,000 higher education professionals who represent approximately 2,600 institutions in more than 40 countries." The mission of AACRAO is "to provide professional development, guidelines, and voluntary standards to be used by higher education officials regarding the best practices in records management, admissions, enrollment management, administrative information technology, and student services" (American Association of Collegiate Registrars and Admissions Officers [AACRAO], n.d.).

According to AACRAO (n.d.), the association "represents institutions in every part of the higher education community, from large public institutions to small, private liberal arts colleges. The association promotes the well-being and advancement of professionals in the higher education community by engaging members in the collaborative pursuit of excellence in admissions, registration, and enrollment services." Additionally, AACRAO provides "relevant programs, professional development tools, 
and information resources necessary to chart the course for professional success" (n.d.). Because most registrars in the United States belong to this organization, I was able to access the participants from its membership lists and conferences I have attended.

Since participants need to give their consent, "an element of self-selection" (Seidman, 2013, p. 51) was involved. According to Seidman, randomness can and should not be a goal of an in-depth interview study; therefore, I used "purposeful sampling" to the degree that I would be able to provide readers with a wide variety of experiences and perspectives without losing focus.

In the end, nine registrars agreed to take part in my study. It is important to mention that the purpose of this research did not include particular interest in gender, age, and race/ethnic background; therefore, the demographics mentioned before were not requested from the participants as I considered it would not affect the study on investigating the role of the registrar.

Altogether, I interviewed nine registrars (see Table 3); the selected registrars helped me understand their roles and perspectives, and that offered me the best “opportunity to learn" (Stake, 1994, p. 243). Finally, I did not give the participants an option to select a pseudonym; therefore, I chose one for them. I selected Nahuatl and Mayan pseudonyms because I wanted to keep names that meant something to me, something close to my culture.

\section{Ethical Issues}

The nature of the study and its reliance on individual human subjects mandated careful consideration of several ethical issues, including the informed consent of 
participants and the confidentiality and anonymity of respondents by using an ID identifier (Creswell, 2003). The informed consent form (Appendix A) is a mandatory requirement by FIU that participants signed before the interviews. The email messages requesting permission to conduct the study, interviews, and data analysis included an explanation of the nature of the study and what to expect during the process.

Participants were notified of their right to withdraw their information and participation at any time. One participant canceled the interviews three times and then decided that s/he could not continue participating in the study because of time restriction. I decided not to bring another registrar into my study as I felt I had collected enough information to continue the study. Finally, I completed the required Responsible Conduct of Research course and sent my research plan to the Institutional Review Board at FIU.

Table 3

\begin{tabular}{|c|c|c|c|c|c|}
\hline Registrar ID & $\begin{array}{c}\text { Current } \\
\text { Institution }\end{array}$ & $\begin{array}{c}\text { Years of } \\
\text { Employment in } \\
\text { Higher } \\
\text { Education }\end{array}$ & $\begin{array}{c}\text { Years of } \\
\text { Experience as } \\
\text { a Registrar }\end{array}$ & $\begin{array}{c}\text { Number of } \\
\text { Institutions }\end{array}$ & $\begin{array}{c}\text { Education } \\
\text { Level }\end{array}$ \\
\hline Yaotl & $\begin{array}{c}\text { College } \\
\text { Private }\end{array}$ & 17 & 14 & 4 & Masters \\
\hline Cualli & $\begin{array}{c}\text { University } \\
\text { Public }\end{array}$ & 34 & 12 & 2 & Masters \\
\hline Tenoch & $\begin{array}{c}\text { University } \\
\text { Private }\end{array}$ & 26 & 17 & 4 & Masters \\
\hline Cancu & $\begin{array}{c}\text { University } \\
\text { Private }\end{array}$ & 20 & 2 & 7 & Bachelors \\
\hline Tikal & $\begin{array}{c}\text { College } \\
\text { Private }\end{array}$ & 11 & 5 & 4 & Masters \\
\hline Montezuma & $\begin{array}{c}\text { University } \\
\text { Public }\end{array}$ & 24 & 13 & 1 & Doctorate \\
\hline Xoco & $\begin{array}{c}\text { University } \\
\text { Public }\end{array}$ & 38 & 8 & 1 & Masters \\
\hline Nenetl & $\begin{array}{c}\text { University } \\
\text { Private }\end{array}$ & 20 & 10 & 1 & Masters \\
\hline Ocotlan & $\begin{array}{c}\text { College } \\
\text { Private }\end{array}$ & 14 & 2 & 4 & Masters \\
\hline
\end{tabular}




\section{Data Collection}

The data collection for my study included two components of data collection in order to develop a comprehensive and meaningful understanding of the role of the registrar. In the study, in-depth, semi-structured interviews and document analysis were used to gather qualitative data on the role and perceptions of the university registrar as a primary research procedure.

I used a semi-structured, in-depth interview scheme adapted from Seidman (2013); this approach was used because I think it was the best technique in understanding the experiences of people as they see it, as well as the meaning they make of those experiences. The second component was document analysis; content analysis of the participants' job descriptions and curricula vitae were used to supplement data from the semi-structured interviews and to gain another perspective on the role of registrar.

Around 50 to 80 university registrars were initially approached in person at different AACRAO or ACRAOs events such as workshops, regional meetings, and annual conferences during 2018 and 2019. I introduced myself and discussed my interest in the topic and the purpose of the study. After the initial approach, university registrars were contacted via email (Appendix B) as a follow-up with more information such as the research question, an overview of the interview structure, timeline for the interviews, etcetera. Two follow up emails were sent as needed if no response was received within a month's time. It is important to note that registrars are always busy and took longer than expected to get any replies. All interviews were scheduled in the Summer and Fall 2019 terms. 


\section{Interviews}

My study used a single semi-structured interview format of a sample of nine university registrars to gather qualitative data for the study. As mentioned by Rubin and Rubin, "the researcher is looking for rich and detailed information, not for yes-or-no responses" (2012, p. 29). I used an adaptation of Seidman's (2013) in-depth interview scheme.

Seidman proposed a three-interview design, each interview lasting 90 minutes. Because my participants were not likely to sit for three 90-minute interviews, I only interviewed the participants in one session for up to 2 hours in which I focused on their experiences as university registrar and understanding of their roles. The shortest interview was conducted in 1 hour, and the longest took 1 hour and 45 minutes. On average, each interview lasted 1 hour and 15 minutes.

The interviews followed a semi-structured format with many open-ended questions to determine how the participants understand their roles, professional development, and professional identities. It is important to mention that by following the in-depth interview method, the intended questions are not fixed. This means that, as indicated by Rubin and Rubin (2012), I may or may not follow the given set of questions or ask them in the given order. I changed the order of the questions and skipped questions when they did not make sense or were appropriate based on the interviewee's perceptions or experiences.

Also, an interview guide (Appendix C) was used to help the interviewer stay focused on areas of interest. The interview guide was not meant to serve as a definite 
script that has to be adhered to, but rather as a guide that lays out the general direction of the conversation. This method allowed me to adjust to the participants and thereby collect information that enriches the data set.

\section{Data Recording Procedures}

I used several procedures to collect and synthesize the data, as suggested by Rubin and Rubin (2012) and Bogdan and Biklen (2007). First, because participants resided in different states from where the researcher resided, each participant was interviewed only once via a video conference call. Video conferencing is inexpensive and allows for recording conversations, which has the benefits of preserving the words of the participants and original data.

Recording the conversations allowed me to return to the source, and check accuracy should something not be clear in the transcripts. It is important to mention that before each interview, participants were asked if they would mind that the interviews would be recorded. In some instances, getting previous permissions is the law in some States.

After researching multiple video conferencing software, I decided to use FreeConference.com to conduct the interviews and record the interviews. This software offers a transcribing feature, which I did not find very useful. I also used a phone application called "Otter"; this app was used as a support and backup for FreeConference.com since it records and transcribes as well. The transcribing feature was better in this app. I ended up using FreeConference.com as a conference call recording and Otter for transcribing. The video conference files are stored in the application apps 
and are password-protected, and the transcripts were stored on my home computer, which is password protected.

\section{The Document Analysis}

The second source of the data were the copies of the participants' job descriptions and curricula vitae. These data supplemented the information derived from the interviews in order to gain more insight into the role of the registrar and to determine how participants view their roles. The job descriptions allowed me to provide an insight into organizational expectations regarding the role of the registrar. The curricula vitae provided additional details on the educational and employment background of the registrars. This opportunity to conduct comparative analyses strengthens the study's overall design and ensures that it would produce consistent results.

\section{Data Analysis}

Bogdan and Biklen (2007) advised that researchers regularly review field notes after each interview to pursue leads in subsequent interviews. However, Seidman (2013, p. 116), recommended avoiding in-depth analysis of the interview data until all interviews have been completed. Initially, I considered starting to transcribe after each interview.

I rapidly realized that the amount of time required to transcribe each interview was going to take longer than expected. However, data analysis began after the first interview. Each interview allowed me to gather specific information about the registrar's role and professional identity. This helped me in adding new probes, getting ideas for upcoming interviews, and reorganizing the order of some of the questions. 
As mentioned by Bogdan and Biklen (2007, p.129), transcripts are the main data of many interview studies. The recorded video conferences were transcribed in their entirety by the researcher. Seidman (2013, p. 118) emphasized that transcribing interviews is time-consuming and potentially costly work; "the ideal solution for the researcher is to hire a transcriber since it will take from 4 to 6 hours to transcribe a 90minute tape." Since I wanted to keep as close as possible to my research, I transcribed all nine interviews.

However, contrary to Seidman's timing of transcribing interviews, each of the interviews took an average of 11 hours to transcribe. Seidman also pointed out that "interviewers who transcribe their own recordings come to know their interviews better, but the work is so demanding that they can easily tire and lose enthusiasm for interviewing as a research process." Transcribing all my interviews took close to 110 hours in total. I agree with Seidman that this process brought me closer to my material; however, the whole transcribing process took almost two months. If I were to do this all over again, I would hire a transcriber.

\section{Interview Analysis}

Hahn (2008, p. 86) described that by this point in the study, the researcher has mixed feelings of excitement, exhaustion, and pride-- which is totally accurate. According to Hanh, level 1 coding, identifying codes, consists of multiple stages, and it is a "cerebral" process of "sifting" through your data to gain the insight necessary to answer my research question. According to Hahn, the goal of the coding process is to focus ideas and to organize data in order to identify concepts, codes, categories, and themes. 
After all the interviews were transcribed, I read the transcripts several times; I highlighted words and quotes that were interesting or that appeared salient to my purpose. After reading the transcripts, I got a sense of the data, which helped me in developing codes, and from there, themes. As Bogdan and Biklen (2007) suggested, I attempted to limit the number of codes, starting with 30 codes in the initial discovery phase.

I started level 1 coding in Microsoft Word as suggested by Hahn (2008, p. 87) by converting the entire transcript to a five-column table; then each paragraph became individual rows. Next, I made notes in the margins as "word comments," then, I compiled a list of these comments and organized them into preliminary codes. Finally, preliminary codes were converted into final codes, themes, and sub-themes. For example, words and phrases "policy," "policymaking," "policy decision," "policy interpretation," and "policy implementation" turned into code "policy making" which eventually became the subtheme "Roles \& Responsibilities - Policy Making" under the theme of "What I really do." Each code, theme, and sub-theme was captured in a "Table of Contents" for each transcript.

Level 2 coding started in Excel after defined themes and sub-themes were identified; as suggested by Hahn (2008), the use of Excel for qualitative research is attractive for researchers who are proficient with this program. All level 1 coding from all interviews were transferred to excel. Six columns were created with the following labels: Registrar, Theme, Sub-theme, Theme 2, Sub-theme 2, and comments. Then I filtered each column; this allowed me to gauge the frequency for each theme and sub-theme in 
order to identify lead themes and sub-themes. For example, "what I really do" became my lead theme.

\section{The Document Analysis}

The participant's job descriptions and curricula vitae supplemented the information derived from the interviews in order to gain more insight into the role of the registrar and to determine the extent to which the participants view their roles. The job descriptions allowed me to provide an insight into organizational expectations regarding the role of the registrar and helped to use data for the theme "what my institution thinks I do." The curriculum vitae provided additional details on the educational and employment background of the registrars. It allowed me to create the participants' table, which included Registrar ID, type of current institution, years of employment in higher education, number of total institutions, and education level. This opportunity to conduct comparative analyses strengthens the study's overall design and ensures that it would produce consistent results.

\section{Chapter Summary}

The study centered on the role of the university registrar. The study was designed to examine how the registrars see their own roles. I used a qualitative interview study and document analysis to gain insight into the experiences of nine registrars from public and private universities. More specifically, my study used a semi-structured, in-depth interview scheme adapted from Seidman (2013) because "at the root of in-depth interviewing is an interest in understanding the experiences of people as they see it, as 
well as the meaning they make of those experiences" (p. 9). The document analysis provided additional qualitative data that supported the interviews.

A valuable lesson learned about conducting qualitative research studies is that there is a significant number of qualitative research books and authors available which recommend different methods and approaches on how to conduct your study. At the end, each researcher creates his/her own qualitative research system. My study is grounded in the ideas and suggestions from many authors but at the end, it was adapted to meet my study's needs. This chapter should serve to explain my method of inquiry and the following chapters present the findings of my study. 


\section{CHAPTER IV}

\section{TO BE OR NOT TO BE A REGISTRAR}

I love being registrar, it has been, I think, one of the best decisions I've ever had. I think it fits my personality, fits my goals. I'm very detail oriented. I like things done properly. I'm very good with laws and regulations. So, personally, this is my full career. I don't foresee or intend to do anything else.

When I started my research, I was hoping to better understand the role of the registrar based on the participants' own perceptions. From my interactions with multiple registrars and my own perception working at the registrar's office, I had an idea of what the role was, and it is not how the 2015 AACRAO's Career profile portraits the role to be.

The nine registrars that I eventually interviewed graciously shared their thoughts, feelings, experiences, and perceptions with me about their role. One thing is true about what people say about the university registrars... you give them the floor, and they will not stop talking. They like the attention; they are used to it; they are at the center of the university.

The following four chapters present the culmination of 9 interviews, over 120 hours of transcribing, over 200 pages of transcripts, and countless hours of observation of many registrars in the profession. My study attempts to make meaning of the understanding of the role of the registrar based on the perceptions of 9 university registrars from institutions across the country.

This chapter begins with the theme "To Be or Not to Be a Registrar" because it lays the foundation for understanding how the participants became a registrar. This first 
theme is divided into three sub-themes: "How did I get here anyways?", "What my institution thinks I do" and "To retire or not to retire...as a Registrar?" These three subthemes, in conjunction with document analysis of the participants' job description and curricula vitae, helped me in creating profiles for each participant.

The job descriptions allowed me to provide an insight into organizational expectations regarding the role of the registrar and helped to use data for the sub-theme "what my institution thinks I do." It was interesting to realize that some institutions still get confused with their understanding of the duties and responsibilities of the registrar and the duties of the "office of the registrar." The curriculum vitae provided additional details on the educational and employment background of the registrars. These profiles should serve as an opportunity for the readers to get to know the participants of my study.

Chapters IV, V, VI, and VII present the four major themes that emerged from my data analysis. These themes are: To be or not to be a registrar, what I really do, what keeps me up at night, and what my family thinks I do. What I really do theme is divided into two sub-themes. These sub-themes are (1) skills and (2) roles and responsibilities. What keeps me up at night is divided into two sub-themes: (1) challenges \& emerging trends and (2) professional development.

For the next four chapters, for each theme, I included excerpts from the interviews to support my analysis. Finally, during my analysis, I will use "they" as a gender-neutral pronoun to refer to the registrars. This serves two intentions, first to maintain their anonymity, and second, I did not want to assume their preferred pronoun since it was not requested as part of the study. 


\section{Yaotl}

Yaotl has worked in Higher Education for more than sixteen years. They have worked at four different institutions. Before becoming a registrar, Yaotl has held positions such as Operations Manager, Office Manager, and Admissions Counselor. Yaotl holds a bachelor's degree in Arts in Psychology and a master's degree in Communication. Their current institution is a 2-year private college and they oversee a team of 8 full-time staff.

\section{How did I Get here Anyways?}

When I asked Yaotl to describe their pathway to becoming a registrar, they described that their first job in Higher Education was admissions counselor. They said, "I was an admissions counselor recruiting students and so forth for about three years." Then, Yaotl mentioned that they didn't have any registrar experience and that their first position at a registrar's office was "the registrar."

In the following excerpt, Yaotl further elaborates on how they became a registrar:

I became a registrar. Man, back in 2006. There's not a real career path that I followed; I think I had applied to become a registrar at my previous institution. And I think they chose me because I had some admissions experience previously, admissions counselor at my alma mater. I think I had enough technical, maybe technical skills. I think a good decision making regarding like interpretation of policy and stuff like that or collaboration.

Yaotl's pathway to becoming a registrar was not planned, they indicated they needed a job, and they thought they could do well in this job; therefore, they applied to their first registrar position. 


\section{What my Institution Thinks I do}

Yaotl's current institution describes their role as:

A Senior Administrator in the Academic Division, the Registrar plays a critical role in the collaboration among academic, student development, and administrative units in advancing the undergraduate and graduate academic enterprise and supporting the progression and success of students, while maintaining a strong students services orientation. The Office of the Registrar administers a broad portfolio of responsibilities involving operational, policy, compliance. Information systems, and customer services components.

Then, the institution defines Yaotl's responsibilities as provides leadership and support for the Office of the Registrar and its staff; strategy, reporting, and student support; policy, compliance, and governance.

Yaotl's institution understands the role and responsibilities that their registrar should be doing. It does not go down the rabbit hole of confusing the duties of the registrar versus the duties of the "office of the registrar." The minimum education qualification is a master's degree in an "appropriate field"; however, Yaotl holds a bachelor's degree in Arts in Psychology and a master's degree in Communication.

When I asked Yaotl if their education prepared them to become a registrar and if they believe their degree is in an "appropriate field" as required by their institution; they replied with:

Well, I think one of the things that I understand why I was hired, it's kind of to look at our processes again here at because I've learned that our processes have not really been updated. I think there's always been a new project or systems project." I think they hired me because of my technology, my technical skills, and I think I had, I had good decision making in regard to [silence] interpretation of policy and stuff like that or collaboration. 


\section{To retire or not retire... as a registrar?}

When I asked Yaotl about the next step in their career, Yaotl mentioned that "if I stay as a registrar, you know... as registrar [silence] that would be fine with me.” Then, they added, "If I have the opportunity to, you know, be promoted, you know into like a VP role or something like that. I would consider it. But I'm not necessarily chasing after it though either, because...I think [silence] I like being a registrar.

\section{Cualli}

Cualli has worked in Higher Education for thirty-four years. They have worked at two different institutions. Prior to being a registrar, Cualli has worked in positions such as Office Manager, Financial Aid Advisor, Assistant to the Dean, Dean of Students and Administration, Director of Admissions and Registration, and College Registrar. Cualli holds a bachelor's degree and a master's degree in Business Administration. Cualli's current institution is a 4-year public research university and oversees a team of 23 fulltime staff.

\section{How did I Get here Anyways?}

When asked about their pathway to becoming a registrar, Cualli declared that "I actually began my career at INSTITUTION1 and that was my whole life. I began in financial aid. So, I was always in student services for a long time." Then, they continued to mention all the different positions they have held in the same institution until they mentioned that "and then the one that catapulted to becoming registrar eventually was that I began working as the assistant campus Director of Admissions and registration at the South Campus of INSTITUTION1 in 2001." 
Cualli was appointed college wide registrar after their predecessor left the college. Cualli commented that "and then after John left, I became college wide registrar at INSTITUTION1 and like I said it involved overseeing all registration and admissions functions, which involve all the campuses, all eight campuses and online program. I oversaw about 150 people college wide."

\section{What my Institution Thinks I do}

Cualli's current institution describes their role as:

Provides institution level leadership in implementing and maintaining academic standards, policies, and procedures. The position is accountable for the accuracy, security, and utility of the student records and its supporting business processes. Provides division wide leadership in all matters related to the student information system and any other related technology. Interprets, develops, and recommends changes to academic policies as needed.

Cualli's institution started describing their responsibilities as: oversees the implementation of policies, oversees departmental personnel selection and "training," serves in university committees; then, as I have experienced with AACRAO when describing the role of the registrar, the institution started describing duties that are part of the "office of the registrar" and not part of the actual duties described by Cualli. Similar to Yaotl's institution, the minimum education qualification is a master's degree in an “appropriate field"; Cualli holds a bachelor's and master's degree in Business

Administration.

\section{To retire or not retire...as a registrar?}

When I asked Cualli about the next step in their career, Cualli mentioned that:

In reality, if you look, I was Campus Solutions Director for INSTITUTION1, which is a big deal; and I came back to be a registrar. It's 
a field that I really enjoy. I really love this position. I like [silence] I love being registrar... has been I think... one of the best decisions I've ever had. I think it fits my personality, fits my goals. I'm very detail oriented. I like things done properly. I'm very good with laws and regulations. So personally, this is my, my full career. I don't foresee or intend to do anything else.

\section{Tenoch}

Tenoch has worked in Higher Education for twenty-six years and seventeen of them as registrar. They have worked at four different institutions. Prior to being a registrar, Tenoch has held positions such as English Teacher, Department Chairperson, and Senior Operations Officer. Tenoch holds a bachelor's degree in Secondary Education and a master's degree in Education. Tenoch currently works in a 4-year private university and oversees a team of 35 full-time staff.

\section{How did I Get here Anyways?}

When I asked Tenoch to describe their pathway to becoming a registrar, they described that "I started off in public schools teaching junior high in high school, and began work as an adjunct at a Business College locally in Syracuse, New York, and join them full time going into department chairmanship and into the Dean's role and sort of grew into educational administration from there." Furthermore, they explained that:

Every position I've held since then except one has been under the registrar title. The only time that I veered from that I took one with INSTITUTION2 in Baltimore, which was called senior Operations Officer for the registrar's office. So, there was a dean and the deans of the programs, there was a registrar, but I was the operations manager that sort of ran teams within the Office.

Then, Tenoch said to me "you know, I tell people when I present on registrar, that it is not a degree deal that anybody chooses. It's not a career that anybody aims for." 


\section{What my Institution Thinks I do}

Tenoch's current institution describes their role as:

Oversees the management and processing of academic records, which include registration, grading, evaluating prior learning credit, articulation agreements, awarding of experiential learning credit, and transcripts and graduation processes. Acts as both professional practitioner of student record management and supervisor of staff responsible for the detailed tasks of recording and reporting student academic information. Maintains compliance with The Commission on Colleges, Southern Association of Colleges and Schools (SACS) and adheres to regulations mandated by Family Educational Rights and Privacy Act (FERPA). Serves as a liaison between the Registrar's Office and the Worldwide community.

It is becoming a trend in the study that institutions have a hard time differentiating the role and responsibilities of the registrar and the duties of the office of the registrar. Therefore, I stopped attempting to write the "responsibilities" described by the institution as they were describing the duties conducted by the office of the registrar and not the responsibilities of the registrar.

Similar to the two previous institutions, the minimum education qualification is a master's degree in an "appropriate field"; Tenoch holds a bachelor's degree in Secondary Education and a master's degree in Education Administration. Tenoch shared that the job description does not actually reflect how their institution sees their role; they say that "but this university in particular tends to not look at the registrar, as a clerk, they want us to be a person with a higher level vision. They want us to be somebody who can manage operations and manage people, and those people can in turn manage the processes." 


\section{To retire or not retire... as a registrar?}

When I asked Tenoch about the next step in their career, they paused and said, "you know man, I have 26 years in Higher Education" [silence] "for me at this point in

my career, I have moved about considerably, moved from school to school, up and down the coast and so on. This is my job...I plan to hold till retirement."

\section{Cancu}

Cancu has worked in Higher Education for twenty years and two of them as registrar. They have worked at seven different institutions. Prior to being a registrar, Cancu has held positions as Student Services Coordinator, Administrative Analyst, Administrative Assistant, Scheduling Coordinator, Assistant registrar, and Associate Director. Cancu holds a bachelor's degree in History of Art and Studio Arts. Cancu currently works in a 4-year private university and oversees a team of 25 full-time staff.

\section{How did I Get here Anyways?}

When I asked Cancu to describe their pathway to becoming a registrar, they described that "to be honest, I never really had the goal of becoming a University Registrar, I really was focused more on roles that were interesting to me"

Furthermore, they explained that:

The opportunity came up to me to consider the role of University Registrar when my predecessor, the person who was hired me into the associate registrar role here, left the university, resigned and moved on to consulting. I was faced with the opportunity to decide if I wanted to apply for the role of University Registrar deal. And I was a little ambivalent; I really hadn't considered that this was a role that would be one that I would be eligible and ready for or be something I would really want. 
Then, Cancu said that they are only a year and a half into this position, and they pointed out that "it's one of the best decisions I've ever made. I would have not ever thought myself to be in the role. But I absolutely love it. It's probably the best decision I've made in my professional career."

\section{What my Institution Thinks I do}

Cancu's current institution describes their role as:

Reporting to the Deputy Provost for Academic Resources, the University Registrar provides strategic direction and leadership for a range of policies and processes relating to student academic records, data, and security; enrollment policies and procedures, and improvement of student systems, processes and services in support of the university's academic mission.

The University Registrar oversees registration, scheduling, and academic records functions for the university, and provides support and coordination around systems and policies to the registrar's 12 professional schools. The University Registrar is the lead data steward for the university and the key administrator concerned with confidentiality and security of student academic records and compliance with academic policies and FERPA regulations in all schools. The University Registrar is responsible for creating a vision, establishing and maintaining policy, and implementing best practices that enhance service to all constituents, uphold the integrity of academic programs, and serve a diverse and growing academic community. The University Registrar oversees four direct reports and a total staff of 31 full-time and term individuals.

Like Cualli and Tenoch's institutions, Cancu's institution starts with a strong summary of the role, but then it has a hard time differentiating the role and responsibilities of the registrar versus the duties of the office of the registrar. The minimum education qualification is master's degree "preferred"; Cancu holds a bachelor's degree in History of Art and Studio Arts.

Cancu shared hat their position is a new role for the university as well as their office. They pointed out that "because the role is relatively new, and the office is 
relatively new, and the institution just doesn't know how quite what to do with us yet. It also may be the fact that it's just a faculty role, and there's a heavy weight placed on that. That that title and the fact that the faculty have the they rule the roost. That, to me is probably the most challenging thing overall."

\section{To retire or not retire...as a registrar?}

When I asked Cancu about the next step in their career, they said "I am new to the position, I have no ambition for you know, I'm not saying I really want to be something else. There is [pause], there's nothing out there that I have my eye on"; then they added that "I would be happy to continue in this role until I retire, it would not be [pause], I would not see myself dissatisfied with that world.

\section{Tikal}

Tikal has worked in Higher Education for eleven years and five of them as registrar. They have worked at four different institutions. Prior to being a registrar, Tikal has held multiple positions in Higher Education, such as Degree Progress Specialist and Senior Assistant Registrar. Tikal holds a bachelor's degree in Music and a master's degree in Central and Eastern European Studies. At the time of the interview, Tikal worked at a 2-year private college and oversaw a team of 4 full-time staff.

\section{How did I Get here Anyways?}

Tikal stated that "like, I definitely knew of the registrar when I went to college, but I honestly don't know if I ever even thought of it when I was looking for jobs." Then they stated that "I never expected to become a registrar...for sure." When I asked them, 
why they applied to be a Registrar or if their education helped in landing them this position; they explained:

One of my colleagues out here said something that was really funny, She said, what being registrar is like the "thoughtful of professions," like, you just wake up in one day you fell into it and I think that pretty much happened for most of us. I've been in [pause] I worked at four different institutions within the registrar's office.

I ended up getting my first job as an assistant registrar at an international business school; and because I had done my master's degree abroad and had that experience, you know, working with a lot of people from different countries and cultures, I think that that was a good match for me. I've been a registrar for 11 years; No, this is my first role, I did teach abroad for a bit. I taught English but that was at a private English School for adults primarily. So, I that was you know, it wasn't education before, but this was my first gig in higher ed.

\section{To retire or not retire... as a registrar?}

When I asked Tikal about the next step in their career, they stated, "I am interested in seeing what kind of doors would open after getting a doctorate but are not in the registrar's office." They expressed they did not want to continue to follow the registrar path. They pointed out that "I have also had a hard time, either been many years while I've been doing this type of work, where I wasn't sure it was the right fit for me. And then, really, something changed for me probably about like, four or five years ago. And then I started really seeing the difference that I could make in other type of work in Higher Education.”

\section{Montezuma}

Montezuma has worked in Higher Education for twenty-four years and thirteen of them as registrar. They have worked only at one institution. Prior to being a registrar, Montezuma has held positions such as Coordinator of Curriculum, Assistant Registrar, 
Associate Registrar, and Interim Registrar. Montezuma holds a bachelor's degree in English, a master's degree in Instructional Systems, and a Ph.D. in Instructional Systems. Montezuma currently works in a 4-year public research university and oversees a team of 20 full-time staff.

\section{How did I Get here Anyways?}

I asked Montezuma to describe their pathway to becoming a registrar. They pointed out that "I started because I needed a job. I had an undergraduate degree in English, and they needed an editor for the bulletin. So, getting a job with the university and benefits was my big driver." Then, they explained that "I came up through the ranks in the registrar's office. I started as a catalog curriculum editor and worked my way up through spaces scheduling and became an assistant registrar for space and scheduling."

Montezuma kept explaining how they kept coming up the ranks; they emphasized that "then jumped from there over to current records, and was an assistant registrar for student records and then went from that to an associate registrar, predominantly still over student records but branching into other areas." Montezuma expressed that in the end, they ended up making basically a career decision to commit to the registrar's office as a career path.

Montezuma mentioned to me that they were at the right place at the right time when they were named registrar. Montezuma provided the following statement as to how they became the registrar:

It was a little bit of all of that with a healthy dose of being in the right place the right time. I have worked my way, I've been one of the things that I when I started, the registrar's office had just shifted out of the 
dummy green screen terminals into computer-based desktops or everybody's desktop with terminal emulation software.

They further asserted that:

I was one of the younger people in the registrar's office and I was more technically oriented than a lot of them. So, by personal choice and support from the registrar at the time I came, I grew, into become the [pause] when you needed a technical solution for somebody. I sort of became the outward facing face of the registrar's office for, you know, if there was a campaign committee that they needed, the registrar or the senate needed the registrar to come speak on something...I would go and represent at those meetings. Our Assistant Vice President ended up naming me as the interim registrar while he focused on some health issues and then after about a year, year and a half, I was named as the registrar and he sort of stepped aside and became a special projects and research type person before he retired; basically that's how he finished out his last year to before he retired [pause] and that's how I became a registrar.

\section{What my Institution Thinks I do}

Montezuma's current institution describes their role as:

Responsible for the overall planning and direction of University wide programs related to registration, records, graduation, reporting, enrollment certification and classroom scheduling. Administers and interprets resulting policies for Deans, Directors, and Administrative Staff. Coordinates the preparation of legislatively required programs for the registrar's office. Has administrative responsibility and conducts all aspects of long- and short-range planning and implementation of enhancements to the Registrar's function.

Montezuma's institution understands the role and responsibilities that their registrar should be doing. The minimum education qualification is master's degree "preferred"; Montezuma holds a bachelor's degree in English, a master's degree in Instructional Systems, and a Ph.D. in Instructional Systems.

Montezuma made a comment about how the role of the registrar is still seen as a record keeper, even at professional associations dedicated to the profession. "I went to 
my first ACRs, this was very early in my career and I went to a workshop about the registrar role; it was a workshop before the start of ACR. I remember sitting in there very earnest taking notes on everything [pause]; then, they said, "the registrar does not make policy, the registrar implements policy." Furthermore, Montezuma mentioned that they wrote that down and thought about that for a while. Then Montezuma emphasized "I was like, okay, you know, we're records keepers."

\section{To retire or not retire... as a registrar?}

When I asked Montezuma about the next step in their career, they said "if I could pick, I would choose not to retire as a registrar, I would like to be an assistant or Associate Vice President for Enrollment Management. I do enjoy enrollment and I actually do quite a bit of policy analysis."

\section{Xoco}

Xoco has worked in Higher Education for thirty-eight years and eight of them as registrar. They have worked only at one institution and they take pride in it. Prior to being a registrar, Xoco has held positions such as Research Associate, Systems Analyst, Programmer, Assistant Registrar, Student Records Lead, Senior Associate Registrar and Interim Registrar. Xoco holds a bachelor's degree in Mathematics and a master's degree in Environmental Sciences. Xoco currently works in a 4-year public university and oversees a team of 26 full-time staff.

\section{How did I Get here Anyways?}

I asked Xoco to describe their pathway to becoming a registrar, and they shared,

"You know, the short story on that is that I got my master's degree and I promised my 
wife, I would put her through to let her finish her undergraduate degree. As a result of that, I had to get a job here and in town where I was going to school, and I got a job in the registrar's office as a programmer."

Xoco explained further how they became a registrar:

So, I am cooking on 39 years here in the office. And It's not your right. It's not what I trained to be. I was, I was a mathematics undergraduate, and graduate student in environmental science studying groundwater flow under landfills. When I started, I was a programmer, then, I was an assistant registrar, I was promoted. And a few years after that, I was promoted to associate and quite a few years after that, I became the registrar. And now I'm the registrar. I have financial aid, our one stop shop, the reporting shop and desktop support services. All that report to me. And I personally, this is not off the record, but I had I spent from 1990 until 2011 as the associate registrar of systems. And in that capacity, my primary job was to run the technical platforms that supported the operational work of the registrar and the am the data and the data repository and all of that work, decision support work [pause] all of the reporting that needed to happen. I loved that job. I really did.

\section{What my Institution Thinks I do}

Xoco's current institution describes their role as:

Directs the Office of the Registrar for the University, a complex operational unit. Responsible for strategic planning and coordination for a campus unit with responsibility for enrollment policy and management, registration, records, certification, institutional research and student data analysis in compliance with the University, state, and federal regulations. This position contributes to overall resource planning for maintenance, future developments, cross-modular collaboration and support, and problem solving for integrated student information systems. This position works collaboratively with academic officers and campus, institutional, state, and national partners on complex issues in support of academic policies and processes related to registration, records, and enrollment planning. Contributes to deliberations with academic units in ensuring compliance with university policies and procedures pertaining to the academic calendar, grading policies and practices, enrollment, academic performance, commencement and the awarding of degrees. Provides strategic leadership, planning and the allocation of resources for the Office of the Registrar. 
Xoco's institution understands the role and responsibilities that their registrar should be doing.

Xoco expressed their thought about how the role is seen at their institution in the past: "Let me also say that at the time, the registrar, as with the principal secretary to the faculty was also considered a partner in the academic world. You know, there were academic themes, and the registrar would be always be part of that Always be part of that realm. Often, it was the registrar will report to the Dean of the faculties, or they report directly to the provost, or the Chancellor, whatever the specific structure of the institution was. And I tell you, as, as this has migrated over time.

\section{To retire or not retire... as a registrar?}

When I asked Xoco about the next step in their career, they said "you know, honestly, I just thought, you know, I've already heard that I've been here, close to 39 years, Yes, I'm nearing the end of my career, at least my professional career. So, I don't anticipate going on to another job, at least another full-time job.

\section{Nenetl}

Nenetl has worked in Higher Education for twenty years and ten of them as registrar. They have worked only at one institution. Prior to being a registrar, Nenetl has held positions such as Assistant Director of Enrollment Services, Associate Director of Admissions, and Director of Admissions. Nenetl holds a bachelor's degree in Political Science and a master's degree in Higher Education Administration. Nenetl currently works in a 4-year private college and oversees a team of around 20 full-time staff. 


\section{How did I Get here Anyways?}

I asked Nenetl to describe their pathway to becoming a registrar; they mentioned that "So my first job in higher ed, outside of being a college student was working in a IT, then the first job I ever had in the registrar's office was registrar." Then they added "not to mention the four years that I worked as an undergraduate student for the university. And I mentioned that as supplemental because I was a manager as a student job there. So, without that student working experience as a college student, I am quite certain I would not have realized that I specifically wanted to have a career in higher education. So that those four extra years were important developmental for me."

Nenetl mentioned that "so how does one become a registrar? You could, you know, back into it, like I did in, in the, in the context of, I'd never intended to be a registrar, I never set out to be a registrar, it happened to me." Nenetl provided the following statement as to how they became the registrar:

So, I was the Senior Associate Director of Admissions at a school, a small professional school, within the same university where I work now. And there was an idea to consolidate the various components of enrollment services into a capital E enrollment services on this. So, we combined admissions registrar and financial aid into one office. And at that time, my boss and her boss decided that perhaps I could do both and I agreed to it. So, at that, I became the Senior Associate Director of Admissions, and registrar. So, I didn't apply for it, I was appointed it. The idea was to take these two offices, particularly admissions and registrar, that work that needed to work together better worked, and make it kind of a cohesive, integrated operation, which is what I did. So, when I became registrar in this role, I had, I was approximately 13 years of professional experience in higher education.

\section{What my Institution Thinks I do}

Nenetl's current institution describes their role as: 
The Registrar will lead and oversee the Office of the Registrar. The successful candidate will have the ability to foster collaborative working relationships in a diverse, multi-cultured workplace and to lead and manage change. He or she will have a credible presence and the ability to gain trust and confidence from a broad cross-section of campus colleagues. He or she will have excellent judgment, the ability to communicate openly among colleagues at all levels, a "hands-on" approach, and the ability to think strategically and produce strong results.

Furthermore, Nenetl's institution define their responsibilities to include:

- Play a lead role in modernizing Registrar's Office functions and processes, and in creating, launching, implementing, and maintaining a state-of-the-art student information system.

- Manage and lead a staff of forty people.

- Oversee records for approximately 6,600 undergraduate and 4,000 graduate students; certify enrollment and degree requirements; ensure compliance with FERPA guidelines; plan for and lead the ongoing development and effective implementation of office information systems; represent the Registrar's Office on various committees and on a University-wide basis.

- Oversee all Registrar's Office functions.

Nenetl's institution understands the role and responsibilities that their registrar should be accomplishing; it describes some of the functions of "the office of the registrar." The minimum education qualification is master's degree, but a doctoral degree is preferred; Nenetl holds a bachelor's degree in Political Science and a master's degree in Higher Education Administration.

Nenetl made a comment about how the role of the registrar is still seen as a record keeper; they stated that "you still had to persuade people that that this was not a clerical job anymore."

\section{To retire or not retire... as a registrar?}

When I asked Nenetl about the next step in their career, they said "I don't know the exact answer, which tells me [pause] I'm [pause] you know, I'm not highly motivated 
to move right now. Then they expressed that "I would doubt that my next title would be registrar. But it might be a position that oversees the registrar, for example, or has some sort of administrative oversight or financial oversight of a registrar's office."

Finally, Nenetl expanded on their desired next step "so a, you know, every university call it something different, but a vice president or vice provost of administration, or finance or something like that, or a dean for administration of Finance. I think that's, probably, or you know, something... something comparable, that might not sound like what I just said, it might not oversee a registrar's office. So, it could be a vice president for campus operations or something like that."

\section{Ocotlan}

Ocotlan has worked in Higher Education for fourteen years and only two of them as a registrar. They have worked at four different institutions. Prior to being a registrar, Ocotlan has worked in positions such as Assistant Director of Admissions and Assistant Registrar. Ocotlan holds a bachelor's degree in Psychology, a master's degree in Chicana/o Studies and is currently a Doctorate candidate in Educational Leadership. Ocotlan's current institution is a 2-year private college and they oversee a team of 3 fulltime staff.

\section{How did I Get here Anyways?}

When asked about their pathway to becoming a registrar; Ocotlan explained that:

So, I would always pass by a school, it was a for profit institution, it was an Art Institute and they were hiring for admissions. And I was like, Oh, I can do that [pause] I think I can do that. I went in and I got hired; so, I got my interview, and I got hired pretty much instantly. And then I quickly realized I'm not admissions material. I started doing registration and, you know, change of majors and stuff like that. And I liked it, I was like, Oh, 
I'd rather do this than have to call people and ask them if they want to spend thousands of dollars on education. So, I started looking for registrar jobs and then I got hired at the INSTITUTION2 and I became the assistant registrar there in 2008. I stayed the assistant registrar there for nine years. [long pause] way too long to be an assistant registrar. In retrospect, I think that hurt my career trajectory a bit, but you know, it's too late now. I was there for nine years, and then made the leap to registrar. So, I've got I got tired and quickly realized that, that institution was not a right fit for me. It was awful. It probably one of the worst experiences professionally of my life. But you live and you learn right? And Finally, I landed this current role.

\section{What my Institution Thinks I do}

Ocotlan's current institution describes their role as:

Responsible for the maintenance and security of all official Fellow academic records as well as overseeing the collection, analysis, interpretation, distribution, and warehousing of Conservatory data and information.

Ocotlan's institution's minimum education qualification is a master's degree in an "appropriate field"; Ocotlan is a doctoral degree candidate.

\section{To retire or not retire....as a registrar?}

When I asked Ocotlan about the next step in their career, they mentioned that "my

dream job, I guess, you could say would be to be registrar and a VP of Academic Affairs. That's my goal; I'd be okay with just one or the other, maybe be registrar at a larger institution or a VP of Academic Affairs, one or the other would be fine with me. But I do want to stay on the academic side of the house. I don't want to move to the student affairs side of the house. Yeah, that's my goal."

\section{Chapter Summary}

To be or not to be a registrar was the first emerged theme. This first theme is divided into three sub-themes: "How did I get here anyways?", "What my institution 
thinks I do" and "To retire or not to retire... as a Registrar?" These three sub-themes, in conjunction with document analysis of the participants' job descriptions and curriculum vitae, helped me in creating profiles for each participant.

Each participant provided me with many stories that described their experiences on becoming a registrar and their future goals within Higher Education. Chapter IV not only served as the foundation for understanding the registrars' pathway to becoming one but also helped in creating a profile and a persona for each participant. Their perceptions and backgrounds are unique to their persona and helped me in understanding their beginnings, how their institutions perceive their roles, and what their career goals in higher education are, if any.

Sub-theme "How did I get here anyways?" described the journey of the participants on how they became a registrar. The main pathway to becoming a registrar was, "I was in the right place at the right time." The majority of the participants have made a career working the ropes up the office of the registrar. Once their predecessor retired, most of the participants were next in line. Sub-theme "What my institution thinks about me" comes to no surprise that some institutions do not have a clear understanding of what the role of the registrar is, at least on paper. However, institutions seem to be clear on what the role should be in the summary part of the job description. 


\section{CHAPTER V}

\section{WHAT I REALLY DO}

I think also a lot of people who are registrar say, it's like we have different personalities, like we tend to be like very organized people, we tend to be people who have a natural problem solving and it's sort of a weird mix, I think because you have to also be good at people, people problems as well.

One of the main drivers to conduct this study was the lack of empirical research about the role of the registrar, how they spend their time, and how this role has evolved. A second driver was AACRAO's 2015 Career Profile Survey about the role of the registrar. This survey list functions and responsibilities that are directly related to the duties of the "office of the registrar" rather than to the role of the registrar.

"What I really do" is presented in Chapter V as the second emergent and major theme of the study. For my study, the role and responsibilities of the registrar are discussed by the participants based on their own experiences and perceptions. Participants were asked about what they do in their role; there were not prescribed questions. They were given the floor, and they did not waste any time.

The purpose of my study was to let them describe their experiences, and this made analyzing the data and finding themes harder than expected. The data and excerpts associated with this chapter are closely connected to the study research question: How do university registrars perceive their roles in higher education?

This lead theme is divided into two sub-themes: (1) Skills and (2) Roles and Responsibilities. The Skills sub-theme analyzes participants' understanding of the skills needed to perform the registrars' role. The Roles and Responsibilities sub-theme analyzes 
the roles and responsibilities of the participants; it is interesting to observe how they have a well-defined sense of what they do when they are asked directly about their roles and responsibilities. However, you will confront a different experience in chapter VII when they describe what they do in family reunions. All the sub-themes presented in this chapter are in relation to participants' perceptions about their skills and roles and responsibilities.

\section{Skills}

I would say the greater skill that a registrar should have what I'd be looking for the next one is the ability to manage people, to motivate people.

(Tenoch)

Skill is the first sub-theme of Chapter V. It describes the skills the participants think they should have to practice their position. Three main skills were discovered while analyzing the responses of the participants; these are (1) diplomacy, (2) technological competence, and (3) managerial skills. Diplomacy is the skill that was mentioned the most and the most important skill to have according to the participants.

\section{Diplomacy Skills}

Nenetl explained that they really think it is important to have "what you might shorthand called diplomacy." Then, Nenetl said:

I don't mean that as simply as a receptive skill, meaning, if someone comes to me, I can be professional with them. It means doing outreach, it's an act, to me, that is an active act, which is redundant, but so being diplomatic is not only how you react to people, but it's the relationships that you made. To me, diplomacy is relationship building, and nurturing, maintaining. And so that requires you to be a colleague, with faculty members, with deans and vice presidents, but also with, you know, staff members that have, you know, outsized influence on your work, even though they don't have titles to go with it. 
In the excerpt for their interview, Nenetl explained that with large diplomacy skills, which includes networking and credibility building, "people have to see you as someone they can work with, so, I say that is the number one skill you need to have as a registrar." Yaotl mentioned that "you need to be an effective communicator and able to interpret policy," that's it, "you need to be a "people" person. Others need to like you [pause], need to trust you."

Cualli mentioned, "you know, you need to have connections," they further explained that "one of the skills you need to have is knowing the laws and regulations that affect registration activities." Cualli emphasized that 'you accomplish this on how well you make yourself known with others." Cualli further explained that "you not only need diplomacy within your school but also with other players within the "State."

In a similar manner, Tenoch explained that "you need to be able to navigate through the constituencies that you have at the university to be able to manage your academics, your managers, to work on relationships with admissions, with financial aid... to cultivate those relationships [pause] and be sure that you can work towards mutually beneficial roles."

When discussing skills with Cancu, they stated that:

I see myself as a negotiator, as a facilitator. I see myself as a visionary, and not in a grand scheme, although sometimes that's true. I'm connecting dots, whether its people making connections with different individuals on campus, who may have skills or motivations to get things done. I would be less interested in their operational skills, though that's important for understanding the landscape. But more interested in their ability to relate to individuals on campus, a wide variety of people and their ability to be able to read a room, understand individual needs, and specific academic 
and operational area needs. And to be able to draw common thread between them solve problems.

Nenetl further described that a registrar should be visionary and "have the ability to be able to relate to the community."

Ocotlan mentioned in terms of diplomacy that "yeah, diplomacy and organization. Those are number one. I think you need to have; I would personally look for somebody that has, that is equity minded. But no, actually, everybody needs to be equity minded, not just the people that are working with students. I think you need to also have an openness to change; that's a big one."

Xoco emphasized that "First and foremost, political skills, analytic skills, your ability to work in a team environment, in order to maintain the mission of the office, I think those are the critical factors." Xoco further explained that the other thing is an awareness of security and access: "you know, it's not just FERPA anymore GDPR is the word of the day and your ability to connect with other and bring this new policy into place to universities; you need help from your other colleagues."

When discussing skills with Montezuma, they explained that "I would say they've got to have excellent people skills." Montezuma asserted that:

They've got to be able to build collaborative communities across their campus. Working with diverse people, diverse in terms of race, ethnicity, you know, all those standard bio demo, things of diversity, but also diverse in terms of understanding what drives a dean's office, what drives a department what, how does faculty senate look at things that are different than the way the university administration looks at things. 
Then, Nenetl stated that "if you're going to try and get things through or be a resource to them, you have to be able to relate to them and understand where they're coming from." This is very important-- they need to know they can trust in you, they concluded.

Tikal emphasized that:

I think a huge part is having a collaborative spirit and having very strong emotional intelligence, because you have to collaborate with report points and institutions, definitely collaborate with professors, students, faculty, IT, all of the administrative staff within the academic departments and Student Affairs and colleagues in the intellectual responsibility area in IR. It really requires a different mix of diplomacy skills and like interpersonal skills, as well as intellectual skills, you know, you have to be, I think, above and beyond, you have to be meticulous with your attention to detail.

Nenetl concluded that they think that is a really important skill to have: "I think because you have to also be good at people, people problems as well." As you can see from the different excerpts from the participants, having a diplomacy skill is quite an important skill to have as a part of the registrar's role.

\section{Technological Competence Skills}

Although diplomacy was the lead skill, technological competence was the second skill that was mentioned the most by the participants. However, some participants did not make a big argument about why the need of having this skill; for example, Cualli stated that "I think registrar need to be very technologically savvy; so that, they cannot just rely on their IT folks or others for data, I think they need to be technologically savvy for sure."

Similarly, Tikal mentioned that "you have to especially more and more, you have to have technological skills." Yaotl also was short on their argument about technology as a skill by saying "you need to be able to interpret policy and have technological skills to 
work with your IT group to translate your needs; that's it, you really need to be funckytech."

Nenetl stated that:

but technology, you have to understand something about it and you don't have to be a programmer, or computer engineer or a computer scientist. But it can't be an alien language to you, you know, understanding something about the technology that you're relying on is important. Understanding the mind of a technologist. So, you know, how do you motivate programmers and technology managers and is I have found has been important, recognizing that what people might see as some, like technical geek; geek is actually a very highly creative person. And How would you approach working with an artist has more applicability to working with a computer programmer than some other type of position.

In a similar approach, Xoco mentioned that registrars need to have fundamental knowledge and maintain current knowledge of technology. They said:

And I don't mean necessarily how to program, what I mean is to understand how do platforms work? What's necessary in order to operate those platforms, and to maintain the integrity of the operation, and to maintain the validity of the practices that you've put in place. It'll be impossible to lead this office if you don't have a fundamental notion of how technology works.

Like Xoco and Nenetl, Montezuma mentioned that "registrars have to be comfortable with technology, they can't be afraid of it." Montezuma further explained that:

Registrars have to understand how they can leverage data. Whether or not they themselves are actually querying the data out, they have to be able to articulate to somebody, I've tried to solve this problem, go find me the number of students that did this, that and the other for the last three years. So, they've got to be able to essentially frame a research problem and then build a strategy or plan for tackling it. They don't necessarily have to know the outcome they're working towards.

Xoco, Nenetl, and Montezuma agreed that technology is important for the role, and they cannot be aliens to the technological world. 


\section{Managerial Skills}

Managerial skill was within the top 3 most commented skills by the participants.

Nenetl stated that in this role, "you need to know how to manage [pause] and that's different than leadership." I found it interesting that "leadership" was not mentioned as one of the participants' top three skills. Nenetl said:

I literally mean, you have to know how to run an office. And a big part of that is knowing how to hire good people and how to identify good people to help you run it; and then being a good manager means letting them run it, You know, running their part of it, but also understanding that you accept responsibility for their successes as well as their failures, at least in the eyes of your boss.

Tenoch mentioned that "I would say the greater skill that a registrar should have what I'd be looking for the next one is the ability to manage people, to motivate people, and I think the people skills, the management skills, the personnel skills are much more important to me and to success in this position."

Xoco sees their main skill as the ability to manage people. They stated that "you need a foundation of, you know, management skills to rise to a level, certain level of administration, the level of jobs, vital level of competency, and some organizational skills, all of those, and we take those for granted." Xoco further explained that "we need to recognize talent, because the person who does the job after me can't really be a detailed person, they have to be able to rely on others to do that work."

Ocotlan mentioned that registrars could not be so detailed oriented, registrars need to manage and they acknowledged that "I see this a lot where registrars will get so caught up in the one thing that they're doing, and then just can't figure like they can't balance everything, like they need to finish the one. So, I think just being flexible and able to 
balance stuff that makes any sense and delegate to their teams." Tenoch feels that technology skills were important, but you can acquire those skills later. They explained that in their role as a registrar "I feel like I'm a little bit higher level management now."

\section{Roles and Responsibilities}

I like this job a lot. And I think there's a lot of things I can accomplish. I was I was hired specifically to do some things. All of which I've accomplished, The things that other people have assigned to me like, Hey, here's what we want the registrar to do, doesn't mean they haven't given me more things, but the things I was hired to do, we have done. But I have not necessarily hit all the goals that I set out for myself.

(Nenetl)

I present Roles and Responsibilities as the second sub-theme of Chapter V. The narratives presented in this section describe the participants' perceptions of how they spent their days and what they really do as a registrar. Contrary to the 2015 AACRAO survey, I did not present the participants with a pre-selected list of the functions "considered" to be part of their duties. I let them drive the conversation and tell me about their experiences and perceptions about their role. Four main roles and responsibilities were identified while analyzing the responses of the participants; these are staff development and management, policy making, technology management, and liaison.

\section{Staff Development and Management}

Participants referenced "management" as one of the major responsibilities of their role. In analyzing the participant narratives on management, the participants often referenced that the main goal of the registrar is to advocate for their offices and their staff. Xoco mentioned that "first and foremost, I manage staff, I manage the budget and I am the principal liaison to the campus." Xoco explained: 
I plan for the future, in other words, I have both tactical and strategic plans that I have to put in place, I have to identify and allocate resources, whether that be people or money or service providers from outside my organization, in order to accomplish either our short term or long term goals.

The quote above demonstrates that Xoco's notion of management wraps around planning for budget and resources.

Montezuma asserted that one of their responsibilities is to clear the barriers out of the way of their staff so they can do their jobs. They said: "if that means I need to get people hired, or I need to call a Dean's office and tell them: We've called you three times you haven't gotten your stuff in, I need your stuff in. The registrar as a position is the one that represents the office when we have to make the case on campus for our resources." Montezuma explained to me that they think that the main goal of the registrar is to advocate for their office and staff.

Similar to Montezuma, Nenetl mentioned that "I view my career as management. And I'm a manager, I'm in the management field, or I'm in a management career in higher education field. And so, I focus more on the higher education and the management aspects that I do of being registrar" They further explained that their main responsibility is to "enable teaching and learning." He said:

You have to realize that you are here to help people be successful, they're not here to make you successful, that you are successful when other people are successful. So that's the management side of it like, so you have to recognize I can't do this all myself. But It might take 10, 20, 30 people to do this kind of work. And each one of them needs to be successful to do it. So, how do you make that happen? How do you hire managers who recognize that they have to make that happen for their team? 
The excerpt above clearly demonstrates that Nenetl is fully invested in teaching and learning and that transfers down to their managers and supervisors. They understand the value to teach and train staff and, most importantly, the ability to delegate work.

Cualli explained that, to them, management means "to oversee the integrity of the work that is done by the staff in the registrar's office." They asserted, "you need to oversee the personnel." Tenoch described that:

Management is selecting staff members, training staff members, motivate and keeping staff members focused on their jobs, being the personnel manager, doing the HR pieces of the job, it is a pretty important constituency too. I would think that actually motivating, informing, cross training my management team within my office is one of my primary responsibilities as well.

Tenoch also believes that training, cross-training, and motivating their staff is an important aspect of their role as a registrar.

When I asked Cancu about management, they said to me that "one of the things I needed was step out of the way and let my very talented team do their work. So, I see one of my most important responsibilities to support and enable a competent registrar's office team to do their work." They further explained that 'I use the leverage of my role to secure the resources, and the attention, and the whatever is necessary to obtain tools that my team needs to do their work well, do it confidently, and do it successfully. That to me is one of the most critical parts of my role." The quotes above are clear examples that Cancu is fully committed to supporting their staff and making whatever is necessary to obtain resources to get the job done.

Cancu asserted that management not only involves "manage people" but also making good decisions. They implied that: 
Making good decisions and standing by them whether or not they end up being ultimately ones that that proved to be the wrong decision down the road but making decisions and sticking by them moving forward with them being direct, being confident in those choices and saying this is the way we're going.

Cancu philosophy is to stick with "your" decisions; they said, "being able to make it be a confident decision maker is a very important part of my role."

Ocotlan mentioned that "one of the most important responsibilities that I have as a registrar is to support my staff." They explained to me that this is important to them because they know what it is like not to be supported. They asserted, "and I don't ever want that, I don't ever want my staff to feel like they're not supported." It was clear that Ocotlan care about the wellbeing of their staff.

\section{Policy Making}

All the participants referenced "policy making" as one of the major responsibilities about their role. In analyzing the participant narratives on policy making, they often referenced to faculty, faculty senate, deans, or other governing boards. The participants in general expressed that they preferred to "shape than be shaped" and this is not always the case.

To begin, Cualli stated that "the registrar has always played a big role in different policies and procedures for colleges and universities. They further described:

Currently, I'm in the process of revising several procedures for the institution. One of them is FERPA working with a college attorney, I'm also working with the Office of Compliance on that. So, we also work a lot on any accreditation issues with facts. We write a lot of the documentation for that. And we maintain a lot of the documentation that's required for that. 
This excerpt demonstrates that Cualli is involved and consulted in policy making; according to their narrative, they have written a fair amount of policies and procedures.

Nenetl stated that they are very closely involved in policymaking at their institution. They claimed:

I think it's safe to say that I spend probably $50 \%$ of my time on, in some way related to policy review, formulation, creation, and change. It may not be obvious that I'm doing that in any one moment; when I'm having a conversation with the, you know, Dean of Undergraduate Education or director of studies or something like that, we don't just talk about, you know, so and so is doing great this year at school, you know, we're talking about policy, and we're talking about ways that we could improve it, or that we should stop doing things or start doing things. So that is all policy in some way or the other.

Nenetl recognized that policymaking is not always in formal ways and he stated that "I think if you are doing this job right, you are leading people to make good policy decisions." They then asserted that "I prefer to shape than to be shaped, and it is evident in the initiatives that I've been involved in, and it is not always evident in the decisions that come out but I probably have had a hand in shaping it in some way." Nenetl further explained that this was not always the case:

Whereas when I started this job, I think there [pause] there was less thought given to like, let's ask for their opinion on this, or how is this going to affect them, or their office or the university through registrar work, Because when you're new, wouldn't nobody really gives you much credence on, you know, they don't have trust, because they have no record of you; seeing how you operate or understanding your judgment for your perspective. And so, you have to earn that.

In the excerpt above, Nenetl recognized that it takes time for keyholders to trust "your judgement" but once they do "I would say it's rare now that a policy decision is made without my input, or even without my instigation.” 
Yaotl and Xoco are both involved in policy committees. They did not have a lot to contribute to the narrative other than, Yaotl stated "I am involved with the academic policies committee that's the standing committee for Faculty Senate" and Xoco commented "The right answer, and sometimes if it comes to the right structures; the answer is, they do consult me." Both registrars acknowledged that they influenced policy making.

Montezuma explained that their experience with policy making has been different in different points of their career. They stated that:

I went to my first ACRAO, this was very early in my career. And I went to a session [pause] it was a registrar one, a workshop before the start of the conference. And I remember sitting in there, very earnest taking notes on everything; then, they said "the registrar does not make policy, the registrar implements policy"

Based from that experience, they thought that their role was only to safeguard academic integrity of the record, preserve the record, record keeper, and all those types of things; however, Montezuma promptly realized that "then what I found, over time, was that I am the one making policy, now I'm not the one approving it but I'm the one that's typically identifying that there's a gap in the policy. I'm the one that's going to powers [pause] that be wherever they are and saying, I think there's a gap and policy here, I think there is a gap.” Montezuma claimed that they function at a more strategic policy level and they represent the registrar's office not only out to the campus but to the state.

Policy making plays a different role in different institutions. The narratives and excerpts above clearly demonstrated that those participants are directly involved in this process; however, Tenoch, Cancu, and Tikal have different experiences with policy 
making. They do not consider themselves as decision makers in policy but somewhat contributors or influencers. For example, Tikal said:

probably the most important is whatever academic governance body you have, whether that's your provost office, or faculty senate, whatever that might be where the academic policy comes from; because one of the main responsibilities, I believe, of the registrar's office is to uphold academic policy, which we do not create, right, so that we think it's really, really important to have a good understanding of the expectations of policymakers, whoever that might be in the institution.

The excerpt above demonstrates that Nenetl understands they do not make policy, but they need to understand it in order to follow the expectations of the policy makers.

In a similar approach, Cancu stated that "I make it make it very clear that I do not create policy, I do not set policy [pause] I interpreted it and I enforced it. They further explained that:

I see myself as an advisor in a very, very general sense. Maybe an influencer on occasion. But it is not [pause] something that I steer very clear from in an institution like the one that where I am. The faculty and the deans are, are [pause] the rules and the policies are their realm and I'm [pause] I'm respectful of that.

The quote explains that they do not see themselves as policymakers but an advisor to faculty and deans. Cancu asserted that "most of the time, I will make multiple recommendations and I will advocate for the choices that I think are closest to a standard; but I really do not see myself as a policy maker."

When I asked Tenoch about their role in policy making, they implied that they have always been in favor of the registrar having a role at the policy level but that they "have found it to be less successful in places where academics tends to put together a 
curriculum or when the administrations tend to put together policies and procedures without involving registrar's office." They explained that:

When they bring you something that is fully baked and then you are more or less stuck with the idea of how to do the challenges of how to implement, how to weaponize it, and how to support it. If you can be a player in the procedure earlier on, it gives you the ability to change what they want to do, but it needs to shape it, to allow them to implement it in ways that are system compliant, that work within existing policies.

The quote above demonstrates that registrars are not always involved in policy making and they end up with difficult decisions on how to adapt policies to the current system. Tenoch further explained that "so sometimes the feedback is later than it should be; but they do ask [pause] sometimes."

\section{Technology Management}

Technology in higher education is always a hot topic. However, technology is always trending, expensive, and ever changing. A "paper form" was technology 40 years ago, the same with a typewriter or even a fax machine that was used to send grade rosters to faculty. The registrar's office depends so much on technology to create automation. The role of the registrar based on the participants' narratives is not to use technology for them to do transactional work or to run processes; their role is to assess, liaise, and recommend new technologies to help their offices.

Nenetl asserted that "I have to be careful when I say technology, registrar's office 50 years ago had technology, typewriters, microfilm, and micro-fiche, things like that; they used technology, so that technology has changed." They explained:

Technology to me means, what can we do to erase the needless bureaucratic hurdles that students and faculty face so that they can get on with teaching, learning and research. And we've done a phenomenal 
amount, I think, in introducing procedural like, you know, process changes, but also technology to do that.

They commented that implementing technology has not been an easy task; it requires an investment in money and difficult decisions. Implementing technology is not only investing in software and systems, it means also investing in staff. He said:

In eight years, I've had to make the case that we're doing this wrong, or structured incorrectly, we have the wrong people to do it. And therefore, most importantly, we're not serving the interests of this University. And the university listened to it and said, okay, we understand it's an investment in technology, and a concurrent investment in reorganizing, reorganizing the staff, which included a lot of you know, tough conversations and decisions.

The quote above states that not only technology changes but also the need to have staff that is willing to learn these new technologies. Nenetl stated that "we are not hiring clerks anymore to this work." Finally, Nenetl asserted:

My take is that it's expensive, it's ever changing, and that it drives people nuts, you know, the users, drives them nuts. In that, you know, if you're constantly pushing for new development and new functions, you're constantly changing things on people, and people that don't live in that kind of world. Meaning if they're teaching, and they've been teaching the same way, for 30 years, they just want to keep teaching and it aggravates them sometimes or worse.

When I asked Xoco about technology, they stated that it was very important to their role.

They did not make a big argument about why but rather said:

You know, the transcript is a chronological record, right? It's a ledger, chronological ledger with specific attributes of the curriculum that the student took, you know, for his number, title, number of hours, which is the basis of the transcript and, and a performance grade. And then some summary statistics like term GPA, total hours, that kind of thing. And that has been true since the 1800s, the 19th century. We, in the 21 st century, coming up to 2019, basically still do the exact same thing. We put it out in an encapsulated PDF, it's electronic, it can be transmitted that way; but fundamentally, it's the exact same thing. And I find that really funny. 
Xoco has the same perception about technology as Nenetl; they think it is expensive, and it is always changing.

Ocotlan's perception about technology is like those of the previous two participants-- they think it is always evolving, intimidating, and processes are more and more automated. Ocotlan explained: "so when I started out, pretty much everything was paper based and I feel like there's like this weird kind of division between, like the battle for paperless or not paperless, you know, the battle for paper; and technology is pretty much involved in all of this" Ocotlan stated:

I feel a lot of times, we're almost kind of like ITish, you know, like, we have to be looking at certain technologies that are coming out, or certain technologies that are evolving our profession. Because a lot of stuff can be automated now. Even, you know, even transcripts, like sometimes you don't even have to process transcripts anymore, we can have somebody else do that now for us. I think a lot of it's just the technology is what's evolving. And a lot of times, it's way faster than the people are ready to accept.

As part of their statement, Ocotlan recognized that technology is always evolving. However, they asserted that "I think that technology is just going to help evolve our profession in a good way."

Montezuma's experience has been different from the previous three participants. Montezuma's experience with technology and their progression through the ranks made it difficult at the beginning to distance themselves from creating new processes or implementations. They explained that "I was still the proton predominantly tech person that if we needed a new process developed or we needed a new interface created or something like that. I was the one that was working with technology people and that was 
a carryover from my progression up through the ranks." They further discussed "the first year was a very hard thing to let go, but in part because I did not have a lot of trained people that could take that on. So, I fell into the trap that it was easier for me to do it than train somebody else." Montezuma asserted that with time they let go the daily technical operations and now they only identify technical gaps and propose new technologies to the deans, provost and central IT.

Cualli, Cancu, and Tikal mentioned that technology is important, but their narratives were not rich enough in content about why they believe it is important to their role. Cualli stated that "I think it's important that the registrar be solid on the technology that you're using," while Cancu mentioned that "I don't think we can escape technology as registrars. There must be if not in a thirst for at least an interest in and a, an ability to be good technical. From there has to be a strategic planning that involves an understanding and appreciation of how the registrar's office is entirely impacted by technology." Tikal asserted "IT is huge now; I think it's really important to have strong relationships and to have collaborative relationships where people are on the same page."

When I asked Yaotl how technology influenced their role, they said, "I mean technology is a great resource for the registrars to do their work, hopefully to make processes more efficient for staff, to make the student experience or faculty experience easier, or a little less confusing." They agreed that technology is an integral part of the registrar's office and that their perception of technology is 'it's a tool to help registrar's get their work done." 


\section{Liaison}

All the participants referenced "liaison" as the major responsibilities about their role. In analyzing the participant narratives on liaison, they often referenced to making connections, belonging to multiple committees, and connecting the dots. The participants, in general, expressed that they are at the center of the university, and their main responsibility is to connect offices with each other. The narratives below describe the committees the participants belong to and the departments and/or office they believe are more important to work with.

Tikal expressed that:

I think it's really important, very important to have strong relationships with academic administrators and various academic departments. I think it's really important to make academic partners. So, to include them, and, you know, the planning and ask them, what would be best for them in terms of moving forward and changing things. I think that's really, really important, because you'll be way more successful. People feel included, especially academic, administrative staff.

The quote above demonstrates that relationships are important for Tikal; they added that Student Affairs and the Office of Diversity and Inclusion is very important for them as well.

Montezuma stated that "I think that's the biggest change I've seen in the registrar's role is that we can't be silos anymore. To me extends way beyond, I can't be a silo, I have to work with everybody, I need to be a change of agent and recognizing where things need to change and having the connections and the relationships across campus to make my case." They further explained:

And then, I guess a thing that I do a lot on this campus is what I've already talked about; it is relationship building. Keeping open lines of 
conversation, open lines of dialogue, schmoozing for lack of a better word, but it's, it's if I'm to be effective, I have to understand what drives other offices, what their pain points are, what their goals are, the things that people struggle with.

The quote above demonstrates that cultivating relationships is important to Montezuma.

Montezuma's narrative also mentioned that:

Another big role is serving as a resource to administrative offices, colleges, departments and faculty. When they have a problem, and they can't figure out how to solve it. They generally know what needs to happen, but they don't know what order to do it in. So, a lot of times I serve as a resource and a lot of people tell me all the time, we didn't know who to call, but we figured you know the answer.

When I asked Montezuma with which group of the university they have closer ties with, they asserted that:

I will start with the faculty and the faculty senate. Anything that I want to do that affects academic policy, I have to work with them within the administrative side of it, so the academic deans, the provost office. The various vice presidents were sort of under the same level of governance, if you will, the faculty and the faculty senate or a whole other side of governance for the university. So there are a lot of things I would want to do administratively that I can't if the faculty don't agree with me.

Working with faculty is the most important partnership for Montezuma; they said to me that "actively working with the faculty and explaining to them why some of these things that I want to do matter because they don't live in my world."

In a similar context, Xoco expressed that working with faculty and serving as a resource is important to them. Xoco said, "I'm on the Faculty Council, the educational policies committee, and on the timeline committee; I'm on the new student transition committee. I'm actually the chair of that one. And those are just what I'm rattling off the top of my head." Ocotlan also expressed that having connections and representing their 
office in multiple committees is an important aspect of their role. Ocotlan belongs to the following committees: policy committee and leadership committee.

When I asked Nenetl how many committees they belong to, they mentioned that they belong to somewhere between 15 to 20 committees. Nenetl said that the registrar is at the center of the university "whereas admissions might not connect with facilities, or even with student life very much, they connect with us and we connect again with all of those plus a whole bunch more. And that's what I've really grown to appreciate about it." When I asked to mention some of the committees they belong to, Nenetl described:

Some of the ones that are centered on technology are really important. So, the university's student information system, executive steering committee, is important. And some other ones related to technology, like enterprise content management; those have been really important. The University Security Committee, disciplinary boards and even though we are ostensibly there to not enact policy, but to enforce or apply policy, actually, every year we come up with policy changes, rule changes based on the work that we do, and we propose it.

I'm on handbook committees, where we take the ideas that we have throughout the year, and then make them into reality. And some of those have to go and be voted by the faculty, the equivalent of the Faculty Senate, in this institution.

The excerpt above demonstrates that Nenetl belongs to several committees across the university. They emphasized that their role is beyond management but that they liaise and connect people. Nenetl mentioned that belonging to committees is not the only method to connect with people and they considered the following offices as important keyholders:

Student Affairs and I use that term really broadly because every college or university calls it all something different. And I'm, I'm using the word expansively. So, anything, any office that is not academic related, but 
support students, whether it's Residential Life, or whatever, so something related to student affairs. Student Affairs, and registrars often, you know, situated either between those two things, or sits more on one side than the other. So those are really important.

Financial offices and by that, I mean, you know, bursar, controller, financial aid offices, that sort of thing. As well as the finance, literally, the finance offices, and Alumni Affairs is really important. And I would say physical resources, because of classrooms and that sort of stuff.

Yaotl mentioned that part of the registrar's role is building collaborations with academic departments and understanding what they are trying to do. Yaotl stated that they belong to three committees: curriculum committee, graduate curriculum committee, and the academic policies committee. They explained that having good collaboration with other offices across the university is important for their role and their office. Yaotl described that:

Definitely working with technology and IT it is very important, we worked on new projects all the time. I report, up through the Assistant Provost for Academic Affairs. So, having a good relationship with them it is essential. Then, I know some of the other department/office coordinators, and you know deans, division department chairs. It's hard to pick which of those is the most important. And probably financial services/financial aid. Director of financial aid and director of admissions, those are probably the other key ones I'd say.

Yaotl and Cualli both mentioned that working with IT is important to them; this is because there is always a need to troubleshoot, implement, or adapt new policies to technology.

Cualli mentioned that "it is a collaborative effort. I am part of several standing committees now." They said to me that they attend the Faculty Senate meetings, curriculum committees, and several enrollment management committee meetings. Cualli 
emphasized that the vice president consults with them for a variety of policies and procedures "before they become law of the land." They described that:

I work with a lot of the different colleges, for example the College of Business and the College of Arts and Sciences. I work with a variety of offices; I work with the Office of institutional research and reporting. And I would say the other one that you know, we work hand in hand are student financials and financial aid as well to service the students. And the other one is IT we're like tied at the hip with our IT staff we meet literally every day.

Cualli acknowledges that at their previous institution, they belonged to many more committees. They are new to their current institution and are working on putting their name out there.

Tenoch described:

The ones that I work, probably most closely with at this point, is the admissions enrollment people who bring the students to us, who line up the applicants that we're going to see, the transcripts for evaluation. The other piece is academics, because we do a lot with helping to design program bill, fulfilling graduation requirements, things of that nature.

Tenoch further explained that the longevity in the institution has allowed them to become a more integrated player and the enrollment management team and to give them a greater voice within the academic structure.

When I asked Tenoch if they belong to any committees, they replied with "I'm not part of the Faculty Senate, they guard it very jealously and there are really not department representatives that go into that." Then they described the ones they belong to "So, the primary standing committee that I am in, is what we call the ASAC committee is the academic standards and admissions committee. What that one is, is all of the students who have left the university for any particular reason it could be suspension, could be 
dismissal, could be walked away owing money, those kinds of reasons." Tenoch also mentioned they belong to the "data governance" committee.

Finally, Cancu expressed that they belong to the University Calendar Committee, which is convened by the Office of the Secretary and Dean of Student Life, the Identity Steering Committee, and the Data Governance Committee. Cancu mentioned they belong to many others, but "it's hard to keep count" they are cyclical, and sometimes they meet only once a year. The main stakeholders Cancu interacts with are:

My associate CIO actually is an incredibly good partner. Of course, IT, Academic Affairs, who are, I wouldn't be able to get any worked on if I didn't have them on speed dial and vice versa. The Director of our institutional research, office, is a very good partner. We have a monthly meeting that I host with our associate CIO, with all our student information systems partners and stakeholders, which includes financial aid, undergraduate and university level, includes admissions undergraduate and graduate, and international students and scholars. The bursar, student employment and accounts payable, all of these different offices where we regularly update and discuss what's happening in the student space. In regard to technical projects, in regard to business process design, so we have ample opportunity to interact with each other.

As part of their statement, Cancu recognized that having connections and belonging to multiple committees are essential to their role.

\section{Chapter Summary}

The analysis provided in the skills section should serve as a starting point to begin to understand how participants perceive their role and what skills are needed to perform their duties. It is interesting how they start attaching these skills to what will be discussed in the next section: their roles and responsibilities; and how the top three skills directly correlate to the top three roles and responsibilities, which are liaison, staff development and management, and technology management. This and the following section set the 
foundation for beginning to answer the research question of my study. The following section focuses on the roles and responsibilities of the participants.

The literature review in Chapter III demonstrated that there is not enough information about the role of the registrar but only origins, definition of processes, and guidelines about the profession. Today's challenges demand the university registrars to be prepared to deal with changes in policies, cuts on public funding, and technology and innovation.

This chapter begins with the major theme, "What I really do." Chapter V provides rich narratives of the skills and responsibilities of the participants. Overall, participants provided many narratives that demonstrated how they perceive their role and what they really do in their day to day duties. The narratives provided in Chapter $\mathrm{V}$ should serve to answer the research question by demonstrating that participants of my study described their roles and responsibilities from their own perception. 


\section{CHAPTER VI}

\section{WHAT KEEPS ME UP AT NIGHT}

In Chapter VI, I introduce the third theme of my study, which is comprised of participants' narratives that described their profession's challenges and emerging trends and professional development. This chapter is split into two sub-themes: (1) challenges \& emerging trends and (2) professional development. Chapter VI should serve to explain and contribute additional participants' thoughts about their roles as a registrar; I considered that it was important for these to be part of my study.

\section{Challenges and Emerging Trends}

I have been in an institution where the faculty brought up a new academic policy that was nearly impossible to implement with the system.

I present challenges and emerging trends as the first sub-theme of chapter VI. This sub-theme emerged because the narratives of the participants about the role of the registrar went beyond what they do on their day to day operations. It expanded onto what they perceive as challenges and trends for their profession. Some of these narratives might intersect with sub-themes from chapter V. Also, it is important to mention that some participants might have not commented on both topics; therefore, their narrative might have both challenges and emerging trends or just one of the two.

Yaotl expressed that "I'm so new, like right now I feel like I'm just learning everything, you know like, I'm learning a new system, I'm learning degree works, I'm learning my team, I am learning their policies, and their culture." From the quote above, it is evident that currently everything is a challenge for Yaotl, as they were recently hired 
at their current institution. Yaotl did not have any narrative about emerging trends when the interview took place.

Nenetl discussed technology and generations as emerging trends; they said:

So, you know, I think, you know, to say that there's an emerging trend in technology, you could have said that any year in the past, it has been since our profession, registrar, existed. But I think, you know, what's interesting to me is that there are [pause] there are some new things that like I would say, are really fresh, really new in technology, that are not just faster ways of doing the same thing, or ways of doing things yourself rather than have someone else do it. To me that that's where technology has been and will continue to be. But then the emerging new stuff is how can I, as a learner or student, be more in control of my data and my student record and you know, so I think some of the areas of like digital credentials, have some real possibility for revolutionizing the way we do our work.

In the narrative above, Nenetl admits that technology is a hard thing to say because it is “omnipresent," but it is also constantly changing.

Nenetl further emphasized that "I think that's just always going to be a thing. But to me, it is it's a means not an end, the end is teaching and learning." They also acknowledge that technology aside from being a trend is also a challenge because "but on the other hand, many people are saying why does your technology suck? You know, why don't you improve it? Why do you go so slow? And, you know, I think they're both understandable impulses." It changes so fast that faculty, staff, and students get easily frustrated.

Nenetl mentioned that a current trend right now is working with different generations. They further explained:

The other thing that's new is, and again, I would admit, this is also a continuum. But you know, recognizing that the newest generation of workers that are coming to your office, in my view, have pretty phenomenal skills and temperaments and abilities. Which is seems 
contrary to the public narrative about millennials or something like that, my experience has been quite the opposite. That I've been, I've been really excited by the, the, the native technological skills, The, the curiosity, and the hard work of this generation.

Similar to Nenetl, Montezuma discussed generations as an emerging trend. They said:

I think the generations of students that we have coming on our campus have very different values, comfortable with technology, comfortable with what they were going to put out there. And I also think they have a less of a developed sense or, or they just don't care about things that used to be very formal.

Montezuma also mentioned technology being a trend within new generations; they further explained that silos in enrollment management is a trend for them. Montezuma said "I see is the enrollment management notion of breaking down the silos because if you're working with a student, that student has lots of things going on their academic, their life, their life skills. So, taking that sort of classic enrollment management approach of how you work with the student on the problem they have and not route them from here to there and just trust that they'll figure it out." Montezuma described technology and generations as a trend and that it is important to acknowledge that these new generations need a lot of more holding hands than previous ones.

Xoco described that they have seen a couple of different new trends: "the rise of ERP, enterprise resource planning and holistic services to the student" and "enrollment management." Xoco stated:

I've seen a couple of different trends. One we've already talked about with which is the rise of the ERP and holistic services to the student. Rather, that they've done all things to the Office of the Registrar, which is to make them managers of systems, on par with all the other managers of systems like the bursar, or like the financial aid director, like the Dean of Students, they have all of those things, they may have become one of those 
administrative managers. As a result of having to take this large responsibility for managing the integrated system in such a way that it makes sense and allows the institution to operate.

Xoco suggested that the registrar's office is becoming a central place to manage all the systems that connect to student data; at the end "we are the gatekeepers of student data."

Xoco described the second emerging trend as:

The other big trend has been enrollment management. That it I alluded to it a couple of ways by looking at student service in a holistic manner. But it also means that the registrar has been placed into a role that is most associated with service towards students, rather than the traditional role of service towards faculty. And in that, in that role, it would be most common to see a registrar reporting to something like the Dean of the Faculty, or the Provost, or Dean of Faculty Affairs or something, you know, something along those lines.

In the narrative above, Xoco admits that they find themselves living in a world of serving students. Xoco further explained that "I have to find my administrative network, so that I can reach out and still maintain my connections to the, to the academic administration side of the shop."

Cualli mentioned that their biggest challenge is "the needs of the different areas you served." When I asked Cualli if they could elaborate more about that statement, Cualli just mentioned "you know man, they think we know everything, but we don't; and they think we have the answer of everything and depend on us for everything." When we discussed trends, Cualli explained:

I think technology played the biggest piece of lot of how it evolved. Technology is the one that has played the biggest role in the changes. It's going to be technology, or looking to go to the cloud, eventually. So that's going to be a big change. And like I said, a lot of some of the things that we currently do right now, are still paper and pencil here. And I am looking to change some of those to improve services to make them more automated. 
The quote above proves that technology is an emerging trend and a driver for change at their institution. Similar to Cualli, Ocotlan made reference to "the cloud" as a form of online education. Ocotlan expressed:

An emerging trend is how online education is impacting us. I feel I still feel like people don't get a don't have a full grasp of what's happening or how that's going to impact the future. Like, you know, is it gonna increase? Is it going to decrease? Like, it's, you know, there's always the whole, you know, education is just getting so expensive. But I think the, which is why people are a lot of people are switching to online options, because they usually less expensive because there is less maintenance. Right? I think that's going to make a huge, or that's, that's, that's a big change that is happening. And I think it's going to continue to kind of evolve our role.

Ocotlan is convinced that technology is and will continue to shape the role of the registrar.

Cancu discussed both challenges and emerging trends; for challenges, they described:

You know, there are times when it was when I'm a little stymied by the fact that I there's a lot of expected of our office, and we produce a lot, we have good credibility on campus. Faculty turns to us for a lot of solutions, they want us to fix problems for them. But when we need something of them, we are still regarded as an administrative or bureaucratic office. And it's hard to, you know, there's I don't have the clout, or the leverage of the provost office or the faculty office. And so it's, I feel a little bit like we're in a limbo land in terms of, And I don't know if this is unique to me, or unique to a subset of us, or if this is consistent across the across the profession, of having a great deal of exposure, and interaction and engagement with a peer group or a set of colleagues who I can have open discussion with and, and solve problems. But when it comes to something, have a difficult discussion, or a need to implement something where I need their buy in, I don't have the same leverage.

In the narrative above, Cancu admits that they do not have the full support of the faculty or deans. Cancu further explained "because my role is relatively new, and the office is 
relatively new, and the institution just doesn't know how quite what to do with us yet. That, to me is probably the most challenging thing overall."

When discussing emerging trends, Cancu mentioned that "data" is an emerging trend for them. They said "Data [pause] I see it changing in front of my eyes and then the tools available to analyze it and punches and minus and presented in different formats and, and ways and shapes and forms. As more as those tools begin to mature and become more accessible. The appetite for information increase to help tell a story." Data is a trend for Cancu; it might not be for others but being the founding "father" of the office; they are requesting a lot of it. Cancu mentioned "I spend a lot of time discussing request and access to data."

Tikal finds "policy making” as their main challenge, they described:

For me personally, it's challenging when faculty, for example, implement a policy that they think is fabulous, and it's going to the whole institution, but they've never asked the academic administrators how to implement that. So more than once I have been in an institution where the faculty brought up a new academic policy that was nearly impossible to implement with the system. And I think it's really hard to get, I don't know, I think it's challenging for to get that kind of real collaboration with faculty who are coming up with your academic policies, because I think, for sure, they have expertise in ways that maybe administrators don't, but I think collaboration would really make those discussions more beneficial for the entire learning community

The excerpt above indicates that collaboration between faculty and Tikal is a challenge when it comes to policy development. They further explained "Yeah, I think, faculty governance thinks are creating policies for a positive purpose. But If you don't consult with the people who are actually implementing those policies, I have to make them happen either in the student information system, or with working with the students." 
Diversity for Tikal is both, a trend and a challenge. They expressed that diversity is becoming a trend but also a challenge. They said:

In previous institutions, I didn't see diversity and inclusion within the registrar's office as an imperative. That was hard for me, because I have issues with that and ethically, I think, we really need to radically look at the way we're doing things. Because, you know, the people who are on campuses are not the people who were there when policies were created 30 or more years ago. So that is, that is personally challenging when you know, people don't see why it's really important to be inclusive of all students. And that means policy reform A lot of the time because that is just like the core of it. I think education is really such an important thing in terms of upward mobility and in terms of expanding people opportunity, so that they can really live to their full potential.

Diversity and Inclusion is an important aspect for Tikal; it is becoming a trend in our institutions. However, as you can tell from multiple narratives it is not a concern for the majority of the participants. I identify myself as Latinx and according to 2015

AACRAO's Registrar's Profile survey, only 5\% of Latinx are Registrars. It is a concern for the researcher that the chance of me becoming a registrar, or to hold any position in top leadership in higher education may be limited to $5 \%$.

Tenoch stated that "personnel management" is an emerging trend and a challenge. They said:

I would say, personnel management is certainly one of the more challenging aspects for the larger team. I have people who have been with me for a long period of time who retire, younger people who will come in and I know when I, when I hire them, they're coming in to take advantage of the universities, the perks, that you get that you can earn a degree while you're here, some people will come in and are their masters and then shut out in the industry.

Tenoch further explained that "I would say relationship Management is something that takes up more of my time. I am meeting more often cultivating consciously relationships 
with other managers through enrollment management, because we do report through a same structure, it gives us the opportunity to work either in a mutually cooperative way that benefits everybody." Additionally, they stated that "personnel management" is also a trend. Tenoch said:

I think personnel management is the other piece where I think the registrars don't pay enough attention, training, motivation, hiring skills, things that allow you to assemble a team that will work together and work functionally. I don't know that there's a lot of attention paid to that at conferences, and probably should be, I think it's a lot more. It's not an HR role, but it is a personnel role.

\section{Professional Development}

To me professional development, is, is acquiring new knowledge, acquiring new contacts, and skills.

(Nenetl)

As discussed in the Literature review, AACRAO is the sole professional association that focuses on the university registrar - and the office of the registrar functions. According to Henderson (2006, p. 465), since its inception, AACRAO has provided services for its members by sharing issues of mutual interest amongst registrars. The association gradually became how members could develop guidelines and standards of practice in defining the registrar profession. This sub-theme is provided to demonstrate if participants attend other means of professional development other than AACRAO.

Nenetl spoke to me about their experiences with professional development. I asked as a Registrar, what professional development meant to them. they remarked:

To me professional development, is, is acquiring new knowledge, acquiring new contacts, and skills. I mean, skills are a little different than knowledge in the sense that skills are specific things that I need to do to do something, you know, if I need to run a computer program, I need the skill to do that. Or if I need to even just operate a computer, that's a skill, 
Knowledge could just be knowledge of my field, keeping current on what's trending, or emerging in higher education, or in the greater political landscape that's going to impact higher education

The quote above explains that professional development is important for Nenetl. They mentioned that they are "pretty active" with AACRAO and the their regional AACRAO. Professional development is "really important to me and my staff." In a similar approach, Yaotl mentioned that "I mean professional development is a big thing, I think, at least for me, a priority for me. Not just for myself, but also for to give opportunities for my team to be able to go." Yaotl said:

I mean, professional development for me is also just having consistency like team meeting one on one with my team. You know, setting, giving opportunities up to us to attend conferences and so forth, and report back, but also doing, you know, try to do like training or, you know, it doesn't have to be going to a conference, it could be just, you know, we're going to create a vision statement or mission statement for our team and think about what are those, what are those things, or pain points that they have, you know, that sort of thing.

Yaotl sees professional development not only as attending a conference but as the means to do transfer knowledge with their staff. Working together towards a common goal such as "writing a mission statement for the office." Additionally, Yaotl explained their roles within AACRAO and Regional ACRAO:

I've been fortunate to have some leadership roles within the state and regional AACRAO. I've been a district chair, professional activities officer, and then most recently now is president, President Elect and now I'm currently serving as past president, immediate past president. and that's been great to be able to kind of, you know, grow professionally and collaborate with other state regionals as well. For AACRAO, it's really been just API caucus chair the last two years and then, now with nominations and elections, I'll probably be stepping down as API caucus chair. And, you know, stepping into the Vice Chair for AACRAO. I really enjoyed being part of the leadership. 
The quote above demonstrates that Yaotl is really involved with AACRAO nationally and regionally and has had and has multiple leadership positions within the organization. For them, it is important for their career to belong to and actively participate in

\section{AACRAO.}

When I discussed professional development with Tenoch, they mentioned that they used to attend conferences as a "young professional." They mentioned that "I went because I was looking for ideas, looking for solutions, looking to see how other schools do what I do, what you see other schools, all problems that I have." However, they stated "I tend to look at professional development now is an opportunity for me to chance to share what I have gone through on my journey with young professionals who are facing those same things that I did 20 years ago." Tenoch is more interested now to mentor young professionals; they said, "you can become the person who has the answers to those who has the background."

When I asked Tenoch if they have any involvement with AACRAO, they asserted:

I also try to participate, not just through being you know, like on the FACRAO Executive Committee, but I also try to participate, I'm writing fairly frequently for AACRAO; now participating in professional publications, working on committees and from the different levels when you can.

Tenoch further explained "So, it's important that a professional development basis to continue getting yourself out there. You shouldn't get to the point where you think you have nothing left to learn. Because it's surprising to me that I still do. But I find out that in sharing what I do, that also helps others to learn. So, it's sort of a dual benefit." 
Cualli described that "I think as far as professional development, it's, it's the most important thing is, is speaking with other colleagues, who share the same kind of experiences. So, for example, I speak to a lot of the state registrars, we have a little working group that we ask questions on the big listserv, actually, we have just emails of the nine to 11 of us." Cualli mentioned that they belonged to the Regional ACRAO a long time ago but that they have recently presented sessions in the regional organization.

Xoco mentioned that AACRAO is very important to them but that there are other associations that bring knowledge and are useful for their role. From my narrative with them, it did not seem they have active participation within AACRAO. They described the other professional opportunities as:

The first one is the AAU (Association of American Universities) registrar's group. We meet once a year, it is all the registrars and only the registrar; we meet for four days, I find it enormously helpful. The second group that I find enormously valuable, it's called The Big 10. It's called The Big 10 academic Alliance, registrar group. You know, the other professional organization that I get a lot of value out of its EDUCAUSE. I find that there is set of resources and often in even their annual program. I have made Terrific Contacts when I've attended the EDUCAUSE meetings. To get a different perspective on higher education, technical issues of how they and how they relate to student information systems.

Here Xoco discussed how other associations, meetings, and conferences bring other benefits and experiences that they cannot find at AACRAO.

Cancu, similar to Xoco, believes that AACRAO is good to attend but they think it is not for everybody and that "there's a very small representation for the opportunities that are there." Cancu further explained:

So, as I've gotten to a point where I've experienced AACRAO for a number of years, it's not that it isn't giving me what I need anymore, but it's giving me less than what I need. I've kind of saturated, I'm starting to 
think about looking at the equivalent professional groups for my peers for financial aid.

Cancu asserted further regarding AACRAO, "I learned more from my colleagues directly and the opportunities to network and to expand my knowledge through my discussions with them and their experience than I do sometimes from conferences, through sessions. So here, mentoring and networking is where I gained a lot of my knowledge and where I find a lot of benefit in my growth."

When discussing professional development with Montezuma, they stated that visiting the vendors area is a "must" when going to conferences. They asserted "I always make a point of walking through the vendor hall to see who is out there and what are they offering, because I never know what I might need down the road.” Montezuma said that they do not participate actively in any AACRAO committee and does not plan to do it. They also mentioned that aside from attending AACRAO conferences, they also attend EDUCAUSE.

Ocotlan said about AACRAO:

AACRAO has been awesome. But for me, because I was an assistant registrar for so long, I never really got to go to AACRAO. So, I actually was more involved with my Regional ACRAO and I still am. I mean, no shade but, I've gotten so much more from the regional that I have from the National. Sometimes, I feel like the Nationals are just so big, Right? It's just too much happening.

To Ocotlan, regional conferences and associations are more important than attending national AACRAO. They further stated:

Whereas the regional is a lot more focused. And what I love the most about the regional is that all those people are within your reach. Not to say that AACRAO isn't; but even just like for like just getting this call setup like you're on the East Coast. I'm on the west coast, like, you know, there's 
that whole-time difference. Where the regionals know, a lot of us are accredited by the same agency; so, we can talk about that. You know, like, how did you handle your last walk? How did you handle this? You know, the, but I feel like the camaraderie is a little bit tighter on the regional level.

The excerpt above clearly indicates that Ocotlan finds more value working with institutions in the same region and time zone.

When we were discussing professional development, Tikal said to me that they are really passionate about it. They said, "for me, it's a critical part of what keeps me interested in my work." When I asked Tikal about AACRAO, they stated:

AACRAO, I think it's very important. I've made some excellent connections, going to AACRAO. But I will say something that's also, I think it's very important, but I don't think perhaps, maybe everyone does, I think it's really important to have exposure to other professional organizations within higher education.

Tikal further explained that they are most engaged at work when they are learning something new, either with a new idea in an office or having some sort of professional development opportunity outside of the office. Tikal asserted:

So, I don't think it's, I don't think it is for folks in the registrar field professionally, to only go to AACRAO conferences, for example, I think it's really important to see what else you can learn from NASPA (National Association of Student Personnel Administrators) or ACTA (American Council of Trustees and Alumni), or, you know, I took some professional development courses at another institution this past year. See, what you can learn from other people in different places.

Tikal further explained that they focused a lot on the last year and a half on leadership skills, and especially in leadership development for women. They also asserted that "I also focused on a lot of collaboration with folks in diversity and inclusion. So, for example, this summer, I worked on preparing session proposals for conferences, that are 
related directly to diversity and inclusion work. So, that's the kind of training that I enjoy the most."

\section{Chapter Summary}

The challenges and emerging trends sub-theme should serve to demonstrate how participants find trends and challenges as a significant aspect of what they do. As you can see, there is not a one size fits all; each participant's narrative differs from one another. For example, for Yaotl, everything was new for them. They expressed that working for a new institution, everything becomes a challenge and a trend. In a similar way, Cancu, although not new to the institution, their role and office is. They find themselves navigating in new waters. Generations, technology, and diversity were also a common challenge and/or trend amongst the participants.

Overall, participants provided many narratives that demonstrated how professional development is an important aspect of their profession. Registrars 1 and 9 are actively engaged with AACRAO and with their Regional ACRAOs as well. It is interesting that some participants prefer to attend regional conferences than annual ones as they appreciate more the collegiate level of their region.

Some participants (mainly seasoned registrars) also mentioned that at the beginning, they found that AACRAO was very helpful, but after a couple of years, they started losing interest in attending sessions; however, they enjoy networking, mentoring and presenting sessions. Other important conferences mentioned that participants attend are NASPA and EDUCAUSE. 


\section{CHAPTER VII}

\section{WHAT MY FAMILY THINKS I DO}

I get that all the time. Like, are you in admissions? No. And then I'll say, we do everything after admissions.

(Cancu)

Finally, I present "what my family thinks I do" as my concluding theme because when I asked the participants: when you are in family reunions, and they ask what you do, what is your answer? I asked this question at the end of the interview. The intent was for the participants to give an honest and impromptu answer. However, most of the participants answered the question with the functions of the "office of the registrar" instead of describing what they really do.

Once I made the participants aware that they answered with the functions of the office of the registrar instead of what they do, the narratives extended, and the participants added more thought and changed their answers. Some of the registrars thought it was a clever approach to make them aware that even within the registrars, they tend to confuse their functions and the functions of their offices. Some of the narratives mentioned in this chapter intersect with some themes and sub-themes form Chapters IV, V, and VI but mainly with theme "roles and responsibilities" discussed in Chapter V.

\section{Nenetl}

When I asked Nenetl how they describe what they do in family reunions, they stated, "I tell them I'm the registrar and some people, probably a minority of people get it. They know what it is because maybe they've had some interaction with it, or because they know me. Most people, you have to be prepared for a second sentence." Nenetl 
further explained that often people don't know what a registrar is or does, and they just say, "if I'm joking, I will say, I'm basically the chief bureaucrat at a university. If I am being a little more descriptive, I will say that, well, to start with, we're kind of the chief record keeper for students and I describe us in comparison to another offices it whereas admissions office is responsible for admitting students, it is our responsibility to get them out, usually through graduation."

Nenetl expressed that if people still don't understand what they do, they further describe their functions as:

Like, we produce the course catalog, we enable course registration, we produce credentials, such as transcripts, diplomas, and certifications, we manage classrooms, schedule exams, and manage technology, and track students' progress to a degree and bill students. By the way, I often get to that third sentence, you know, so it's start with the snarky one where the chief bureaucrat, and I'm like, we're, you know, the primary record keeper for student records. And then third sentences, I tell them exactly the scope of functions within our office, and it usually ends up where people are like, Wow, that's a lot.

The excerpt above is a clear example of how Nenetl describes their functions as the daily operations of their office, but that is not what Nenetl does as we learned from their narratives in previous chapters. Nenetl added to the narrative, "if you ever asked my parents while they were still alive, what does Nenetl do? My parents would answer: Oh, Nenetl works in computers."

Nenetl asserted that "if I am, answering honestly, what is your career, I go back to where I started in this conversation. I'm a manager in higher education. That's, that's really my career. That was my intentional career. And it's, it's what I've been doing. They further explained: 
You know, I answered with my title and then I talked about the functions of the people that work for me, without mentioning that the registrar is a manager. And, you know, it's, it comes up to me in this way. It's, this is a weird way to describe it but in an organizational chart, you have the registrar's office, you will find me at the top of the organizational chart. In terms of the organized terms of the university, I am someone on someone else's chart, but my staff aren't. So I happened to report to a specific leader at the university, not because I am the, you know, the manager of 20 some people, but because I am the registrar for that school, and that that implies something different. Everyone in the registrar's office is a part of the registrar's office board, except me, I'm part of the dean's office.

The quote from Nenetl acknowledges that they realized that they described their role with the functions of their office and not with what they actually do.

Nenetl further explained that they don't feel like they are part of the "registrar's office but part of the "dean's office." Nenetl believes it is "weird" and stated that "when I interact with my boss, I almost never talked about being a registrar, like as a manager, or even to get into the weeds of the functions that we perform. I am talking about policy in almost all cases, or I'm talking about major initiatives or changes like personnel changes." Nenetl further explained:

But again, like I'm serving my boss in two ways. One is to manage this office and If I'm doing it right, or things are going well, that is, you know, my boss is oblivious to all of it. The second way is actually by being a support to my boss. That means being basically an advisor. You know, and it's someone who can render assistance for their initiatives not mine, it's a weird thing. I've always felt this way. From when I started this job, more so than the past registrar job that I am like, I am like a representative of this office to the leadership structures.

Based on Nenetl's previous narratives on "what they really do," they started connecting back the dots to the theme "roles and responsibilities," specifically to 
the "liaison" sub-theme. Nenetl considers themselves as a representative of their

office that connects "people" with each other. Nenetl stated:

So, I'm the person in the room, so that this office can do the work that it does. So I might spend an hour or two hours with a bunch of Deans a couple times, you know, every day, some dinner other; I'm meeting with, and it's in service of the operation here, that is a lot of times invisible to them. I feel like a generalist, a general officer of the university, because of the very things that I'm involved in. So you might have me in a meeting of curriculum policy, I might also be in a meeting picking up chairs for a classroom, I might also been a meeting about where the bike rack should be for the new building on the other side of campus, all within the last week, I was in meetings for these things. So, I might be in a meeting telling the university what type of person they should hire to run health services. I might be in a meeting with General Counsel talking about giving my input on a lawsuit. Like, I've just described to you the last five days of my job.

Nenetl explained that they are not only a "liaison" but also a "policymaker"; they asserted that "I'm helping this place to keep running; otherwise, students and faculty alone, do not make the university, they are the essential ingredients, but so are we." Nenetl concluded with "one of the recent Deans here described the registrar's office as the central nervous system of the university."

\section{Yaotl}

When I asked Yaotl how they describe what they do in family reunions, they

stated:

I say I am a registrar and I oversee records and registration of students. Sometimes they go what does it mean, and I answer, you know, we set up registration, we maintain student records, post grades, graduate people, oversee commencement, and all that sort of thing. And I think some of those functions are just kind of what we oversee. 
Similar to Nenetl, Yaotl described what their office does and not what they really

do as described by themselves in Chapter IV, V, and VI. As Yaotl assimilated that

they described what they do with the functions of their office, then they stated:

I mean, if you say, hey I interpret policy or I make sure that people are following FERPA or hey I am the leader, I'm a technology implementation person, I review petitions. We say more what our office does than what we do. I think part of that, I think, that I see that sometimes though, I think maybe this is a trait of the registrars or not. We are more like humble or humility servant leader, because, you know, we're more behind the scenes.

It was interesting to witness how Yaotl still sees themselves as a "behind the scenes" administrator at times, but at other times they described themselves as:

However, I think the registrars, the old, old school registrar was more just policy, policy, policy, no exceptions, it has to be this way. Now people are more open to, how can we collaborate together. I think that's one of the things I've seen more so in terms of the demands of the position. Having a very strong working relationship with a Director of Financial Aid and knowing enough about financial aid to help guard against, you know, audit issues or the findings right. But also, I think working collaboratively more with student development between Title Nine. You know, personal pronouns, those things, whatever those are just different ways to collaborate and making sure that students feel welcome, are, are accepted and supporting that the work of the institution.

The quote above describes how Yaotl sees their functions as a "liaison"; this quote can be referred back to the findings stated by Yaotl in Chapter V.

\section{Cualli}

Cualli described what they do as:

I would say, well, I help students register, I oversee that they have, you know, I oversee their grades are posted correctly. I oversee from when they register all the way up until they graduate, and we send them their diploma. That's what I do if you want to put it in a nutshell. I think it's, you know, our office supports the functions that help a student register, up until they graduate. I enjoy helping the students, you know, making processes that help them. I think it's, it's very important work. 
When Cualli realized that they answered with what their office does, they corrected with "I manage staff," and they did not elaborate more on that topic.

\section{Tenoch}

When I asked Tenoch how they describe what they do in family reunions, they

described:

I generally tell them, that we are the folks who deal with more or less every aspect of student records. So, it's sort of the cradle to grave supportive student records within the university system. We are the gatekeepers for everything that come here from admissions and down and we support all the way through graduation, we do everything in the middle of the current student, but even after graduation, or even after student leaves, we continue to do enrollment verifications, we do transcripts support, we do re-enrollment. So, once a student gets through admissions, they come to us, and in the sense, they never really leave, they'll come back to us for the rest of their active working career as long as they need to order a transcript. Other than that, we are also federal records compliance, we are audit compliance, we are regional association compliance. It never really makes people look excited when I talk about the role, but they tend to at least understand it that way.

The narrative below is the statement after they realized they answered with the

functions of their office instead of their own functions:

Yeah, I say it's kind of weird. I don't know if it is just because I am managing the largest group that I ever have at any university in my career, but I have been removed from the daily operations than I ever have and I don't consider my role to be what it was in the past. I am not owning a transcript and mailing it out for students, I'm not evaluating transfer credit, you know, I am not posting a graduation and I have to be very careful about that now, I am not directly responsible for them, I'm responsible for the people who are responsible for that.

Tenoch acknowledges that they do not do any of the functions they mentioned above and further explained, "this university in particular tends to not look at the registrar, as a clerk, they want us to be a person with a higher-level vision. They 
want us to be somebody who can manage operations and manage people, and those people can in turn manage the processes."

Tenoch expressed curiosity, based on the other participants in this study about their functions. Tenoch mentioned that "I'd be curious to know, amongst the interviews that you have, like the registrars that you speak, but how many of them still run a transcript to mail to the student or post a graduation? I would bet many, if not most of them are removed from those daily processes."

\section{Cancu}

Cancun mentioned that "I get that all the time. Like, are you in admissions? No, and then I'll say, we do everything after admissions. I'll say as soon as a student is admitted, they have to register for a course, and in order to do that, they need to look at a class list or a catalog, and in order to do that they have to and then they have to know where to show up and to sit in the classroom and, and learn." Cancu, as the other participants, also described the functions of their offices and not their own responsibilities. Cancu kept describing the functions of their office:

And once they've received a grade, that grade has to be entered, and once that grades are entered, it goes on to the transcripts, and then once they have all those grades collected at the end, and they're looking to see if they have all the right courses to get that degree that has to be somebody has to review that and then that gets that gets approved. And then they get that diploma and they get that transcript and then all that's done. And then they go wow.

For Cancu, describing the functions of their office is easier than describing their

own. Cancu explained, "it seems to be the easiest way to relate back to people; at 
some point people has ordered a transcript for themselves. So, it seems to be in once there's that association they have they seem to be able to remember recall what a what a registrar office is. I'm the person who signs the transcript."

\section{Ocotlan}

When I asked Ocotlan how they describe what they do in family reunions, they asserted:

I just say, I'm the person that signs your transcripts at the bottom. Oh, like, yeah, I was like the person that put you in your classes, the person that graduated you, ordered your diploma; that's what we do. So, once you put it in that way, because everybody knows what a transcript is, everybody knows what a diploma is.

Needless to say, it is becoming a common practice or a recurrent pattern that the participants describe the functions of their offices rather than what they described in previous chapters. Ocotlan stated that when they got hired as a registrar, "I had one perception of what my job was going to be and it's kind of being a little something different. And it was intentional, because when I sat down with my boss, and I was like, well, what do you like? What do you need me to do?"

Ocotlan's supervisor responded with:

"I need you to look at the bigger picture stuff. He's like, the last registrar was way too in the weeds and could never stop to look at what else was happening. She was very involved in like, the day to day curriculum stuff, or like, the course schedule changes, or, you know, just some of the smaller things that happened on a daily basis. But she was too involved, to the level that she couldn't do research, how to do other practices more efficiently. Right. He's like, I need you to figure out how can we do things more efficiently. Like, what are we doing wrong? And how can we fix it?

The excerpt above indicates how Ocotlan have an idea of what their job was going to be, but it turned out to be different from what they were expecting. 
Ocotlan further explained that "I think one of the cool things about the role of the registrar is that it's constantly evolving. The only thing that's tough about it is that the people don't always evolve as fast as the role does."

\section{Tikal}

When I asked Tikal how they describe what they do in family reunions, they said "that's a really good question, because we do so many different things and we have to collaborate with so many different parts of university that it's hard to describe because it's so nuanced. And it's also so dependent on the type of institution where you work." Tikal further explained: "so, if I don't really want to get into it, and I want to make it a very short conversation, I would say, you know, I clear people for graduation and help them register, make sure that they're on track certain degree."

Tikal acknowledged that they respond to what they do based on how much time they have or how much they want to get into the conversation. Tikal stated:

But If, if I have a little more time, if I want to really get into explaining more, I would say, you know, overall, the biggest responsibilities I have is a folding academic policy and implementing it, and helping students be successful at the institution. And I manage a lot of important technology to something like that.

The functions described by Tikal in the quote above were mentioned in previous chapters as to what they really do. Tikal's answer differs a little from the other participants in a way that they tell what they do based on how much time they want to spend explaining their role.

After reasoning for a couple seconds, Tikal further explained that by not describing their role is a lost opportunity for others to learn about what they do. 
Tikal further stated "I feel like that is just a lost opportunity, right? Because everybody knows what housing office does. Everyone knows what financial aid does, right? So maybe, we could build stronger relationships, if we could really sum up what we're doing, I don't know, I think that's a really interesting point.”

\section{Montezuma}

When I asked Montezuma how they describe what they do in family reunions, they stated:

Depends on who I'm talking to, you know, I usually tell them I'm a jack of all trades and I solve problems for people across University. Yeah, and then I might go on to elaborate to say that could be anything from figuring out how to get you registered for a class, to printing a transcript for you to getting you graduated, solving life's problems. Generally, I'm a jack of all trades and I just do a little bit everything.

Montezuma rather than adding to the narrative about what they really do, they expressed, "the thing that I always come back to, so I still laugh about that SACRAO workshop where they said the registrar doesn't make policy; they implement policy and that's very true from the implementation standpoint, but I think the days of that traditional registrar role for most registrars at complex universities it doesn't have to be a large university could just be a complex one. I think those days are dead."

\section{Xoco}

When I asked Xoco how they describe what they do in family reunions, they mentioned:

I'm the registrar. And they say, well, you're the one who takes the money, and then I say no, I collect grades and send out transcripts. And that usually says, Oh, okay, So, that's what I usually tell them. I usually don't 
go into much greater detail than that because it usually don't mean anything to them.

The narrative below is the statement after Xoco realized they answered with the functions of their office instead of their own functions:

But I think we're headed into a set of years where this profession is going to change due to two things. One is multi-tenant platform.

Number two, is student's self-sovereignty. And you know what I mean, when I say that, so much like, and you know, the word blockchain always comes up. The key word there is disintermediation. So, what is a registrar? It is an intermediate officer who stands in between the faculty and the institution and the students. And basically, the outside world is a platform like blockchain and security systems, the same thing we do with PKI or encrypted PDFs that we do at the moment. What if every time we got a record, we put it out in a blockchain? Basically, an area where we have already given it to the student, it's already been verified, it's already been validated. It contains the same integrity, and we have the electronic means to ensure its integrity, and that it's immutable at the time that someone who sees it.

In the quote above, Xoco described the "future" role of the registrar as a "trend" that might affect their profession. Xoco further explained, "that these trends are coming in and if the registrars don't pay attention to how they would conduct their work in the advent of these kinds of trends, others who completely understand what that might mean, may, in fact, take over that work."

\section{Chapter Summary}

The literature review demonstrates how AACRAO's publications, in which many of the authors are registrars, have the divided or troublesome idea of what the functions of the registrar should be versus the functions of the office of the registrar are. Therefore, the current theme presents narratives that clearly describes that it is common even within 
registrars to list the functions their offices do instead of their own functions and duties as a registrar.

The theme, what my family thinks I do, includes narratives where participants described what they tell family and friends about what they do. One fact we can agree upon is that the duties and relationships of the registrars differ widely by institution. However, the narratives in this theme show that registrars make the mistake of not describing what they do, but instead, they describe the functions of their team.

Nenetl clearly identified that "I answered with my title and then I talked about the functions of the people that work for me, without mentioning that the registrar is a manager." In a similar approach, Tenoch stated that they would be curious to know how many registrars "still run a transcript to mail to the student or post a graduation? I would bet many, if not most of them are removed from those daily processes."

This final chapter of my findings is the culmination of the reason why I decided to conduct this study. I find it interesting how, during the interviews, the participants explained and described every detail of what they do, and it goes from technology to policymaking to management. They once described running a transcript, enrolling a student, conferring degrees, or configuring degree audits as part of their functions. However, that is how they describe what they do in family or friend reunions. 


\section{CHAPTER VIII}

\section{DISCUSSION AND CONCLUSION}

You know, I answered with my title and then I talked about the functions of the people that work for me, without mentioning that the registrar is a manager.

(Nenetl)

How do university registrars perceive their roles in higher education? My study provides an understanding of the role of the university registrar, particularly their perspectives on their professional practice, professional development, and professional identity. In this chapter, I discuss the findings of my study and draw conclusions. The chapter begins with a review of the research project.

Then I will answer the research question to my study; however, it is important to note that the answer to the question presented in my study is not a singular one. The various answers to my research question are embedded within the themes presented in the study. I should note that my study is not grounded in any theoretical approach or concept; it does not seek to conceptualize either the findings or define terms such as skills, responsibilities, management, technology, professional development, etcetera. My study only seeks to know more about the role of the registrar through their narratives. Finally, I will address the overall implications of the study and recommendations for future study.

\section{Review of the Study}

According to Taylor $(2015$, p. 1), the president of the university or the college in the United States, used to run the administration of it by himself (or herself), but "with increased enrollment, and the demand for expanded services," one person could no longer handle all the administrative functions. Taylor stated that "due to the necessity of 
increased record keeping, one of the earliest of these administrative positions to emerge was the registrar."

According to AACRAO, the central role of the university registrar historically has been "to preserve the integrity, accuracy, and privacy of all academic records; to interpret institutional and governmental policies to members of the academic and general community; and to efficiently distribute these records in full compliance with applicable policies, laws, and regulations" (Lauren, 2006, p. 2).

Today, the university registrar operates at the interface of all organizational functions in university life: between academic and administrative work, between governance and policy making, and between faculty and students' interactions. Empirical research on university registrars, their professional development, training, and their role identity is sparse. According to Sauter and Shanken (2014, p. 310), the importance of the registrar role has not been well documented.

During the literature review, it became evident that there is not enough information about the role of the registrar but only origins, definition of processes, and guidelines about the profession. This association, AACRAO, offers a wide range of conferences and workshops where attendees can network and learn from each other; this is an invaluable opportunity for the profession. However, networking and participation are not enough if we do not know the essence of the role of the registrar and how this profession has evolved.

As we learned from the findings of my study, one of the registrar's major responsibilities is to manage the office of the registrar in an effective, efficient, and 
responsible manner, but that doesn't mean that the registrar should be involved in every single transaction. Therefore, my study addresses the gap between subjective guidelines and the lack of empirical research of the actual role of the university registrar based on their own perspectives.

Semi-structured interviews, document analysis of the job description and curriculum vitae, and the researcher's journal entries served as data to gain insight into the experience of nine registrars from public and private colleges and universities. The transcripts were transcribed entirely by me; then, these were coded and analyzed to detect themes.

Over the course of data analysis, four major themes and their respective subthemes emerged. These themes are presented in Chapters IV, V, VI, and VII. These themes are: "To be or not to be a registrar," "what I really do," "what keeps me up at night," and "what my family thinks I do." "What I really do" theme is divided into two sub-themes. These sub-themes are skills and roles and responsibilities. "What keeps me up at night" is divided into two sub-themes: challenges \& emerging trends and professional development. In Chapter IV, I presented profiles for each participant that allowed the readers the opportunity to familiarize themselves with the registrars who participated in my study. These themes and sub-themes helped answer my research question: How do university registrars perceive their roles in higher education?

\section{To Be or Not to Be a Registrar}

As stated in Chapter II, the literature review on the role of the registrar is sparse. The available literature on the origins of the registrar shows that the role was developed 
out of the faculty from the need to record and authenticate student educational records (Kisling, 2014). Taylor (2015, p. 39) pointed out that the duties of a registrar were not time-consuming in the early days because faculty appointed as registrar also had teaching obligations. McGrath's survey shows that over time, the number of registrars who also taught decreased significantly, from 75 percent in 1860 to 21.4 percent in 1933 as cited in Taylor (p. 40).

It is only within the last decade that the registrar has been considered a leading administrative official in higher education. Each participant provided me with many stories that described their experiences on becoming a registrar and their future goals within higher education. Chapter IV not only served as the foundation for understanding the registrars' pathway to becoming one but also helped in creating a profile for each participant. Their perceptions and backgrounds are unique to their persona and helped me in understanding their beginnings, how their institutions perceive their roles, and what are their career goals are in higher education, if any.

\section{How did I get here anyways?}

This sub-theme described the journey of the participants on how they became a registrar. It is interesting that the same internal joke happened in every interview I conducted, "we don’t wake up one day and decide we want to be a registrar." My findings indicate that none of the participants were looking to become a registrar as part of their career path. For example, Nenetl described, "I'd never intended to be a registrar, I never set out to be a registrar, it happened to me" meanwhile Cancu mentioned that "to be honest, I never really had the goal of becoming a University Registrar." 
Out of the nine participants, two had never worked at the registrar's office at all; in other words, the registrar position was the first time these two participants had interacted with this office before. Nenetl mentioned that "the first job I ever had in the registrar's office was registrar" and Yaotl said that "I mean I didn't have any other registrar experience, other than, you know, when I first was hired as a registrar and 2006."

It is interesting to note that once the participants started their careers in the office of the registrar; they have stayed in that pathway. Six out the nine registrars have been appointed or served as interim registrar before being named "registrar" in their current or previous institutions. Cualli was appointed college wide registrar after their predecessor left the college. In as similar way, Nenetl mentioned that "so, at that, I became the Senior Associate Director of Admissions, and registrar. So, I didn't apply for it, I was appointed it." While the most common career path to the registrar position is from the area of records and registration, others came to their current position as registrar from a wide variety of positions and experience both inside and outside of higher education.

The findings show that participants were not looking or intended to become a registrar. The three main reasons they became one were: (1) they were at the right place at the right time, meaning they had worked for the office of the registrar and had worked the ropes up. Once their predecessors had retired or left the university, participants were appointed as registrars. (2) Their institutions decided to merge offices and combined titles; and (3) participants had worked in higher education before and either had worked at the registrar's office or other departments and applied to be a registrar in another 
university. Regarding implications for practice, the study should justify programs within AACRAO to create a clear pathway for those interested in becoming a registrar. For example, AACRAO offers a Registrar 101 workshop for new Registrars, but they should consider creating a workshop for Assistant and Associate Registrars interested in becoming a registrar.

\section{What my institution thinks I do}

The findings of my study show that it is not a surprise that some institutions do not have a clear understanding of what the role of the registrar should be, at least in the job description. The summary of the job description seems to be clear on the expectations of the role; however, the description of roles, duties, and responsibilities start conflicting with the duties of the "office if the registrar."

For example, Cualli's institution started describing their responsibilities as oversees the implementation of policies, oversees departmental personnel selection and "training," serves in university committees; then, as I have experienced with AACRAO's literature, the institution started describing duties that are part of the "office of the registrar" and not part of the actual duties described by Cualli in Chapter V.

One of the registrar's major responsibilities is to manage the office of the registrar in an effective, efficient, and responsible manner, but that does not mean that the registrar should be involved in every single transaction. According to Geyer (2018, p. 27), the administration of academic records, registration, and schedule adjustment, class schedule, transfer credit, official transcripts, graduation, and many more all fall under the purview of the "registrar's office." 
As the literature revealed, the registrar's position has been considered as a "clerkship" and back-office position; however, the role has evolved, and now even universities have a hard time understanding the role of the registrar. As discovered in the narratives, some institutions want the registrar to see the "big picture"; however, the list of functions of the registrar includes tasks such as schedule classrooms and print diplomas.

My study also shows that institutions have different educational requirements for this role. Some institutions only require a bachelor's degree; others preferred master's degrees, and only one or two would prefer a "terminal" degree. Most of the institutions require an "appropriate degree"; however, it is difficult to understand what "appropriate" degree means when there is not a clear pathway or education on becoming a university registrar.

Regarding implications for practice, my study should encourage AACRAO and institutions to come and work together in creating a "registrar curriculum" and propose standardizing the profession of the registrar. Discussions should include a well-developed curriculum for a certificate or a master's degree that solely focuses on courses that will help the registrar to succeed in their role.

\section{To retire or not to retire... as a registrar}

The available literature about the career goals of the registrar is sparse at best. There are no guidelines or research that solely focuses on what registrars want to do with their careers. My study shows that eight out of nine registrars emphasized that they like what they do; only one, Tikal is not sure they would like to continue in the registrar's 
career path. Six out of the nine participants want to retire as a registrar, they love what they do, they are good with policy, and it fits their personality. The other three participants still would like to remain within Enrollment Services but perhaps overseeing the registrar-- a vice provost or vice president position. Similar to the section above, the implications for practice should justify the creation of workshops for sitting registrars that would like to keep exploring careers outside the registrar's office, for example, enrollment management.

The analysis provided in this section should serve to answer my research question and as an opportunity for the readers to get to know the participants of my study. It served as an opportunity for the readers to get to know their institutions and their career goals. It was evident that participants enjoy what they do, and the majority of them expressed that taking this position was the best professional decision they could have made.

\section{What I Really Do}

Schipporeit (2018, p. 3) described that key elements of the registrar's role include professional, functional, and technology roles, basic office management duties, leadership, project management, and policy making. However, Schipporeit (p. 5) also described that the functional roles of the registrar are the publication of the catalog and academic calendar, curriculum management, master course inventory, registration, records management, graduation, commencement transcripts, and management. "What I really do" is presented in Chapter V as the second emergent and major theme of the study. The research question of my study is answered in this chapter by the participants 
describing their skills, roles, and responsibilities based on their own experiences and perceptions.

\section{Skills}

"Skills" is the first sub-theme of Chapter V. It describes the skills the participants think they should have to practice their position. Three main skills were discovered while analyzing the responses of the participants; these are diplomacy, technological competence, and managerial skills. When comparing the skills discovered in my study and the ones published in the AACRAO 2015 survey, only one of three was mentioned in both studies-- technology. Communication and project management were the other top two skills, according to the survey.

Diplomacy was the top skill to have as described by the participants of my study; Diplomacy was defined by Nenetl as “ It means doing outreach, it's an act, to me, that is an active act, which is redundant, but so being diplomatic is not only how you react to people, but it's the relationships that you made." According to the participants, diplomacy is a relationship-building that requires nurturing. It is a way to connect with people.

Participants agreed that technology is an important skill to have, and that does not mean a registrar should know how to code but to understand the nature of the needs of their office and their constituents. Participants associated technology with data as a means that they need to be qualified to obtain their own data and should not depend on IT "folks." It was important for the participants to be "funcky-tech." The participants described that registrars should be able to "adapt policy to the technological needs of their offices." 
Managerial skills were mentioned by participants as the ability to manage people and run an office. I think management was not the first skill because registrars depend on their associate and assistant registrars to manage their own teams. Participants mentioned other skills that they thought were important to have for this role; however, they did not elaborate much or provided examples to justify the skill. Effective communication and leadership were skills that were mentioned without examples.

I found it interesting that Nenetl mentioned "systematic" as a skill to have, but they were referring to it as a good skill to have "in the past"; they explained that "if you'd asked me this years ago, I would have said that probably the skill you need is systematic; that you need to know how to do evaluations, you need to know how to produce transcripts, you need to know how to man the front desk. But so much of what we do has moved into systems support areas." The analysis provided in this section should serve as a starting point to understand how registrars perceive their role and the main skills needed to conduct their work.

\section{Roles and Responsibilities}

Roles and Responsibilities is the second sub-theme of Chapter V. The narratives presented in this section described the participants' perceptions of how they spent their days and what they really do as a registrar. Four main roles and responsibilities were identified while analyzing the responses of the participants; these are staff development and management, policy making, technology management, and liaison.

When comparing the three most important roles and responsibilities discovered in my study and the ones published by AACRAO in their 2015 survey, only one of three 
were mentioned in both studies-- policy making. Managing student records and effective and efficient student service were the other top 2 roles and responsibilities, according to the survey.

I found it interesting that within all the roles and responsibilities published in multiple publications by AACRAO none reflect the top three responsibilities described by the participants of my study. The participants' narratives in my study when discussing their roles and responsibilities did not make any reference to "functional responsibilities" as part of their portfolio when discussing this section specifically.

Policy making was one of the top two roles and responsibilities described by the participants. Participants expressed that at least $50 \%$ of their time is spent in some way related to policy review, formulation, and creation. The participants, in general, expressed that they preferred to "shape than be shaped," and this is not always the case. Policy making plays a different role in different institutions, and not all the participants are directly involved in this process. The participants agreed that they influence policy in one way or another.

Being a liaison as part of the participants' roles and responsibilities was the most important aspect of their role. Tikal mentioned that "I think it's really important, very important to have strong relationships with academic administrators and various academic departments. I think it's really important to make academic partners.” In a similar approach, Montezuma stated that "I think that's the biggest change I've seen in the registrar's role is that we can't be silos anymore. To me extends way beyond, I can't be a silo, I have to work with everybody." 
The participants agreed that part of the registrar's role is building collaborations with multiple departments within the university; and, in some cases, not only within the university but within the state, region, or nationally. Yaotl asserted that "part of the registrar's role is building collaborations with academic departments and understanding what they're trying to do."

The analysis provided in this section should serve to directly answer my research question: How do university registrars perceive their roles in higher education? Through their narratives, they expressed what skills are essential to their position; they also described what they considered to be the most important roles and responsibilities in their profession. Participants were appreciative of having this opportunity to discuss what they do and how they spent their days.

Regarding implications for practice, my study should serve to add to the literature on how registrars spend their days, and what skills, roles, and responsibilities are important to them to perform their tasks. These narratives should serve AACRAO and institutions as a base to build the curriculum of a certificate or terminal degree; these should be the core functions of building the program.

\section{What Keeps Me Up at Night}

In Chapter VI, I introduced the third theme of my study, which comprises participants' narratives that described their profession's challenges, emerging trends, and professional development. This chapter is split into two sub-themes: challenges \& emerging trends and professional development. Chapter VI should serve to explain and 
contribute participants' thoughts about their roles as a registrar; I considered that it was important for these to be part of my study.

Challenges and emerging trends emerged as a sub-theme because the narratives of the participants about the role of the registrar went beyond what they do on their day to day operations. It expanded unto what they perceive as challenges and trends for their profession. Some of the narratives intersected with sub-themes from chapter V. Technology, diversity, and generations were presented as the main key points for this sub-theme.

For example, Ocotlan is convinced that technology is and will continue to shape the role of the registrar. Nenetl asserted that technology is always evolving and will always be a trend and a challenge. In a similar way, Tenoch also mentioned that technology is constantly changing: "so, we are constantly also in a training, retraining, redevelopment, testing phase for some new piece of technology."

Diversity and inclusion were a challenge and a trend for Tikal, Cancu, and Ocotlan; they described that it is challenging when policies are implemented not taking into consideration "underrepresented" students. Tikal stated that "in previous institutions, I didn't see diversity and inclusion within the registrar's office as an imperative. That was hard for me, because I have issues with that and ethically, I think, we really need to radically look at the way we're doing things. Because, you know, the people who are on campuses are not the people who were there when policies were created 30 or more years ago. So that is, that is 
personally challenging when you know, people don't see why it's really important to be inclusive of all students."

Weber (2018, p. 93) mentioned that there are two emerging trends in higher for the office of the registrar. The first one is "disciplinary notations on transcripts;" according to Weber, discussion at the state and federal levels focused on whether colleges and universities should include disciplinary notations on students' transcripts.

The second trend is "transgender students and name changes;" the discussion around this topic is whether institutions should allow students to select a "preferred name" and "pronoun." The discussion extends as to whether this should also be allowed to be displayed in transcripts and diplomas. It is evident that the challenges present by a recent AACRAO publication differ from the ones mentioned in the narratives presented by the participants of my study. This does not mean that the challenges presented in my study are more important than the ones presented at AACRAO.

According to Schipporeit (2018, p. 103), it is important to keep an eye on not only the latest activities on campus but also on what is happening on the state, regional and national level that impacts the profession of the registrar and higher education. Joining professional associations provides consistent and current access to topics in all areas of higher education.

Professional development was described as "acquiring new knowledge, acquiring new contacts, and skills." Yaotl defined professional development as: 
I mean, professional development for me is also just having consistency like team meeting one on one with my team. You know, setting, giving opportunities up to us to attend conferences and so forth, and report back, but also doing, you know, try to do like training or, you know, it doesn't have to be going to a conference, it could be just, you know, we're going to create a vision statement or mission statement for our team and think about what are those, what are those things, or pain points that they have, you know, that sort of thing.

Participants, mainly the one with more experience in the profession, mentioned that at the beginning, they found that AACRAO was very helpful, but after a couple of years, they started losing interest in attending sessions; however, they enjoy networking, mentoring, and presenting sessions. Other important conferences mentioned that participants have attended are NASPA and EDUCAUSE.

The analysis provided in this section should serve to provide an understanding of how the participants see their role beyond their responsibilities but also on how it impacts higher education with new trends and challenges. Professional development is an essential aspect of the profession; participants not only attend to learn but also to network and mentor new registrars into the profession.

\section{What my Family Thinks I do}

Finally, I present "what my family thinks I do" as my concluding theme. I purposely left this question to the end of the interviews because I wanted to get an honest answer from the participants about how they describe their own role when they are with friends or family. I was interested in getting their reaction after an hour-long interview of how they described their roles, skills, and challenges to end with narratives describing what their office does instead of what they really do. 
I was not expecting that all registrars were going to respond the way they did; however, I was satisfied with the outcome because it builds to my study in a sense that registrars themselves do not have a clear understanding of their role when describing it to others. My findings show that the role of the registrar as a "clerk" or "back office" position is embedded in the culture of the institutions and higher education.

The best quote that describes "what my family thinks I do" was made by Nenetl: "I answered with my title and then I talked about the functions of the people that work for me, without mentioning that the registrar is a manager." The analysis provided in this section should have helped in adding to the literature on how registrars perceive their role outside work.

\section{Recommendations for Practice and Research}

The purpose of my study was to get to know more about the role of the registrar and how they perceive their roles in higher education. I conducted the study with no other expectations than getting to know their role and contribute to the existing literature and practice. Based on the findings and conclusions drawn from my study, I feel compelled to make the following recommendations for practice:

First, AACRAO should create workshops specifically targeted for assistant and associate registrars interested in advancing their careers and becoming a registrar. This will help the profession in starting to standardize the role of the registrar. My study could be used as a base to start identifying the pathways of becoming a registrar and the experience necessary. 
Second, higher education institutions and AACRAO should start working together in standardizing the roles and responsibilities of the registrar. Each institution is different, but my findings demonstrate that registrars considered management, technology, policymaking, and networking as the core functions of their roles. These findings should serve to create a "common-curriculum" in developing specialized training for registrars in creating master's certificates and programs in accredited universities.

Third, according to NCES (2020), there are close to 6,606 (4,360 degree-granting institutions) colleges and universities in the United States, registrars should come together and recommend the type of professional development is needed for their profession. AACRAO is an important and sole professional association but should not be the only venue for registrars to get training. Institutions should invest in the professionalization of the role of the registrar.

Fourth, registrars should describe their roles equally across different situations and events; registrars contribute to the misunderstanding of the roles and responsibilities of the profession. By saying that they print transcripts and diplomas to family and friends does not help in educating people on the true meaning of the role. Every time a registrar lists the functions of their office instead of what they do is a lost opportunity to educate the public.

Fifth, since there is a lack of empirical research about the role of the registrar, future studies should look at job retention and satisfaction, diversity, gender, and inclusion and belonging. Future studies should also take a closer look at where the office of the registrar falls within the organizational chart of the institution. Out of the nine 
participants, only one mentioned their relationship with their supervisor and barely scratched the surface of where their office falls within the organizational chart of the institution. Nenetl asserted that:

You know, it comes up to me in this way. This is a weird way to describe it. But in an organizational chart, you have the registrar's office, you will find me at the top of the organizational chart. In terms of the organized terms of the university, I am someone on someone else's chart, but my staff aren't. So I happened to report to a specific leader at the university, not because I am the, you know, the manager of 20 some people, but because I am the registrar for that school, and that that implies something different. Everyone in the registrar's office is a part of the registrar's office board, except me, I'm part of the dean's office. Weird, you know.

Finally, diversity is a topic of interest that should be studied not only at the office of the registrar but also in higher education. The lack of underrepresented groups in leadership positions is alarming. According to the 2015 AACRAO's survey, 9 out of 10 registrars self-identified as white, and only five percent identified as Hispanic or Latino. As Latinx, these numbers are alarming and are in need of further research, but more than research, we need change. We need more people of color in leadership positions. The study was concluded in the midst of COVID-19; therefore, it would be interesting to conduct a follow-up research study on how the role of the registrar changed, given the current circumstances.

\section{Conclusion}

Using qualitative interviewing and document analysis of job descriptions and resumes, the purpose of my study was to understand the experiences of university registrars, particularly their perspectives on their professional practice, development, and identity. I chose to study registrars across the country that belong to AACRAO because 
of my close ties with the association as well as personal connection and interest in this particular profession.

Before conducting this study, I did not know what to expect because there is so little written about the role of the registrar from an empirical perspective. The findings show the pathways the participants followed to become a registrar, their skills, roles, responsibilities, challenges, and professional development, all based on their own perspectives.

The registrar role has changed over time; the position has evolved from being a "back office" position to one that is at the front level of the university. The role continues to evolve and will adapt to new challenges that come to us. My study started before COVID 19. The way we conduct business and education will not be the same, and the way we operate will not be the same. 


\section{REFERENCES}

2015 U.S. Registrar Career Profile (2015). Retrieved from https://www.aacrao.org/docs/default-source/research-docs/career-profile/aacrao2015-registrar-career-profile-report.pdf?Status=Temp\&sfvrsn=ef865ff5 8

2018 U.S. Registrar Career Profile (2015). Retrieved from https://www.aacrao.org/docs/default-source/research-docs/career-profile/registrarcareer-profile-report-nbsp---march-60-second-survey.pdf?sfvrsn=9c3fc9f3 10

American Association of Collegiate Registrars and Admissions Officers (n.d.). Retrieved from https://www.aacrao.org/who-we-are

Cattell, M. et al (1922). The Collegiate Registrar: His Status and Opportunities. School and Society. Volume XV. New York, NY: The Science Press.

Creswell, J. (2018). Qualitative inquiry \& research design: Choosing among five approaches. Los Angeles, CA: SAGE Publications.

Coffman, L. D. (2016). The registrar: A profession. College and University, 91(2), 3136. Retrieved from http://search.proquest.com.ezpprod1.hul.harvard.edu/docview/1871573010?accou $\underline{\text { ntid }=11311}$

Backes, R. (2006). FERPA - the family educational rights and privacy act. In Lauren, B. (Ed.), The Registrar's Guide (pp. 363-383). Washington, DC: AACRAO Publications.

Bogdan, R.C., \& Biklen, S.K. (2007). Qualitative research for education: An introduction to theories and methods (5th ed.). New York, NY: Allyn \& Bacon.

Diamond, R. \& DeBlois, P. (2007). Don't forget the registrar. Inside Higher Ed. Retrieved August, 15, 2016 from https://www.insidehighered.com/views/2007/01/30/diamond

DiPaolo, T. (2006). Transfer and articulation. In Lauren, B. (Ed.), The Registrar's Guide (pp. 259-272). Washington, DC: AACRAO Publications.

Florida Association of Collegiate Registrars and Admissions Officers (n.d.). Retrieved from www.facrao.org

Geyer, D. (2018). Managing the Registrar's Office. In AACRO (Ed.), Registrar's Basic Guide (pp. 25-32). Washington, DC: AACRAO Publications. 
Hahn, C. (2008). Doing Qualitative Research Using Your Computer: A Practical Guide. SAGE Publications.

Heaton, H.L. (1947). The developing role of the registrar. In American Association of Collegiate Registrars. Journal of the American Association of Collegiate Registrars.

Henderson, S. (2006). AACRAO: A legacy in service. In Lauren, B. (Ed.), The Registrar's Guide (pp. 1-6). Washington, DC: AACRAO Publications.

Katz, D. (2006). Certifying academic eligibility of student athletes. In Lauren, B. (Ed.), The Registrar's Guide (pp. 209-226). Washington, DC: AACRAO Publications.

Kilgore, W. (2010). Building student-centric processes - A guide to business process analysis and reengineering. Retrieved February 15, 2016 from http://consulting.aacrao.org/publications-events/publications/building-studentcentric-processes/

Kilgore, W. (2016). Managing evolving technology needs. Retrieved February 15, 2016 from

http://consulting.aacrao.org/publications-events/publications/managing-evolvingtechnology-needs/

Kisling, R. (2014). The strategic role of the registrar: Changing responsibilities in light of technology. Retrieved August 15, 2016 from http://consulting.aacrao.org/publications-events/the-strategic-role-of-the-registrar/

Krecek, J. (2006). Department of veteran affairs: educational benefits and certification. In Lauren, B. (Ed.), The Registrar's Guide (pp. 239-247). Washington, DC: AACRAO Publications.

Krogh, N. (2006). Implementation of student information systems. In Lauren, B. (Ed.), The Registrar's Guide (pp. 65-77). Washington, DC: AACRAO Publications.

Lauderman, K. (2006). The registrar and curriculum development. In Lauren, B. (Ed.), The Registrar's Guide (pp. 19-29). Washington, DC: AACRAO Publications.

Lonabocker, L. \& Wager, J. (2006). Academic Scheduling and classroom utilization. In Lauren, B. (Ed.), The Registrar's Guide (pp. 101-118). Washington, DC: AACRAO Publications. 
Medley, L. (2006). Degree Audit. In Lauren, B. (Ed.), The Registrar's Guide (pp. 249258). Washington, DC: AACRAO Publications.

Merriam, S.B. (Ed.) (2002). Qualitative research in practice: Examples for discussion and analysis. New York, NY: Wiley.

Merriam, S.B. \& Tisdell, E. J. (2016). Qualitative Research: A guide to design and implementation. San Francisco, CA: Jossey-Bass.

National Center for Education Statistics (n.d.). Retrieved from https://nces.ed.gov/fastfacts/display.asp?id=84.

National Center for Education Statistics (n.d.). IPEDS. Retrieved from https://nces.ed.gov/ipeds/.

Parks, R., \& Taylor, A. (2019). The Emerging Role of the Registrar in Enrollment Management. College and University, 94(2), 25-30.

Peshkin, A. (1988). In search of subjectivity-one's own. Educational Researcher, 17(7), 17-21.

Pikwosky, R. (2006). Graduation, commencement and diplomas. In Lauren, B. (Ed.), The Registrar's Guide (pp. 275-311). Washington, DC: AACRAO Publications.

Preinkert, A. (2005). The work of the registrar: A summary of principles and practices in American universities and colleges. Washington, DC: AACRAO Publications.

Locke, L., Silverman, S., \& Spirduso, W. (2004). Reading and understanding research (2nd ed.). Thousand Oaks, Calif.: Sage Publications.

Rubin, H. J., \& Rubin, I. S. (1995). Qualitative Interviewing: The Art of Hearing Data. Undefined, 1-310.

Rubin, H.J., \& Rubin. I.S. (2012). Qualitative interviewing: The art of hearing data (3rd ed.). Thousand Oaks, CA: Sage.

Sauter, D. (2006). Budgeting in a resource-lean environment. In Lauren, B. (Ed.), The Registrar's Guide (pp. 453-472). Washington, DC: AACRAO Publications.

Sauter, M. \& Shanken, H. (2014). Handbook of strategic enrollment management. San Francisco, CA: Jossey-Bass 
Schipporeit, K. (2018). The Role of the Registrar. In AACRO (Ed.), Registrar's Basic Guide (pp. 3-9). Washington, DC: AACRAO Publications.

Schipporeit, K. (2018). Academic Policy, Student Academic Records, Transcripts, and Grading Processes. In AACRO (Ed.), Registrar's Basic Guide (pp. 41-54). Washington, DC: AACRAO Publications

Schipporeit, K. (2018). Professional Development. In AACRO (Ed.), Registrar's Basic Guide (pp. 103-106). Washington, DC: AACRAO Publications

Seidman, I. (2013). Interviewing as qualitative research: A guide for researchers in Education and the social sciences ( $4^{\text {th }}$ ed.). New York: Teachers College Press.

Spaulding, L. (2018). Information Technology and Technology Leadership. In AACRO (Ed.), Registrar's Basic Guide (pp. 67-74). Washington, DC: AACRAO

Publications.

Stake, R. E. (1994). Case studies. In N. K. Denzin \& Y. S Lincoln (Eds.), Handbook of Qualitative Research (pp. 236-247). Thousand Oaks, CA: Sage Publications.

Taylor, N. (2015). Rise of The Administrator in Higher Education:

Focus on Professionalization of The Registrar at The University of Kentucky from 1910 To 1937. Theses and Dissertations--Educational Policy Studies and Evaluation. 27. Retrieved from https://uknowledge.uky.edu/epe_etds/27/

Technology and education: Policy, implementation, evaluation. (1981). Washington, D.C.: Institute for Educational Leadership.

U.S. Bureau of Labor Statistics (n.d.). Retrieved from https://www.bls.gov/ooh/management/postsecondary-education$\underline{\text { administrators.htm\#tab-2 }}$

Voorhis, S. \& Falkner, T. (2006). Communications with multiple constituencies: calendars, catalogues and much more. In Lauren, B. (Ed.), The Registrar's Guide (pp. 1-6). Washington, DC: AACRAO Publications.

Von Munkwitz-Smith, J. (2016). 90 Years Later: Reflections on "The Registrar: A Profession." College and University, 91(2), 37-38.

Weber, D. (2018). Emerging Issues. In AACRO (Ed.), Registrar's Basic Guide (pp. 93102). Washington, DC: AACRAO Publications. 
Wolk, J. (2019). Three Years and Counting: Lessons from a Newbie to a Newbie. College and University, 94(3), 31-34.

Yin, R. K. (1994). Case study research: Design and methods (2nd ed.). Beverly Hills, CA: Sage Publishing.

Young, R. (2006). The Role of the Registrar: Origins, Evolution, and Scope. In Lauren, B. (Ed.), The Registrar's Guide (pp. 1-6). Washington, DC: AACRAO Publications. 
APPENDICES 


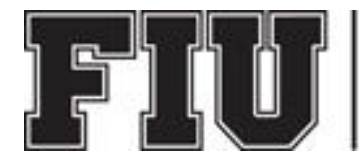

\section{FLORIDA}

INTERNATIONAL

UNIVERSITY

\section{ADULT CONSENT TO PARTICIPATE IN A RESEARCH STUDY \\ Title: From Record Keepers to Decision Makers?: Perspectives of University Registrars about their Role in Higher Education}

\section{SUMMARY INFORMATION}

Things you should know about this study:

- Purpose: The purpose of the study is to understand the role of the university registrar.

- Procedures: If you choose to participate, you will be asked to participate in an in-depth interview.

- Duration: This will take about two hours.

- Risks: The main risk or discomfort from this research is none

- Benefits: The main benefit to you from this research is understanding the role of the university registrar.

- Alternatives: There are no known alternatives available to you other than not taking part in this study.

- Participation: Taking part in this research project is voluntary.

Please carefully read the entire document before agreeing to participate.

\section{PURPOSE OF THE STUDY}

The purpose of this study is to understand the role of the university registrar from the participants' perspectives by interviewing university registrars from public and private universities and colleges.

\section{NUMBER OF STUDY PARTICIPANTS}

If you decide to be in this study, you will be one of ten people in this research study. 


\section{DURATION OF THE STUDY}

Your participation will involve up to two-hours of interview time via video conference.

\section{PROCEDURES}

If you agree to be in the study, we will ask you to do the following things:

1. Participate in an in-depth interview*

2. Submit a copy of your CV or Resume.

3. Submit a copy of your current Job description.

*Please note that it will be a one-time, two hours interview that will be conducted via video conference.

\section{RISKS AND/OR DISCOMFORTS}

The following risks may be associated with your participation in this study: There are no known risks associated with this study; however, you may choose not to answer questions if you feel any discomfort.

\section{BENEFITS}

The following benefits may be associated with your participation in this study: This study will help in having a better understanding of the role and responsibilities of the registrar based on their own perceptions; it will also allow universities in their search for "qualified candidates" and will allow individuals to better prepare for this role.

\section{ALTERNATIVES}

There are no known alternatives available to you other than not taking part in this study. However, any significant new findings developed during the course of the research which may relate to your willingness to continue participation will be provided to you.

\section{CONFIDENTIALITY}

The records of this study will be kept private and will be protected to the fullest extent provided by law. In any sort of report we might publish, we will not include any information that will make it possible to identify a subject. Research records will be stored securely and only the researcher team will have access to the records. However, your records may be reviewed for audit purposes by authorized University or other agents who will be bound by the same provisions of confidentiality. You will be given a copy of this consent form for your records. 


\section{USE OF YOUR INFORMATION}

Your information collected as part of the research will not be used or distributed for future research studies even if identifiers are removed.

\section{COMPENSATION \& COSTS}

There are no costs to you for participating in this study.

\section{RIGHT TO DECLINE OR WITHDRAW}

Your participation in this study is voluntary. You are free to participate in the study or withdraw your consent at any time during the study. You will not lose any benefits if you decide not to participate or if you quit the study early. The investigator reserves the right to remove you without your consent at such time that he/she feels it is in the best interest.

\section{RESEARCHER CONTACT INFORMATION}

If you have any questions about the purpose, procedures, or any other issues relating to this research study you may contact Miguel Sahagun at 305-608-6636, msaha001@ fiu.edu.

\section{IRB CONTACT INFORMATION}

If you would like to talk with someone about your rights of being a subject in this research study or about ethical issues with this research study, you may contact the FIU Office of Research Integrity by phone at 305-348-2494 or by email at ori@ fiu.edu.

\section{PARTICIPANT AGREEMENT}

I have read the information in this consent form and agree to participate in this study. I have had a chance to ask any questions I have about this study, and they have been answered for me. I understand that I will be given a copy of this form for my records.

Signature of Participant

Date

Printed Name of Participant

Signature of Person Obtaining Consent

Date 


\begin{abstract}
APPENDIX B
Dear participant,

I would like to invite you to participate in a research project entitled From Record Keepers to Decision Makers?: Perspectives of University Registrars about their Role in Higher Education
\end{abstract}

The purpose of this study is to understand the role of the university registrar from the participants' perspectives by interviewing university registrars from public and private universities and colleges. If you decide to be in this study, you will be one of ten people in this research study. Your participation will require up to two hours of interview time.

If you agree to be in the study, I will ask you to do the following things:

1. Sign the attached Informed Consent Form

2. Participate in an in-depth interview*

3. Submit a copy of your Curriculum Vitae or Resume

4. Submit a copy of your current Job description

5. Select a date and time for the interview

*Please note that it will be a one-time, two hours interview that will be conducted via video conference.

Attached is an Excel file with available dates and times to conduct the interview (available time slots are highlighted in yellow). Please select up to three dates/times that you are available (EST time), send them back to me, and I will confirm your interview shortly.

Finally, the following benefits may be associated with your participation in this study: This study will help in having a better understanding of the role and responsibilities of the registrar based on their own perceptions; it will also allow universities in their search for "qualified candidates" and will allow individuals in better prepare for this role.

If you have any questions, please feel free to contact me.

Thank you,

Miguel Sahagun

Msaha001@fiu.edu 


\section{APPENDIX C}

How do you become a registrar?

How many years have you been in your current position?

How many total years of experience do you have in higher education?

From what area did you move from immediately prior to your position as Registrar?

What is the minimum education requirement for your current position?

What has been your career path to get to this position?

Describe your role as a registrar

Out of your roles and responsibilities, mention the 5 most important parts of your job.

Mention 5 skills that you believe are the most important as a registrar

When you are in family reunions, how do you describe what do you do?

Describe your perception on technology

Describe your experience with technology

What is your interaction with Faculty or Faculty Senate?

How is your organizational chart divided?

What shapes or changes your work?

Describe your relationship with other governing, administrative, or management structures

Describe emerging trends and key drivers that might reshape your role as a registrar What is your anticipated next career move?

What do you find more challenging about being a registrar? 
VITA

MIGUEL SAHAGUN

Born, Mexico City, Mexico

2003

B.S., Business Administration

Lynn University

Boca Raton, FL

2004

Program Coordinator

Miami Dade College

Miami, FL

2005

Coordinator of Academic Support Services

Florida International University

Miami, FL

2007

Admissions Officer, University Graduate School

Florida International University

Miami, FL

2010

Assistant Director, Academic Advising Technology

Florida International University

Miami, FL

2010

2012-2016

Master's in Latin American and Caribbean Studies

Florida International University

Miami, FL

Adjunct Faculty, First Year Experience, Honors College

Florida International University

Miami, FL

2014

Assistant Registrar, Technology and Systems

Florida International University

Miami, FL

2014-2016

Oracle's Academic Advising Product Advisory Group

Member

2014-2016

President \& Vice President of Professional Development of the Florida Association of Collegiate Registrars and Admissions Officers (FACRAO) 
Assistant Registrar, Enrollment Services

Harvard University

Cambridge University

Director of Membership of the New England Association of Collegiate Registrars and Admissions Officers (NEACRAO)

2019

Co-chair Latinx Caucus of the American Association of Collegiate Registrars and Admissions Officers

2020

Registrar

Bunker Hill Community College

Charlestown, MA

PRESENTATIONS:

"Implementing Degree Audit in a 4-year Research Public University" Florida Association of Collegiate Registrars and Admissions Officers, San Augustine, FL, 2014

"Graduation Success Initiative Implementation using PeopleSoft" Alliance, HEUG Conference, Las Vegas, NV, 2015

"Latinx Caucus" American Association of Collegiate Registrars and Admissions Officers Annual Conference, Los Angeles, CA, 2018

"Latinx Administrators in Higher Education" New England Association of Collegiate Registrars and Admissions Officers Annual Conference, Portsmouth, NH, 2019 